\title{
A comparative study of the fa'afafine of Samoa and the whakawahine of Aotearoa/New Zealand
}

by

Ashleigh McFall

\begin{abstract}
A thesis
submitted to the Victoria University of Wellington in fulfilment of the requirements for the degree of Master of Arts by thesis in Gender and Women's Studies
\end{abstract}

Victoria University of Wellington

2013 


\begin{abstract}
This study explores the meaning of the fa'afafine of Samoa and the whakawahine of Aotearoa/New Zealand. I compare and contrast the experiences of six fa'afafine and four whakawahine. I also examine the historical evidence for the existence of fa'afafine in Samoa and whakawahine in Aotearoa/New Zealand. The theoretical approaches underlying this research incorporate feminist, indigenous, and queer aspects but oral history is the primary theory and method used. As a fa'afafine who researched her own identity and whakawahine, the complexities of insider and outsider are explored.
\end{abstract}

This thesis discusses how narrators understand and/or make meaning of western categories of identification such as gay, transgender, drag queen and/or transsexual. These categories are largely rejected; preference for the culturally specific terms fa'afafine (Samoan) and whakawahine (Maori) are demonstrated. Narrators take issue with western researchers' focus on sexual aspects of fa' afafine and whakawahine. For them, gender role, specifically feminine dress, behaviour and activities more accurately characterise their identities.

This thesis argues that fa'afafine and whakawahine are fluid identities. How one behaves as a woman varies, but narrators insist that fa' afafine and whakawahine are born not made that way, and 'feel' like women. The meaning of fa' afafine and whakawahine is not static; westernisation, colonization and the availability of gender reassignment treatment have all impacted on how each narrator defines her identity.

By focusing on the experiences of fa'afafine, most of whom live outside of Samoa, and whakawahine this thesis adds to the body of knowledge about gender variation. 


\section{Acknowledgements}

I would like to thank the ten participants Latoya, Athena, Viane, Max, Honey, Lia, Renee, Kayla, Chanel and Shaniqua who agreed to be interviewed for this research. This project would have not been possible without your participation. From the bottom of my heart, I thank you all for opening your hearts and stories to me.

I am very grateful to my supervisor, Dr. Lesley Hall, who has guided me through to completion of this thesis. She has encouraged me to follow my passion as a self-identified fa' afafine to conduct research by, for and about fa'afafine. Her knowledge of feminist and oral history theories and methods has given me an understanding of why fa'afafine and whakawahine have previously hidden from history. Her continuous guidance and constructive criticism has been extremely valuable throughout my years as an undergraduate and post-graduate.

I would also like to extend my thanks to ex-Director of Gender and Women's Studies of Victoria University of Wellington, Dr. Alison Laurie; Curator of Oral History and Sound of the Alexander Turnbull Library, Linda Evans; and Oral History Advisor of the Alexander Turnbull Library, Lynette Shum.

As a non-Maori and whakawahine, I was fortunate to have the guidance of people with insider knowledge and experience - previous Chair of Tiwhanawhana Trust and a board member of Lesbian and Gay Archive of New Zealand (LAGANZ), Elizabeth Kerekere; Professor of Research and Development at the University of Waikato, Dr. Ngahuia Te Awekotoku; Organizers of Tapatoru, Karen and Peri Te Wao; Librarian and National IT Coordinator of the New Zealand Aids Foundation (NZAF), Vern 
Keller; and Maori researcher, Kevin Haunui. I thank you all for your help and guidance.

To paraphrase Riki Love (Tapatoru, 2011: p. 13), I think of my aiga (family) and uo (friends) who have helped me along the way and my gafa (ancestors/genealogy) whose blood runs through my veins; I dedicate this thesis to you all.

To my mother Patricia, who seven years ago, migrated from Samoa with me, to further my academic studies in Aotearoa/New Zealand. Thank you for your endless words of encouragement and believing in me. This thesis has truly aided my mother's understanding of fa'afafine. To my brothers Barry, Darren and Elvis; and their families thank you for your love and continuous support.

I am also grateful for the love and support from my mother’s sisters Latoya, Monica and Petra and also my girls.

Fa'afetai tele lava ma ia manuia 


\title{
Narrators
}

\author{
Latoya - $\quad$ self-identifies as fa'afafine \\ lives in Australia \\ age: 40’s \\ Athena - self-identifies as fa'afafine \\ lives in American Samoa \\ age: 30's \\ Viane - $\quad$ self-identifies as fa' afafine \\ lives in Aotearoa/New Zealand \\ age: 30's \\ Max - $\quad$ self-identifies as fa'afafine \\ lives in Aotearoa/New Zealand \\ age: 30's \\ Lia - $\quad$ self-identifies as fa'afafine \\ lives in Aotearoa/New Zealand \\ age: 20's \\ Honey - $\quad$ self-identifies as fa'afafine \\ lives in Aotearoa/New Zealand \\ age: 20 's \\ Shaniqua - self-identifies as whakawahine \\ lives in Aotearoa/New Zealand \\ age: 30's \\ Kayla - $\quad$ self-identifies as whakawahine \\ lives in Aotearoa/New Zealand \\ age: 50’s \\ Renee - $\quad$ self-identifies as whakawahine and queen \\ lives in Aotearoa/New Zealand \\ age: 50's \\ Chanel - self-identifies as whakawahine \\ lives in Aotearoa/New Zealand \\ age: 50’s
}




\section{Table of Contents}

Page numbers

Abstract $\quad$ iii

Acknowledgements iv

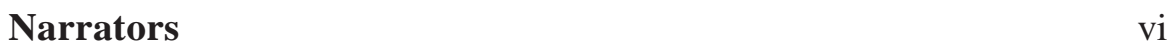

$\begin{array}{lll}\text { Chapter } 1 \text { Introduction } & 1\end{array}$

Introduction

Research Aims

My experience $\quad 2$

Concepts and terminology 4

Organization of thesis 6

$\begin{array}{lll}\text { Chapter } 2 \text { Literature Review } & 8\end{array}$

Introduction

Samoa and American Samoa 9

Aotearoa/New Zealand $\quad 12$

Misrepresentation of Samoans and fa'afafine $\quad 14$

Historical background of fa'afafine 17

Faleaitu (house of spirits) and/or entertainment $\quad 19$

Born or made fa'afafine $\quad 21$

Fa'afafine-tama and fa' afafine-teine 22

Colonial lens (defining fa' afafine using western terms) 23

Religious attitudes to fa'afafines and Samoans $\quad 26$

Review of literature on the whakawahine 28

History of the word whakawahine 29

Maori sexuality $\quad 32$

Conclusion 33

$\begin{array}{lll}\text { Chapter } 3 \text { Methodology } & 34\end{array}$

Introduction

Oral history

Fonofale model of health and Hibiscus flower model 35

Queer theory 37

Gender as performance

Feminist research 38

Why fa'afafine and whakawahine? $\quad 39$

Insider research $\quad 40$

Power, empowerment and ethical behaviour $\quad 42$

Reflexivity 43

Ethics and procedures $\quad 45$

Oral history interview data analysis $\quad 47$ 
Queer methodology

Selection of participants

Conclusion

Chapter 4

Nature versus Nurture

Introduction

The history of fa'afafine

The history of whakawahine 55

Is fa'afafine 'like a woman'? 58

Is fa' afafine a role? $\quad 60$

Fa'afafine are born not made 62

Whakawahine are born not made 64

Femininity and masculinity of whakawahine 65

Conclusion

Chapter 5 The impact of western understanding of sexual 68 identity and sexual orientation on what it means to be fa'afafine and whakawahine

Introduction

Are fa'afafine gay?

Are whakawahine gay and/or takatapui? $\quad 71$

Are fa'afafine transgender? $\quad 74$

Are whakawahine transgender? $\quad 78$

Are fa' afafine drag queens? $\quad 79$

Are fa' afafine transsexuals and/or transvestites? 80

Are whakawahine transsexuals and/or transvestites? 81

Conclusion

Chapter 6

Discussion

Introduction

History of fa'afafine and whakawahine

Meanings of fa'afafine and whakawahine

86

Born and not made that way

87

Culturally specific terms

88

Queer identities

89

Fa'afafine and whakawahine are not gay

The role of whakawahine $\quad 90$

Conclusion $\quad 91$

$\begin{array}{lll}\text { Chapter } 7 & \text { Conclusion } & 92\end{array}$

Introduction

Summary of research

Limitations of study

Future research

Conclusion 
$\begin{array}{lll}\text { Appendix } 2 & \text { Interview Questions } & 98\end{array}$

Appendix $3 \quad$ Participant Information Sheet 100

$\begin{array}{lll}\text { Appendix } 4 & \text { Consent Form } & 102\end{array}$

Appendix 5 Oral History Recording Agreement Form 104

$\begin{array}{ll}\text { Bibliography } & 106\end{array}$ 


\section{Chapter 1}

\section{Introduction}

"The records of missionaries, administrators, traders and politicians have been used to construct histories which reflect the biases of Western academic methodologies. These methodologies gather, sift and validate knowledge from the perspective of the outsider" (Pulotu-Endemann and Peteru, 2001: p. 124).

"Different indigenous communities across the globe have expressed their concerns and often outrage about the problem of research and of researchers. Every indigenous community can probably point to a very specific piece of research (and/or a very specific researcher) that has been furiously contested by the community itself" (Smith, 2004: p. 4).

\section{Introduction}

Western researchers seem to have been attracted to Samoan fa' afafine as an area of study for some time. They seem fascinated with males who perform what outsiders perceive as masculine and/or feminine roles in their family, at work or in other areas of society. They have categorized fa'afafine variously as gay, transvestite, transgender, cross dresser, hermaphrodite, androphilic males, transsexual and drag queen (see Pratt 1862, 1878; Mageo 1996, 1998; Croall and Altmann 2005; Harker, 2008; Wallace 2000; Dology 2000; Worth 2001; Kaltenborn, 2003; Demeter, 2004; Schmidt, 2005; Kusner, 2008; Vasey and VanderLann 2007, 2008; Teake, 2010; Ann, 2012; O’Malley, 2012). This thesis is a comparative study of the fa'afafine of Samoa and the whakawahine of Aotearoa/New Zealand. I examine what it means to be fa'afafine and whakawahine from the perspectives of narrators who claim such identities and how these narrators understand and/or make meaning of westernised categories of identification.

\section{Research aims}

In this thesis, I examine the history of fa'afafine in Samoa and whakawahine in Aotearoa/New Zealand; compare and contrast fa'afafine 
and whakawahine in these societies; and explore how narrators understand and/or make meaning of westernised categories of identification such as gay, transgender, drag queen and/or transsexual. This research aims to capture the stories of self-identified fa' afafine and whakawahine narrators most of whom live in Aotearoa/New Zealand but I also draw on my own lived experience because, as Pringle and Giddings found, '[i]nsider research is modified by hearing alternative stories from other people' (2011: p. 92). I have endeavoured to prioritize the voices of narrators over my own in order to recover their stories and/or revise received knowledge about them. Drawing on oral history theory which has critiqued the absence of minority groups (see for example Patai and Gluck, 1991 re women; Popular Memory Group, 1998: p. 79 re the working class) in conventional history, this research is intended to open the way for what Morrison (1998: p. 7) calls “new horizons” that modify traditional historical views “that excluded the colonized...non-Europeans”.

Significantly absent in the current literature is academic written material about whakawahine. This may be because the use of the term whakawahine is a relatively recent phenomenon that owes much to the increasing presence and possibly greater visibility of fa'afafine in Aotearoa/New Zealand; the terms are linguistically similar. My research aims to fill some of the gaps in the existing body of knowledge.

Employing 'gender as performance’ perspectives (Butler, 1999), indigenous approaches (Smith, 1999) and queer aspects of 'culturally marginal sexual-identifications' (Jagose, 1996: p. 3), this research seeks to explore the meaning of fa'afafine and whakawahine from the perspectives of the narrators.

\section{My experience}

Aspects of fa'afafine were topics I studied for my undergraduate degree. Two television programmes on fa'afafine - an Aotearoa/New Zealand documentary 'Fa' afafine: Queens of Samoa’ directed by Caroline Harker (2008), and an Australian documentary 'Paradise Bent: boys will be girls 
in Samoa' by Heather Croall and Karin Altmann (2005) - triggered my interest in studying the subject in more depth. It was here that I was first alerted to the alleged Samoan tradition of fa'afafine being boys who are raised as girls because of the lack of female labour in their families in Samoa. This did not reflect my own experience; I was never socialised by my family to fulfil a sister and/or daughter role even though I am the youngest of four sons.

Another common theme in these two documentaries was that society's acceptance of fa'afafine in Samoa and Aotearoa/New Zealand is complex. This replicated my own experience; it has been difficult for some members of my family (both nuclear and extended) to accept me as a fa' afafine even though there are many fa'afafine on my mother's side. From a very young age, I was discouraged from acting in a perceived feminine way by my parents and my siblings.

One other theme of the documentaries was the use of western terms such as gay, transvestite, transsexual, transgender and drag queen which do not easily equate to fa' afafine. Parts of my education were spent at Titahi Bay Intermediate School in Titahi Bay, Porirua. It was here that I was called poofter, gay, drag queen and faggot. Such labels were used pejoratively. I was often asked “Are you a boy or a girl?” by many students. However, my college years were spent at Samoa College in Samoa where I was labeled a fa'afafine by Samoan people. I would often perform in my college cultural events dancing the actions of a Samoan girl and this appeared acceptable. I became aware that being a fa'afafine in the Samoan context is quite different to being a fa'afafine in the Aotearoa/New Zealand context where I was often teased for my perceived feminine characteristics.

Later study revealed that these themes: the alleged Samoan tradition of boys raised as girls; the frequent use of western labels (gay, transgender, transvestite and drag queen); and the perceived societal acceptance of fa' afafine were common in western research. Until more recently most 
research into this topic was undertaken by non-Samoan and/or nonfa' afafine academics. My research sought to examine the accuracy of these assertions, to undertake research by, for and about fa' afafine, and to compare and contrast their experiences withwhakawahine.

\section{Concepts and terminology}

The literal translation of fa'afafine and whakawhine is 'like a woman' and/or 'in the manner of a woman' and they are used in multiple ways by people who claim such identities and in previous research. Therefore, I use the terms in a loose manner depending on thecontext.

The theorizing of sex/gender as distinctive has been constantly debated in feminist studies (Butler 1999; Lykke 2010; de Beauvoir, 1984; Oakley, 1986). Sex is often referred to as biological sex (chromosomes and the sex organ you are born with - penis or vagina). Gender relates to culturally constructed femininity and masculinity which includes roles, activities and behaviour deemed appropriate for men and women. I employ the concept 'sex' to refer to the biological sex of a fa'afafine and whakawahine - male; whereas 'gender' illustrates the masculinity and femininity they enact. As Butler (1999: p. 178 - 179) argues, 'gender requires a performance that is repeated and which produces an identity that is constituted in time through a stylized repetition of acts'.

The understanding of masculinity and femininity is not universal. Often descriptions of masculinity or femininity are presented as the way men or women assert what they believe to be their manhood or womanhood (Mosse in Paris et.al, 2002: p. 15). To paraphrase feminist Ann Oakley (2002: p. 37), masculinity and femininity are not biologically given conditions, rather they are constructed. Things that are perceived as feminine are associated with females and things that are masculine are associated with males (James and Saville-Smith, 1994: p. 10). Experiences of masculinity and femininity are intersected and defined by class, ethnicity, race and sexuality (Paris et.al, 2000: p. 13). What it is to be a man, woman, fa'afafine or whakawahine varies according to time, 
place and individual experience. For this study, narrators associate masculinity with testosterone, aggressive behaviour and being the man of the house. Femininity is linked with the gender role of a woman in relation to domestic chores wearing female clothing, western medicine (including hormone treatment, breasts, gender or sex re-assignment), having sex with a straight man, being passive, menstruating and giving birth.

Gender identity is associated with a person's internal, deeply felt sense of being male or female. A person's gender identity may or may not correspond with their [biological] sex(http://www.dol.govt .nz/er/minimumrights/transgender/).

Simone de Beauvoir (1984: p. 267) argues that 'one is not born but becomes a woman'. According to her, gender roles are a result of the environment in which an individual develops (ibid). Feminist Lynda Birke (1994: p. 5) claims that biology is not always as clear-cut as the sex/gender dichotomy implies, while queer theory challenges the often taken for granted binaries of gender and sexuality. Other fluid genders and androgynous identities such as the hijras of India (see Khanna and Kapil, 2004) and the berdache of North America (Besnier, 1994) who assert that they are neither male nor female, challenge this binary.

In this study, queer acts as an 'umbrella term for a coalition of culturally marginal sexual-identifications’ (Jagose, 1996: p. 3); gay, lesbian, bisexual, transgender, transsexual, transvestite or people who do not fit with the heterosexual binary. For this thesis:

- gay refers to males who desire or have sex with other males; 'same sex couples' (Roguski, 2004: p 134).

- lesbian relates to women who desire or have sex with other women; ‘same sex couples' (ibid). 
- takatapui or hoa takatapui is a Maori term used by Maori Lesbian, Gay, Bisexual and Transgender (LGBT) people (see http://www.wellington2011.org/transcript.html?id=2-1305931792-

274) and may or may not include whakawahine (see New Zealand Aids Foundation, 2010).

- 'transvestite/cross-dresser refers to a person who wears clothing and/or accessories that are considered by society to correspond to the opposite gender. They may be heterosexual, homosexual, married or single and may use cross-dressing as a means of sexual arousal. They may be secretive or open as, for example, drag queens (Sparrow, 2008: p. 4).

\section{Organization of thesis}

In Chapter 2 I provide a brief background of Samoa, American Samoa and Aotearoa/New Zealand before and after missionary and colonial contact. I give an overview of the current fa'afafine and whakawahine literature and refer to both indigenous and other studies that have researched these identities.

In Chapter 3, I present the theoretical framework of this study as well as methodology and methods. Oral history is a unique theory and method which provides the main source of information for the analysis of fa'afafine and whakawahine narratives. Also relevant to this study are feminist, indigenous and queer theories. As a researcher researching my own identity and that of whakawahine, the dynamics of insider and outsider research are explored. This chapter also discusses interview procedures and ethical considerations undertaken in the research.

The findings from my research are discussed in Chapters 4-6. In Chapter 4, I analyse the oral data and link this with previous Samoan, Maori and/or western research. This chapter discusses the various definitions of fa' afafine and whakawahine from narrators' perspectives, particularly the history of these identities in their indigenous contexts. It also considers 
common themes that emerged from the data of like a woman, born that way, gender roles and gender identity.

In Chapter 5, I discuss the problem with using western terms such as gay and transgender when discussing fa'afafine and whakawahine. Narrators mostly reject outsiders' fascination with the sexual aspect of their identities, arguing that their identity is more accurately described as a gender role.

In Chapter 6 I expand on the discussion in Chapters 4 and 5 and compare and contrast fa'afafine and whakawahine.

Finally, in Chapter 7, I summarise the key points; discuss the limitations of this study and provide some recommendations for future research. 


\section{Chapter 2}

\section{Literature Review}

"I think yes we [fa'afafine] are misunderstood and a lot of that is due to the representation that happens to fa'afafines in the media and every Tom, Dick and Harry that gets on a plane and comes to Samoa and says 'I want to tell you a story', will always skuwer [sic] it to a sexual aspect... because it's exciting, because it sells. Who they sleep with, what they have between their legs. It really doesn't matter at all!” - [see Ymania Brown: FA'AFAFINE - The boys raised as girls (The Feed) http://www.youtube.com/watch?v=F9xvkCa63Js].

"I think educating people is one strong way to improving the health of our whakawahine and promoting that we are all human. Society really only hears the bad, and they thrive on the negative..." (see Selena - NZAF, 2010: p. 7).

\section{Introduction}

This chapter provides background for my research. I draw on previous research about fa'afafine and whakawahine and present a review of the current literature. Much of the fa'afafine literature is written by nonfa' afafine and/or non-Samoan researchers (see for example Pratt 1862, 1878; Dology 2000; Mageo 1996, 1998; Harker, 2008; Croall and Altmann, 2005; Wallace, 2000; Dology, 2000; Worth, 2001; Kaltenborn, 2003; Demeter, 2004; Miles, 2003; Schmidt, 2005; Kusner, 2008; Vasey and VanderLann, 2008; Teake, 2010; Ana, 2012; O’Malley, 2012). These researchers have made a notable contribution to the study of fa'afafine, particularly in providing western understandings about fa'afafine. More recently research about fa'afafine (see for example Pulotu-Endemann, 1997, 2011; Brown-Acton, 2011; Toelupe, 2011; Vanessa, 2007; McMullin, 2012; Sua'ali'i, 2001) has been undertaken by some fa'afafine and indigenous Samoans.

There is almost a complete absence of research about whakawahine in the current literature (Mead, 2003; Lomax, 2007; NZAF, 2010). Much of what is known about whakawahine is anecdotal or informal. The reasons for the undocumented presence of whakawahine are difficult to determine. 
One possible explanation from a fa' afafine perspective is mentioned by Samoan-Japanese Artist Shigeyuki Kihara (Ana, 2012: p. 1):

“...fa' afafine through the South Pacific are unable to achieve recognition or have their voices heard due to lingering racism and homophobia that can be traced to western conceptions of gender normality imposed by the missionaries and the colonial governments that followed”.

Whakawahine appears to be a relatively new term. However, to understand the present in Samoa, American Samoa and Aotearoa/New Zealand, one needs some awareness of the past, so I provide an overview of relevant history.

\section{Samoa and American Samoa}

Samoa is located south east of the equator and is surrounded by the Pacific Ocean and its neighbouring islands of Tonga, American Samoa and Tokelau (see Appendix 1, p. 98). Apia is the capital and is located on Upolu Island. Samoa consists of two large islands, Upolu and Savaii, together with the small islands of Apolima, Manono, Fanuatapu, Namu'a, Nu'utele, Nu'ulua and Nu'usafe'e.

American Samoa is part of the Samoan Islands and is an unincorporated territory of the United States of America (USA) (see Appendix 1, p. 97). Pagopago is the heart of American Samoa. American Samoa consists of five rugged volcanic islands Tutuila, Aunu’u, Ofu, Olosega and Tau; as well as two coral atolls - Swains and Rose.

The first European to sight the islands of Samoa was a Dutchman, Jacob Roggeveen, in 1722 (see http://www.teara.govt.nz/en/samoans/page-1; Fairbairn-Dunlop, 1996). Later, the French explorer Louis Antoine de Bougainville called Samoa’s islands ‘the Navigator Islands' (see http://www.teara.govt.nz/en/samoans/page-1). The pre-missionary period explains that in Samoa there were many Gods - Gods of non-human origin (Atua) and those of human origin (Aitu) (see Meleisea, 1987). Particularly, God Tagaloa was viewed as the origin of all things, all 
people and the world around them (ibid). Although there was no account of when he came into the world, he revealed and made himself known to the people in ways which were comprehensible to them (Kamu, 1996: p. 29). The war Goddess Nafanua prophesied that a new religion would come to Samoa and end the rule of the old Gods. The first wave of British missionaries was sent by the London Missionary Society (LMS); John Williams arrived on the Messenger of Peace in Samoa circa 1830 (Fairbairn-Dunlop, 1996: p. 2). This influx brought a number of different denominations to Samoa - the Methodist mission in 1835; the Roman Catholic mission in 1845; and the Church of Latter Day Saints mission in 1888 (see Meleisea 1987). These missionaries branched out to teach their Christian principles in Samoa and in American Samoa.

In the late nineteenth century, Britain, Germany and the USA were engaged in a power struggle to control the western and eastern islands of Samoa (see http://amsamoa.net/history). The eastern island group became a territory of the USA (the Tutuila Islands in 1900 and officially Manu'a in 1904) and is commonly known as American Samoa; the western islands became known as German Samoa (see http://www.americansamoa.travel/about; Meleisea, 1987). Aoteaora/New Zealand captured German Samoa from Germany and took administrative control on behalf of the United Nations from 1918 until independence on 1st June 1962 when she became the first Pacific nation to gain independence (see http://www.samoa.travel/about/a13/History/). From 1962 to 1997, the nation was known as Western Samoa, until it dropped 'Western' from its name to become the Independent State of Samoa (ibid).

The missionaries and colonial rulers brought with them the English language, new fashions and new social and political institutions to Samoa and American Samoa. Missionaries sought to change family formation by, for example promoting the idea of the nuclear family (Meleisea, 1987: p. 67). This ideal has never been fully accepted by Samoan people because the extended family household has always been a practical economic arrangement (ibid). Extended families continue to predominate in rural 
areas and in some of the urban areas in Samoa and American Samoa today. Traditionally, Samoans only wore clothing below the waist but the missionaries persuaded them to wear shirts and dresses and to change their hairstyles (ibid). In addition, the missionaries promoted change, for example, by encouraging cooking traditionally carried out by men being undertaken by women (Meleisea, 1987: p. 68). Well known fa'afafine and pioneer advocate for the health and well-being of Pacific people, Fuimaono Karl Pulotu-Endemann (2007: p. 1) claims that:

"When the missionaries, sailors, whalers and travelers arrived there [in Samoa] they brought the attitudes prevalent to their own enlightened, civilized and Christian cultures, (nuclear) families, sexism and homophobia (especially lowly roles for women and fa'afafine) and elevated male roles”.

Overseas influence has resulted in fa'afafine being deemed sinful and/or evil by many churches in contemporary Samoan society (PulotuEndemann, 2007: p. 1). From a post-colonial perspective, Phylesha Brown-Acton argues that the 'fa' afafine, whakawahine, 'akava'ine of the Cook Islands, mahu of Hawaii, fakaleiti of Tonga and vakasalewalewa of Fiji were an accepted part of Pacific life and culture prior to Western colonisation, but have been subject to much stigma and discrimination in more recent times’ (cited in Ana, 2013: p. 2). However, anthropologist Serena Nanda says that "most western writing on gender variance has indulged in romantic notions of the acceptance of such behaviours in nonWestern societies” (Matzner, 2001: p. 1). Christianity and colonization have impacted on Samoan understandings and perhaps practices which relate to fa' afafine. However, there has been some resistance. Meleisea (1987: p. 69) argues that though some adaptation has taken place, changes have also been Samoanized by Samoans.

Samoan migration to Aotearoa/New Zealand began in the 1940s (Sua'ali’i, 2007: p. 161). My maternal grandmother and paternal grandparents, for example, migrated in the early 1950s and late 1960s respectively. Auckland continues to have the largest number of fa' afafine in its population but there are also fa'afafine living in Wellington (see 
Schmidt 2005; 2013). There are approximately 2,000 to 3,000 fa'afafine in Samoa alone, not counting the fa' afafine in the USA, Australia, New Zealand and in Europe [see FA'AFAFINE - The boys raised as girls (The Feed) http://www.youtube.com/watch?v=F9xvkCa63Js]. The population of fa'afafine currently living in Australia is about 100 (ibid).

The date May $1^{\text {st }} 2013$ was significant for fa'afafine in Samoa. The Crimes Act 2012 was passed so that in Samoa it is no longer criminal for a fa'afafine to impersonate a female. The fact that such impersonation had previously been made criminal shows the influence of colonization and British law-making on traditional Samoan society. However, for a fa' afafine to marry in Samoa is a complex matter. Some fa' afafine believe that if gay marriage is legalised they will likely be classified under the 'gay’ label (see ABC Radio Australia, 2013; Keresoma, 2013) and, as Chapter 5 shows, many reject the label 'gay'.

\section{Aotearoa/New Zealand}

Aotearoa is the Maori name for New Zealand and is often translated as the 'land of the long white cloud'. It is located in the South Pacific encompassing two main islands the North Island/Te-Ika-a-Maui and the South Island/Te Wai Pounamu with Wellington as the capital. (see Appendix 1, p. 97).

Abel Tasman was the first European to discover New Zealand during his voyage of $1642-43$, although he never set foot on the land. In 1769 the explorer James Cook arrived in New Zealand and claimed it for Great Britain, but it was not until the late 1700s that the first Europeans began to settle in Aotearoa/New Zealand. In 1835 the Declaration of Independence of New Zealand was signed by 34 Maori chiefs (see http://www.teara.govt.nz/en/history). The Declaration asserted the independence of New Zealand, with all sovereign power and authority residing with the hereditary chiefs and tribes (ibid). 'Large-scale European settlement began in the 1840s, and the subsequent social, political and 
economic changes have moved New Zealand from a British colonial outpost to a multicultural Pacific nation' (ibid).

Like pre-missionary Samoa, Aotearoa/New Zealand had many Gods. Tangaroa was the common God that most Maori people referred to in traditional Maori society. What Samoa had in common with Aotearoa/New Zealand was that Gods were seen to exist and that they related to all aspects of life (Davidson, 2012: p. 22). The first wave of missionaries to Aotearoa/New Zealand was the Church Missionary Society in 1814. Later missionaries brought other religious denominations to Aotearoa/New Zealand - Presbyterian missionaries in 1820s; Wesleyan missionaries in 1822; and the Roman Catholic missionaries in 1838. As in Samoa, the aim of the missionaries was to convert the Maori people to European religious beliefs and customs. Missionaries felt the need to introduce European skills, culture and values to the Maori people (Boon, 1998: p. 3). For example, 'missionaries tried to convert Maori to Christianity, and taught them farming skills, reading and writing' (Wilson, 2013).

On the sixth of February 1840, Te Tiriti o Waitangi (the Treaty of Waitangi) was signed between Maori and the Crown. 'The Treaty marks the historical founding of New Zealand as a British colony and plays a crucial part in determining the legitimacy of New Zealand governments and their right to command the allegiance of New Zealand citizens, both Maori and Pakeha’ (Mulgan, 2004: p. 51). Pakeha and Maori have interpreted the Treaty differently (see Palmer and Palmer, 1997; Mulgan 2004). Maori insist that they never ceded sovereignty and consequently there are continuing problems of definition of the Treaty even though international law states that the indigenous version should take priority.

The number of people who identify as whakawahine today in Aotearoa/New Zealand is unknown. However, there are approximately 10 people per 1,000 male-to-female transsexuals living in Aotearoa/New Zealand (some whakawahine describe themselves as transexuals) [see 
http://www.teara.govt.nz/en/gender-diversity/page-2.]. Male-to-female transsexuals are more visible in Aotearoa/New Zealand because it is less socially acceptable for them to wear women's clothes than the reverse (female to male) [ibid].

\section{Misrepresentation of Samoans and fa'afafine}

Anthropologist Margaret Mead based her research on adolescent girls on the island of Ta'u (one of the Manu'a islands of American Samoan) in the 1920s. In her book, Coming of Age in Samoa (1943), she describes an effeminate boy named Sasi ‘who was skilled at women's work and whose homosexual drive was strong enough to goad him into making continual advances to other boys in the 1920s (Mead, 1943: p. 121). He spent more time in the company of girls and maintained a more easy-going friendship with them than any other boy on the island of Ta’u (Mead, 1943: p. 122). Mead links Sasi with homosexuality and does not describe him as a fa' afafine. However her portrayal of him seems similar to descriptions of fa' afafine. Dr. Tom Poland confirms the depiction of Sasi as a fa'afafine (see Croall and Altmann, 2005). I would argue that being skilled at women's work, normally in the company of girls and making continual advances to other boys are typical characteristics of a fa'afafine both in traditional and contemporary Samoan society.

Mead's study has been challenged by anthropologist Derek Freeman in his book, Margaret Mead and Samoa: the Making and Unmaking of an Anthropological Myth Refuted (1983); and Lowell D. Holmes in his PhD, The Restudy of Manu'an Culture: A Problem in Methodology (1957) (see also Margaret Mead and Samoa - part 1 to 6, 1988 http://www.youtube.com/watch?v=Pw1NZjNkAYI). Several Samoans also strongly criticized Mead's findings (see Margaret Mead and Samoa part 5 http://www.youtube.com/watch?v=S8puR-AaSrg) and entreated Freeman to correct her mistaken depiction of the Samoan culture (Freeman, 1983: xv). Talitiga Dr. Venasio Sele, for example, argued that Samoa and American Samoa have been misunderstood by anthropologists 
ever since Mead wrote about Samoan girls supposed promiscuity (Claire, 2002: p. 2).

Mead's research has been described as a hoax, similar to the Manti Te'o hoax (see http://www.wnd.com/2013/01/manti-teo-meet-margaret-mead/). One of Mead's participants, Fa'apua'a Fa'amu, confirmed and confessed she was lying to Mead about her stories, saying "Samoan girls are terrific liars when it comes to joking but Margaret accepted our trumped-up stories as though they were true” (cited in Kaltenborn, 2003: p. 30; see also Margaret Mead and Samoa - part 5 of 6 http://www.youtube.com/watch?v=S8puR-AaSrg). However it is possible that Fa'apua'a Fa'amu's narrative is not necessarily untrue, in that “wrong statements are still psychologically true and this truth may be equally as important as factually reliable accounts” (Portelli, 1997: p. 51). Freeman commissioned anthropologist Unasa L.F. Va’a, to conduct lengthy interviews with Fa'apua’a Fa'amu at her home in American Samoa in 1987 and 1993. Freeman claims that Mead had been hoaxed by her participant(s) who openly spoke about their sexual freedom.

Pulotu-Endemann (see SPASIFIK magazine issue no.55, 2013: p. 16), states that people, especially Palagi, who are not familiar with the Pacific brand of humour, fall victim to those who twist it and use it for their own gain. It should also be noted that Mead was a target of jealous rivalry from fellow anthropologists who caused much damage to her reputation (see SPASIFIK magazine issue no.56, 2013: p. 30). Whatever the truth of the matter, the key point to make here is how influential Mead's research has been to western understanding of sexualityin Samoa.

Schmidt (2005) encountered difficulties in studying fa'afafine in Samoa and Aotearoa/New Zealand, specifically because she is Palagi. She experienced harsh criticism from older, university educated individuals in Samoa who had considerably more influence and insider knowledge than she had with many of the fa' afafine she spoke to (Schmidt, 2005: p. 71). Some Samoans feared that Schmidt's research would describe Samoa as a 
'gay paradise' (ibid). She explains that the image of a 'gay paradise' was a consequence of Mead's research (ibid). It left Samoans extremely wary of non-Samoan researchers, especially those who evidence any interest in sexuality (ibid). She reports that almost all Samoans seem to know Mead's name and many are aware of the belief of promiscuity among Samoan youth that Mead propagated (ibid). This suggests that some Samoans do not wish for history to repeat itself as a result of Mead's research and may explain why there is such reluctance to participate in research with non-Samoan people.

Independent Study Project by non-Samoan Teake (2010) also experienced problems researching fa'afafine. Participants in Teake’s (2010: p. 5) research were concerned that yet another misinformed representation would be produced with the potential to negatively impact fa'afafine's image internationally. One participant refused to participate in Teake's research because he was concerned that he had no control over how the information would be used (ibid). Another participant remained cautious of any misinformed or distorted study that might centre disproportionately on discussions of sexuality or sexual practices. One other participant mentioned that he did not like Margaret Mead and aimed to clearly ascertain the nature and ultimate purpose of Teake's research, for example, "What is this for exactly?”....Psychology? Sociology?... Sexiology?” (ibid).

Clearly previous research on Samoa by non-Samoans or non-fa'afafine has not been wholeheartedly endorsed. Mead's fieldwork has undermined the trust attributed to ethnographers whose task is to represent others to academic and nonacademic audiences (Goldsmith, 2000: p. 48). I would argue that Mead's research has had a negative lasting impact on Samoan people in general. It is possible that the wary participants exemplify what Rohatynbskyj and Jaarsma (2000: p. 10) describe as feeling “outraged at being talked about, spoken for and represented" by non-fa' afafine or nonSamoan researchers. I suspect that the unwillingness of Teake's and Schmidt's participants' derives from suspicion about sharing information 
with someone who is non-fa'afafine and/or non-Samoan and concerns about how information will be used by the researcher. Another possible explanation for reluctance to participate could be a result of what Smith (1995) calls ‘conjuring up bad memories’ of previous western research. Schmidt and Teake did not have the advantage as I had as an insider when interviewing fa'afafine (see Chapter 3).

\section{Historical background of fa'afafine}

Fa'afafine and non-fa' afafine researchers have different views about the existence and frequency of fa' afafine in Samoa in the pre/post-missionary period circa 1830. Anthropologist Jeannette Marie Mageo (married to a Samoan) links fa'afafine with transvestism while London Missionary Society (LMS), Reverend George Pratt, associates fa'afafine with belonging to women as work (cited in Dology, 2005: p. 7). Mageo claims that:

"Transvestism is not mentioned by early visitors to Samoa....Lack of comment in Samoa therefore, suggests that Samoan transvestism is innovative....therefore I suspect that in old Samoa [before the arrival of the missionaries circa 1830] transvestism was merely an extremely marginal practice that suffered a historical drift into the cultural limelight...Lack of transvestism reports on Samoa is more likely to reflect a contemporary increase than a pre-contact absence: today male transvestites are conspicuous in their numbers” (1998: p. 2007).

She also argues that:

"I was reading missionary journals of the nineteenth century...there were no reports of fa' afafine in these early sources. Between contact or between time of the missionaries arrived circa 1830 and the present [2005], there had been a great increase in transvestism" (see Croall and Altmann, 2005).

Mageo’s claims raise several issues. Linking fa' afafine with transvestites is controversial (see Schmidt, 2005). I disagree with Mageo that fa'afafine is 'innovative', as Pratt's discussion of the presence of fa' afafine in the nineteenth century suggests otherwise. Pratt lived in Samoa from 1839 to 1879 and his writings contradict Maego’s claim of a lack of early reports. Pratt does not label fa'afafine as transvestites, though in a later edition of 
his work, he calls them hermaphrodites (1878: p. 355). One interpretation of Pratt's description of fa'afafine is that it is a gender role in which they take on the work of women. However, he also claims that the identity is a sexual one in which a man has sex with another man. His findings provide some evidence that fa' afafine were present in the mid nineteenth century and prior to Pratt's location in Samoa.

The dearth of early accounts of fa'afafine contradicts research by some self-identified fa'afafine. Painter, writer and fa'afafine, Dan Taulapapa McMullin(2012: p. 86) was informed by Shigeyuki Kihara, that the name fa'afafine originated in the nineteenth century. This leads McMullin to question whether fa'afafine were simply known as fafine (women) precontact (ibid). If indeed the name fa'afafine formed in the nineteenth century, there is little evidence to confirm or counter this claim. Language evolves and possibly colonization and/or religion may have brought about a name change.

Pulotu-Endemann claims that fa'afafine 'existed hundreds and hundreds of years ago before the missionaries arrived to Samoa' (cited in Harker, 2008). His argument is based on early reports of a sailor who went with a very comely lass behind the bushes and found that it was a comely lad (2012: p. 2). Evidence suggests that early visiting mariners consorted with fa' afafine and encountered men behaving as women (Farran, 1997: p 4). Pulotu-Endemann's and Farran's research reinforces the view that some fa'afafine fulfilled the sexual needs of sailors, thereby suggesting fa' afafine is a sexual rather than, or in addition to, a domestic role.

Previous colonial and Samoan research suggests that fa' afafine existed in Samoa and American Samoa for a long time and could have been part of the Samoan culture well before the twentieth century (Teake, 2010; Ana, 2012). American Samoa’s well known fa’afafine, Talitiga Dr. Venasio Sele, asserts that fa'afafine were present at the arrival of the missionaries to Samoa but they all looked the same to the missionaries: primitive natives, pagans and the uncivilized blended with the rest of the Samoan 
people and perhaps did not stand out as different (Vanessa, 2007: p. 68). Fa'afafine might have been something that the missionaries, with the possible exception of Pratt, could not relate to as it was outside of their

previous experience. This could account for their failure to mention them in their accounts. Whether such omission was deliberate or not is unknown. According to Besnier (2000: p. 25), some visiting missionaries and colonial officers had little familiarity with the inner workings of the societies they described and therefore omitted any mention of fa'afafine in their accounts. To paraphrase Hemmilä (2005: p. 8), the status in historical documents of fa'afafine must partly be due to the difficulties some missionaries and colonizers experienced when reporting something alien to them and of which they only had partial understanding.

\section{Faleaitu (house of spirits) and/or entertainment}

The link between faleaitu (house of spirits) and transvestism in the nineteenth and twentieth century is described by Mageo (1996) [see also Sinavaiana, 1992]. Mageo claims that male transvestism in Samoa developed by way of the Goethe effect of the social fictions proffered by Samoan comic theatre, faleaitu (1996: p. 3). Traditionally faleaitu comic plots involved men playing the roles of both husband and wife. She describes fa'afafine as 'lying girls - men pretending to be women' in comic theatre by playing attractive and entertaining dramatis personas (1996: p. 591).

Mageo (1996: p. 4) implies that a fa'afafine’s extravagant dress and provocative gestures served to fill the void left by village females who were discouraged from participating in poula (joking nights) after the arrival of the missionaries circa 1830. Some of the missionaries did not approve of all the elements in joking nights, especially the exhibitionistic dances (Pulotu-Endemann, 1997: p. 1). Consequently, joking nights became faleaitu (house of spirits) (ibid). Mageo claims that village males who undertook domestic work replaced village girls in faleaitu (1996: p. 4). However, Schmidt argues that: 
“The questionable nature of Mageo’s argument can be demonstrated by comparing cross-dressing in faleaitu with similar western contexts, such as pantomime...the logic of Mageo's argument would suggest that because both pantomime and transvestism feature men who wear women's clothes, the two must be causally linked. Beyond the flawed logic of this argument, further consideration also reveals that, in order to support it, Mageo must have looked only to those fa' afafine who do cross-dress and engage in humorous (public) performance, a group that does not encompass all fa’afafine in Samoa” (2005: p. 59).

Schmidt argues that Mageo focussed extensively on the entertainment role of fa'afafine in the post-missionary context. Cross-dressing roles played by men and women is part of British pantomime tradition dating back to the "fifteenth and sixteenth century Italian traditions of Commedia dell'Arte” (Robin, 2013: p. 1); and is not exclusive to Samoa. Women commonly played the roles of men and men played the roles of women in European theatre. For example, the transvestite actor is evident in folk theatre dating back to William Shakespeare’s plays (Howard, 2013; http://www.finchpark.com/ppp/crossdressing/crossdressing-handout.pdf).

This same and/or similar comic theatre can be found in contemporary Samoan comedy in Aotearoa/New Zealand. For example, Aunty Tala and Fai are played by two Samoan males, Tofiga Fepulea'i and Eteuati Ete, of the comic theatre group 'Laughing Samoans' (www.laughingsamoans.com/about/). Samoan writer Sia Figiels's novel 'Where we once belonged' features a fa' afafine character named Sugar Shirley, known for her exploits on the rugby field. I would argue that these modern examples of Samoan humour seem a natural extension or development of the traditional faleaitu plots. The point to make here is that some fa'afafine who act in plays for entertainment purposes, are in some ways similar to the transvestite image portrayed by Mageo heterosexual, married men with children as entertainers. These fa'afafine are quite different to the fa'afafine I interviewed for this research (see Chapters 4 and 5). 


\section{Born or made fa'afafine}

The notion of fa' afafine as born and not made is complicated. There is a difference between Samoan, fa'afafine and non-Samoan understanding of boys raised as girls in Samoa. Anthropologist Benedicte Kaltenborn (2003: p. 75) and sociologist Johanna Schmidt (2005: p. 16), found that most fa'afafine claim that they were born that way and a few stated explicitly that the cause was biological. However, one of the coordinators at the headquarters of Jehovah's Witness in Samoa argues that biology is not responsible for being a fa'afafine (see Kaltenborn, 2003: p. 173). The coordinator based his assertions on nurture - being influenced by surroundings as well as the lack of female labour in a Samoan family (Kaltenborn, 2003: p. 174). From his perspective, fa' afafine is a socially constructed role not biologically determined.

Fa'afafine as boys who are raised as girls in their families in Samoa is a theme in the literature. Kaltenborn's (2003: p. 4, 76 and 173) research shows that several Samoans (including a Samoan pastor) assert that Samoan boys become fa'afafine because the family need a girl in the house to take care of specific feminine chores (see also Demeter, 2007; p. 1). In addition, if a mother only has boys, she will confer a special favour upon one of the boys and gradually form him - make him do the female chores (Kaltenborn, 2003: p. 177). Some Samoans assert that fa'afafine are influenced by their families to fulfil the role of female labour (Schmidt, 2005: p. 16).

The tradition is also mentioned by some self-identified fa'afafine. Frances claims that if a Samoan family has four or five boys, no girls, one of those boys' would be a girl in the family (see Harker, 2008; Seedsavers -

Fafafine: Boys raised as Girls in Samoa, http://www.youtube.com/watch?v=6 x2NU-ewe0; polyfreshtv-FRESH - Know Your Roots - Fa'afafine, http://www.youtube.com/watch?v=MnXmL0vDu8g). Frances comes from a family of three brothers; she is the eldest and has no sisters (see Harker 2008). Leo’s parents had seven children (all boys) and was nominated as a 
fa' afafine by his mother [see FA'AFAFINE - The boys raised as girls (TheFeed) http://www.youtube.com/watch?v=F9xvkCa63Js]. Similarly, Lionel became a fa' afafine because his mother always wanted a daughter; she used to dress him up when he was a baby (Worth, 2001: p. 4).

Lionel's account implies that as he has no female siblings suggesting he was socialized into the fa' afafine role by his mother. However, PulotuEndemann challenges such research:

“...the reduction of all fa' afafine as being men in frocks and subservient, powerless substitute women for heterosexual men's pleasure until a real woman comes along...brought the accompanying myths such as Samoan families that were short of girls would dress boys as girls....” (2007: p.1).

Challenging the assertion that fa' afafine are boys raised as girls, Professor of Samoan Studies Aiono Dr. Fanaafi Le Tagaloa, argues that there is never a shortage of girls in any family in Samoa (see Harker, 2008). She claims that a family in Samoa is always an extended family and there is no problem of asking extended family members such as uncles, aunties and cousins for their daughters' to help with domestic labour (Meleisea, 1987). McMullin (2012, p. 111) argues that he had sisters and was not aware of being chosen to fulfil a role. Self-identified fa' afafine Opera believes there is no truth in the tradition of Samoan boys being raised as girls because her parents discouraged her from being fa'afafine and acting girlie (see Harker, 2008). Opera's parents did not approve of her feminine mannerisms and were uncomfortable with her fa'afafine identity and/or role. My experience was similar. Opera’s and my experience reinforce the view that boys are not generally raised as girls in Samoan families. How this myth evolved is unclear but there is no doubt that many Samoans, including fa'afafine, believe this to be correct (see page 21).

\section{Fa'afafine-tama and fa' afafine-teine}

Many of Kaltenborn's participants distinguished between two types of fa' afafines: fa' afafine-tama (fa'afafine-boy), the one that dresses like a man, and fa'afafine-teine (fa'afafine-girl), the one that dresses like a woman (Kaltenborn, 2003: p. 59). According to Kaltenborn (ibid), 
fa' afafine base their categorization of fa'afafine on dress styles. For example, a fa'afafine-tama would dress in a t-shirt and shorts while a fa'afafine-teine would wear a miniskirt and stiletto heels (ibid). For Kaltenborn, fa'afafine-teine and fa' afafine-tama are descriptions of how fa' afafine dress (male or female clothing). These descriptions shed light on how some fa'afafine identify themselves and other fa'afafine.

\section{Colonial lens (defining fa'afafine using western terms)}

The word fa'afafine has been defined and used in many ways by researchers. Some view fa'afafine as transvestite, hermaphrodite and androphilic males (Mageo 1996, 1998; Vasey and VanderLann 2008) while others see fa' afafine as an indigenous identity (Pulotu-Endemann 1997; Schmidt, 2005; Vanessa, 2007; McMullin 2012). More recent research rejects western labels. The Samoan language contains no equivalent word for homosexual (Shore, 1981: p. 209). Translating fa'afafine into English is difficult. As Schmidt argues:

“Using fa'afafine and transvestite interchangeably implies that a biological male wearing women's clothing carries the same meaning in Samoa and in the West and that it is this act that defines fa' afafine in the same way it does a transvestite. These assumptions of relatively problematic equivalence between Western and Samoan terms and identities also demonstrate a belief that other cultures are essentially a matter of matching written sentences in two languages” (2005: p. 11).

The idea of fa' afafine being associated with transvestitism is problematic. A transvestite is commonly referred to as a 'male who cross-dresses as a means for sexual arousal' (Sparrow, 2008: p. 4). As Kaltenborn pointed out, dressing in female clothing is not universal for all fa'afafine, therefore not all fa'afafine can be described accurately as transvestites. Also there are fa'afafine-tama and fa'afafine-teine who dress differently from one another. From a fa'afafine standpoint, Vaito'a Toelupe (2011: p. 1) argues that fa' afafine is a cultural identity and for one to understand it, one must first understand the Samoan culture. Pulotu-Endemann (1997: p. 1) argues that the unique cultural persona is lost when the term fa'afafine 
is redefined to exclusive Palagi or western terms like gay, transvestite, transsexual and homosexual.

However, not all fa'afafine and Samoan people share the view that fa' afafine are different from gay and transvestite (Schmidt, 2003: p. 3). Some fa' afafine categorize themselves along with gays, transvestites and drags outside of Samoa (ibid). Kaltenborn (2003: p. 65) claims that fa' afafine argue that a gay, a homosexual and a drag queen is the same as fa' afafine. This indicates that there is a tendency for some fa'afafine to use western terms of identification. Schmidt argues that as fa'afafine become westernized through the exposure to makeup and female western clothing, for example skirts, dresses, stilettos, their experiences appear more in tune with those of their western counterparts, transvestites and drag queens (Schmidt, 2003: p. 3).

One factor that may also contribute to the diversity in meanings assigned to the terms homosexual and gay is influence from countries overseas like Aotearoa/New Zealand, Australia and the USA. Some participants in Kaltenborn's (2003: p. 66) research identified with the foreign concepts of homosexual and gay and do not find them offensive. In addition, the fa'afafine gender role has changed and the sexual aspect of the role has become increasingly emphasized by Samoan people in general. For example, a mother of a teenage fa'afafine in Kaltenborn's research said:

"I believe that there are social changes that have given fa' afafine a drag queen outlook. The different exposures Samoans experience have remolded it (the fa'afafine role) to a more daring outlook and sexual orientation. Not that the sexual orientation (of fa' afafine) was not there before, but now even more so" (2003: p.67).

Clearly this mother links fa'afafine with sexuality and appears to claim that the increased focus on this aspect is a result of western influence. Arguably, sexual orientation is part of the fa'afafine identity but most fa' afafine claim that they are more accurately defined in relation to gender identity and/or role (Farran, 2010: p. 15). I suspect that the sexual focus of fa'afafine may have been emphasized as an effect of influence from 
abroad. Schmidt (2005: p. 127) supports this, arguing that western discourses have worked their way through Samoan understandings of gender and sexuality. Another possible indication of Western influence is the differentiation of fa'afafine based on dress style. One fa'afafine participant in Kaltenborn's (2003: p. 68) study claimed that a fa'afafine used to speak only of fa'afafine, whereas now there is a distinction between fa'afafine-tama (fa'afafine-boy) and fa' afafine-teine (fa'afafinegirl).

Mageo highlights the sexual aspect of fa'afafine. She uses 'jocular names' that tag fa'afafine as sexual and homosexual such as 'eat planet', 'eat carrot' and 'fagufagu' (a male who wakes up another male initiating sex) (1998, p. 210). McMullin (2012: p. 87) challenges Mageo, arguing that she uses homosexual as though this English word were cognate in the Samoan language and culture and claims her writings are filled with fa' afafinephobic conjectures. Mageo claims that fa'afafine are not socially accepted in relation to chiefly titles. She argues that:

"In Samoa important titles are normally given to brothers, but sisters may hold titles and this is no disgrace. Homosexuals may also hold titles. Fa'afafine, however are seen as jesters and families will not invest their status and dignity in them” (1998: p. 209).

In addition, Schmidt suggests that:

“...fa'afafine who bare breasts are considered ineligible for matai status... because the manifestation of breasts on a body known to be male and the behaviours usually associated with such embodiments are considered undignified by the (generally conservative) Samoans who are instrumental in conferring matai titles” (2005: p. 118).

Mageo's and Schmidt's claims are not without their critics. There are many fa'afafine who have had chiefly titles bestowed on them by their family in recognition of their services (Pulotu-Endemann and Peteru, 2001: p. 131; McMullin, 2012: p. 87). Choreographer, Seiuli Ailani Alo, for example, was bestowed the Seiuli title by the late Head of State of Samoa, Malietoa Tanumafili II (McMullin, 2012: p. 87). Although sociologist Reevan Dology (2000) found that fa'afafine do receive chiefly 
titles, he had not met any who feminized their appearances in public. I know of fa'afafine who have chiefly titles, some have worn male clothing while others have worn feminine clothing and some have had hormone treatment, for example, Fuimaono Karl Pulotu-Endemann, Talitiga Dr. Venasio Sele, Lealaitagomoa Tuisina Muliagatele Ymania Brown, Naeulumanu'a Tasha Atio'o and Faumuaina Honey (one of my fa'afafine participants). This tends to contradict Mageo's, Dology's and Schmidt's findings.

Clearly, there is not one universal definition of fa'afafine. Researchers variously describe fa'afafine as a gender, sexual identity, sexual role, drag queens, homosexuals and transvestites. Fa' afafine can be a fa'afafine in numerous ways, whether it is a gay person, a transvestite or transgender. There are many ways of being fa'afafine just as there are many ways of being a man or a woman.

\section{Religious attitudes to fa'afafines and Samoans}

The arrival of Christianity in Samoa and American Samoa changed the lives of the Samoan people. The notion of heterosexuality for procreation of Samoan families was stressed by the missionaries in their teachings (Pulotu-Endemann, 2007: p. 1). When Christianity taught the evils of homosexuality to the Samoan people and its consequences, it directed the attention to fa'afafine (Vanessa, 2007: p. 68). The strong association of homosexuality with fa'afafine created more intolerance in the culture, therefore suggesting fa'afafine were now looked on as sinful and evil deviants (ibid). As a result of the influx of Christianity to Samoa, fa'afafine grew up in a society less accepting of their lifestyles than previously (ibid).

The influence of Christianity in Samoa and in American Samoa has had an impact on reactions to sexual behaviour in general and homosexuality in particular. According to the wife of a Samoan Pastor in Samoa: 
"In the church, in the family we accept them as they are. We accept them as human beings... due to our Christian principles. Regardless of what they are, we have to accept them. I strongly oppose the fact that they have changed themselves to fa' afafine because there are no such things. God made man and woman, fa' afafine was never made as a separate sex in God's eyes...” (see Croall and Altmann, 2005).

Despite religious beliefs, some fa' afafine play important roles within their churches as Sunday school teachers, choir conductors and singing in the choirs' soprano or alto sections (Dology, 2000: p. 157). Some fa'afafine (not all) still dress as women in churches at work, in the classroom, in the home with the family and at important social functions. Some dress in frocks, just as other women do in churches (ibid). Contemporary Samoan attitudes to fa'afafine seem to derive from the tendency to confuse homosexuality with fa'afafine. As McMullin argues:

"In the English Bible, Leviticus 18:22, it is written, 'Thou shalt not lie down with mankind, as with womankind; it is an abomination'. In the Tusi Paia [Samoan Bible], Levitiko 18:22, it is written, 'Aua lua te momoe ma se tane, e pei ona momoe ma se fafine; o le mea e inosia lava lea'. Thus it is written that a tane [man] cannot sleep with a tane, but it is not written that a tane cannot sleep with a fa'afafine” (2012: p. 85).

The literature has presented several approaches to understanding fa' afafine from both Samoan and colonial/western contexts. It appears that the role of fa'afafine in relation to the work of women is generally accepted by their families. However, fa'afafine expressing interest in men sexually seems unacceptable to some Samoans. Many fa'afafine see themselves as women and enter into clandestine, short-term relationships with men who see themselves as straight (Ana, 2012: p. 1). This suggests that fa'afafine do not sleep with other fa'afafine (ibid) but instead most fa' afafine desire and go with heterosexual males (Schmidt, 2005: p. 16). This is considered by them (fa'afafine) to be a heterosexual relationship (ibid). The heterosexual male perceives the fa'afafine as like a woman, therefore suggesting she is a female regardless of having been born biologically a male [see Schmidt, 2005; Kaltenborn, 2003; FA’AFAFINE 
- The boys raised as girls (The Feed)_

http://www.youtube.com/watch?v=F9xvkCa63Js].

To recap, fa'afafine is explained variously as a domestic role, a family role, a sexual identity, and/or an entertainment role. The identity or role may be imposed on and/or claimed by oneself.

\section{Review of the literature on whakawahine}

While research has been undertaken to study fa'afafine from numerous Samoan and non-Samoan perspectives, the paucity of historical information about whakawahine in the existing literature has been problematic. Whakawahine have been studied less by non-whakawahine than fa'afafine by non-fa'afafine. Little is known about the term whakawahine and many questions about its origin remain. The relative absence of whakawahine from the literature has led me to 'scavenge' for relevant material in non-traditional places such as leaflets and reports (see pages 48 - 49).

The lack of information about whakawahine does not necessarily mean that there were not men behaving in the manner of a woman in the premissionary and pre-colonial period in Aotearoa/New Zealand. For example, a journal entry from a member of James Cook's crew on the Endeavour shows how he was tricked by a girl who was actually a boy (see Besnier, 1994: p. 292). Although the crew member does not label this boy/girl whakawahine, I would argue that his portrayal of him is similar to that of a whakawahine. Salmond's research also lends support to the view that people we might today label whakawahine existed historically:

"First contact European explorers around the shores of Aotearoa on several occasions noted the striking beauty of Maori maidens, however they soon realised when in more intimate circumstances, these female companions were actually like themselves" (cited in NZAF: 2010, p. 15).

It appears from the two accounts above that 'feminine' men who looked, and presumably dressed, as women were in fact biologically male, similar 
to Pulotu-Endemann's and Farran's descriptions of fa'afafine (see page 18).

Furthermore, gender swapping is rooted in Maori history. For example, in Maori cosmology, Tāwhaki, a warrior came into contact with a spiritual force called Tongameha who had the ablity to change his male form into a beautiful woman (see NZAF, 2010: p. 15):

"Instead [Tongameha] lowered the volume - softened it, sweetened it - and began to tease Tāwhaki: 'Tāwhaki look this way! I am a beautiful woman. Look at my eyelashes, they are like the sea. You like women don't you! Look at how my hips sway. Tāwhaki, here is what you get. Ahaha! Come here so I can embrace you!” (ibid).

This extract could be interpreted as a portrayal of a 'feminine' man, someone who might now be described as a whakawahine.

\section{History of the word whakawahine}

The term and meaning of whakawahine has a shorter history than fa' afafine. As the tangata whenua (the indigenous people), Maori people occupy a unique place in Aotearoa/New Zealand society. So where did the term 'whakawahine' spring from? There can be some confidence in the description of whakawahine when linked to the place Whakatane in Aotearoa/New Zealand. It is worth citing the legend of Whakatane because as Hutchings and Aspin argue (2007: p. 15), Maori history has been filtered through colonial, heterosexual eyes, to the exclusion of stories that reflect Maori, history and traditions. The legend of whakatane explains:

"The voyaging canoe Mataatua sailed into a wide river mouth in what is now the eastern Bay of Plenty. Toroa was the captain; the crew include many women, among them Wairaka, his daughter and his sister, Muriwai. Having made a safe landfall, the men set off exploring the area. When this happened, either Wairaka or Muriwai raced to the rescue and hauled the huge sea craft back in with the rousing cry, Kia whakatane au I ahau! Let me make myself like a man, thus naming the river and the place where this occurred" (Te Awekotoku, 2003: p. 53). 
Possibly the term whakawahine was derived from whakatane: whakawahine 'in the way of a woman' and whakatane 'in the way of a man'. To support this claim, Professor Hirini Moko Mead (2003; p. 246) argues that tangata whakawahine are men who prefer to associate with women and take up feminine occupations such as weaving; tangata whakatane are women who act like men and prefer to take up masculine occupations such as becoming a warrior and engaging in heavy labouring tasks.

Anthropologist David A.B. Murray distinguishes between takatapui tane (men), takatapui wahine (women) and whakawahine or whakatane, "terms which translate roughly to 'becoming' or 'making' woman or man, indicating a transcendent or permeable gendered identification” [2003: p. 240].

These terms are explored in considerable detail and are similar to people who identify with the opposite gender in Samoa. Fa'afatama, for example, are women who are 'like men'.

How convincing though is linking whakawahine to the place Whakatane? Te Awekotuku (personal correspondence) argues that the 'Whakatane' legend is based in historical whakapapa (genealogy) and moteatea (traditional Maori chants) whereas whakawahine probably is not. One possible explanation could be that the term whakawahine has been adapted from other Pacific identities which are similar to Maori. The New Zealand Aids Foundation seems to adhere to this view defining whakawahine this:

“To be like a woman. Used by male to female transgender Māori. This word is the Māori form of the Samoan word Fa'afafine, Tongan Fakaleiti and Cook Island(s) 'Akava'ine, however it must be noted [that] transgender communities in all these nations have their own perception of their history, how they are integrated into their cultures and not all are necessarily transgender" (NZAF: 2010: p. 15). 
NZAF associates whakawahine with transgender and other Polynesian cultures. It appears that some whakawahine self-identify as transgender but not all. Other Pacific Island cultures like Tonga, Hawaii, Niue, Papua New Guinea, Cook Islands and Fiji all have a long-standing tradition of men who behave 'in the manner of a woman'. Murray thinks that this fact may have some significance for Maori:

"A number of neighbouring Polynesian societies have well documented traditions of 'gender-defined homosexual' roles, increasing the likelihood that a similar role may have existed amongst pre-contact Maori. However we should keep in mind ...the appropriateness of labelling this role 'homosexual' or 'third gender' when it may in fact have more to do with context and cosmology than sexual or gendered proclivity” (Murray, 2003: p. 236).

In addition, Murray questions the use of western terms because "all carry their own historical, political and social baggage” (ibid: p.235).

Although both Mead and Murray referred to the term whakawahine in academic literature in 2003, it seems the term was not widely used elsewhere. For example, Rainbow Youth, an organisation who since 1989 has worked with queer and trans communities to raise awareness around sexuality and gender diversity issues in Aotearoa/New Zealand, in its Youth 07 Report defined fa'afafine and takatapui but not whakawahine (see Youth 07 - http://www.rainbowyouth.org.nz/wpcontent/uploads/2013/10/Report-Digital.pdf, pp. 4 - 5). This lends support to my contention that the use, "emergence and increasing popularity" (Murray, 2003: p. 238); of the term whakawahine is very recent.

Tess Lomax, writing in the same year, defines whakawahine this way:

"Whakawahine are males who have been sufficiently compelled by their gender issues to take hormones and/or undergo surgery in order to appear and live as women. These are transsexuals under Western cultural concepts. Whakawahine also include feminine boys who are born like that and who live as females but don't undergo body changes” (2007: p. 83). 
Clearly there is not one unified definition of whakawahine. The NZAF

claims that:

"[i]n the language of our ancestors [Maori], there was no pronoun distinguishing gender such as he or she, there was ia, which was used to distinguish that person regardless of gender. So was there a Maori word for Transgender? Were our ancestors aware that some gender is not defined?” (2010: p. 3).

To paraphrase Murray, whakawahine may be different from transgender and transsexual in that it is not English and therefore operationalizes or code that highlights some form of difference when inserted into an English sociolinguistic context (2003: p. 239).

\section{Maori sexuality}

Documentation of same-sex relations between men in pre-contact Maori society is very sparse (Moloney, 2005: p. 44). It appears that there was little room for homosexuality in European perceptions of Maori society:

"The absence of any mention of homosexuality in early documentation of Maori society has more to with the morals and values of the authors, that is, $19^{\text {th }}$ century Europeans" (cited in Murray, 2003: p. 236).

Previous research seems to support the view that missionaries' 'repugnance towards sexual and gender diversity' (Te Awekotuku, 1991: p. 37) explains whakawahine's absence from the historical record. Much information about Maori sexuality in historical times was distorted or reconstructed in order to make it more palatable to the colonizing powers (Hutchings and Aspin, 2007: p. 5).

Historical accounts of Maori sexuality derive from a limited range of sources including oral accounts, archival material and carvings (ibid). For Maori, oral accounts have always been an important means of transmitting knowledge from generation to generation (Aspin, 2012: p. 115). The arrival of Europeans in Aotearoa/New Zealand in 1769 led to the disruption of a vital channel of communication that had been refined over 
thousands of generations and eventually contributed to the suppression and obliteration of important ancestral knowledge (ibid). From a postcolonial perspective, Maori lesbian activist Ngahuia Te Awekotuku (1991: p. 37) claims that:

"We should reconstruct the tradition, reinterpret the oral history of this land [Aotearoa/New Zealand], so skillfully [sic] manipulated by the crusading heterosexism of the missionary ethic".

More recent Maori literature reveals that whakawahine are different from takatapui. Takatapui or hoa takatapui is a Maori term used by Maori Lesbian, Gay, Bisexual and Transgender people LGBT (see http://www.wellington2011.org/transcript.html?id=2-1305931792-274; http://www.rainbowyouth.org.nz/about/). Maori LGBT may identify as takatapui tane (gay Maori), takatapui wahine (lesbian Maori), whakatane (Maori transwoman) or whakawahine (Maori transman) [Sears, 2005: p. 593]. The identification of self as takatapui or whakawahine/whakatane upholds a specific identity that melds ethnic, sexual and gender identities (ibid). It requires an acceptance of self as both lesbian/gay/transgender, and as Maori (ibid).

\section{Conclusion}

In this chapter I have discussed the various perspectives of fa'afafine and whakawahine by Samoan, Maori and western researchers, including missionaries. This provides a context for my research. What becomes evident from the literature is that there is no universal understanding of what it means to be fa' afafine or whakawahine. Some claim fa' afafine or whakawahine is neither transvestite, gay or transsexual. Some say the identity is imposed not biological in origin.

The dearth of literature about whakawahine emphasises the importance of the oral histories discussed in Chapters 4, 5 and 6. The following chapter describes the theoretical framework of this study. Methods, theories and methodologies are discussed: oral history, feminist research, queer theory and indigenous approaches. 


\section{Chapter 3 \\ Methodology}

"Proponents of an oral history approach argue that by talking directly to people about their memories, past aspects of their lives will be revealed which otherwise might be overlooked through lack of documentation or public record” (Bornat, 2012: p. 1).

"The use of personal experience as evidence is one of the ways feminist scholars and their research participants are actively collaborated to achieve epistemic empowerment” (Foss and Foss, 2013: p. 5).

\section{Introduction}

This chapter addresses theories and methodologies that have informed my study. In undertaking this research, I employed what I found to be the most appropriate methods. I aimed to utilize oral history, feminist, indigenous and queer approaches to the study of fa'afafine and whakawahine to analyse the experiences of narrators. I wanted to obtain first hand experiences of narrators who claim thisidentity.

\section{Oral history}

'Oral history is a unique theory and qualitative method of interview' (Leavy, 2011: p. 9) which 'recognises the significance of individual experience' (Ketchel, 2004: p. 90). It emerged from a recognition that traditional sources have often neglected less powerful groups such as women and the working class (Popular History Group, 1998: p. 4). I argue that fa'afafine and whakawahine have often been absent from the historical record and are also frequently silenced in their own societies.

Participants I interviewed have to date been largely unheard. Oral history offers a means of integrating these participants into 'historical scholarship and provides an inside view of their stories at the time (Sangster, 1998: p. 45). Also, as Robertson argues (2006: p. 3), oral history is a particularly vital research technique in the study of indigenous experiences. When 
applied to fa' afafine and whakawahine 'oral history assumes added significance as a powerful tool for the rediscovery of [their stories] so often overlooked and/or neglected in history and literature alike' (EtterLewis, 1991: p. 43).

Oral history is suitable as both a theory and method for this research because, as my literature review revealed, fa'afafine is an underresearched area, and whakawahine even more so. I chose oral history interviewing as my main method of data collection because it seemed the best way to find out about fa'afafine and whakawahine was to ask them directly. It is an ideal method for this research because stories sought 'straight from the horse's mouth' provide in depth stories about their lives from their own standpoint. When fa'afafine and whakawahine speak for themselves, they reveal their past and current experiences and perspectives that challenge the truths of official accounts and cast doubt upon established theories (Anderson et.al, 2000: p. 224).

\section{Fonofale model of health and Hibiscus flower model}

Pulotu-Endemann’s (2009: p. 1) 'Fonofale model of health’ incorporates and depicts the values and beliefs of Samoans, Cook Islanders, Tongans, Niueans, Tokelauans and Fijians as well as other important components of Pacific people's health. See figure 1 below.

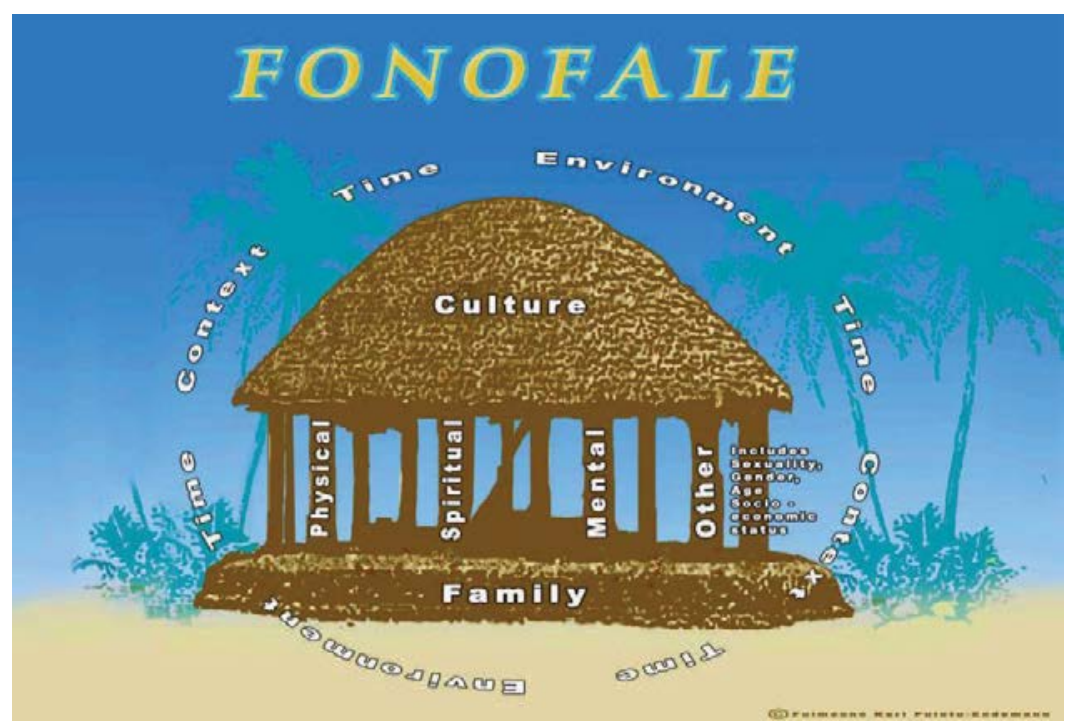




\section{Figure 1: Fonofale model of health}

Source http://www.hauora.co.nz/resources/Fonofalemodelexplanation.pdf p. 2)

The traditional Samoan house is used as a metaphor to explain the floor family; the roof - culture; and the four posts which support culture spiritual, physical, mental and other factors such as sexuality, gender, age, social, economic and status. The 'Fonofale model of health' focuses on Pacific people's health, the components of family, culture, sexuality, gender, age and status that are useful in my research. I adapted the previous model to the 'Hibiscus flower model' which is most appropriate for my research as it signifies and captures a fa'afafine's identity and can also incorporate whakawahine. Specifically, a hibiscus flower is worn by some fa'afafine (not all) in various ways. For example, it is worn on the top of a fa'afafine’s left or right ear or pinned in their hair as well as printed on their Samoan clothing such as a puletasi or a lavalava.

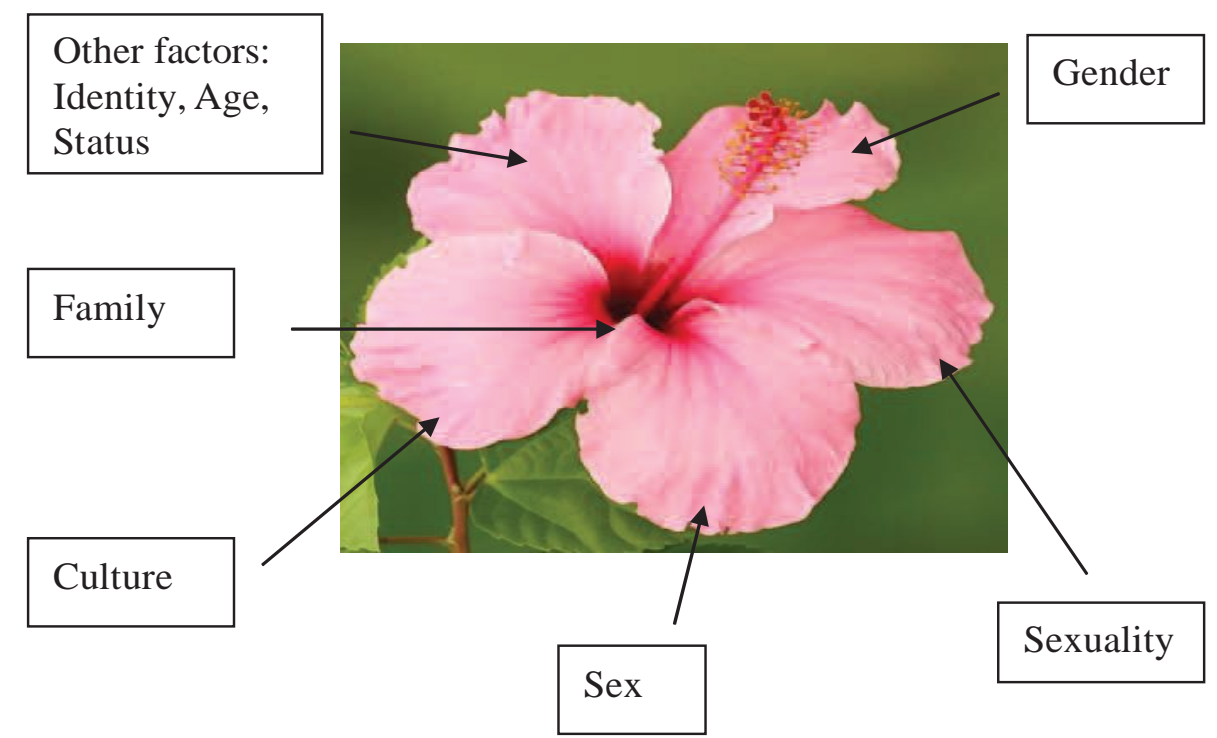

Figure 2 - 'Hibiscus flower model'

The hibiscus flower is employed as a metaphor because it symbolizes the femininity of a fa'afafine and whakawahine. I argue that the 'Hibiscus flower model' is useful to examine the life and experience of a fa'afafine 
and whakawahine drawing on similar components of the Fonofale model of health' from a fa'afafine perspective such as family, culture, sexuality, gender, sex and other factors such as status, age, identity. Defining what it is to be a fa'afafine or whakawahine is to include all aspects of what contributes to being a fa'afafine or whakawahine - the core of the hibiscus is family and each of the petals represent culture, sexuality, sex and gender and other factors such as identity, age and status (see Figure 2).

\section{Queer theory}

I found aspects of queer theory useful for my research. I draw on queer theorist Annemarie Jagose's (1996: p. 3) definition of queer, as an 'umbrella term for a coalition of culturally marginal sexualidentifications'. In a similar manner, John Fenaughty (2004: p. 73) describes queer as an umbrella category consisting of 'lesbians, bisexual, transgender women, gay and bisexual men’. Craig Young (2004: p. 47) claims that queer refers to the 'dialogue and negotiated relationships between lesbians, gay men, bisexuals and transgender people who have diverse gender, ethnic, class and sexual identities'. Similar to Jagose's notion of queer, Denzin and Lincoln (2005, p. 25) state that queer theory challenges the homosexual/heterosexual binary and sex/gender split. The fluidity of sexual categories means that modern lesbian, gay, bisexual and transgender identities are fractured along with heterosexual ones (ibid).

How relevant are queer approaches to this research? Queer theory provides ways to understand and explore terms like queer, gay, and transgender, transvestite, transsexual and examine what they have to offer fa'afafine and whakawahine. It could be argued that if queer is an umbrella term then it may also be used to include the distinct categories of fa'afafine and whakawahine.

\section{Gender as performance}

Feminist theories of gender are well known (see for example, Butler 1999; de Beauvoir, 1953). Butler (1999: p. 18) describes gender as a constituted performance whereby gender is 'always a doing' and 'an act which has 
been rehearsed and requires individual actors as the body becomes its gender through the series of acts which are reproduced, renewed, revised and consolidated through time'. Here Butler describes the action of gender requiring a performance that is repeated and thus this repetition is a reenactment and re-experiencing of a set of meanings already socially established (ibid). I draw on Butler's theory (1999: p. 19) of a 'series of gender acts' to examine and describe the repeated roles already 'socially established' for fa'afafine and whakawahine, for example, the domestic roles of cooking, cleaning and care giving.

Butler's (1999: p. 20) assessment of 'drag' has been the cause of much debate within feminist circles. Drag has not been universally accepted within feminism, it has either been interpreted as fundamentally demeaning to women or when performed by lesbians as based on an unthinking and hence unacceptable appropriation of heterosexual norms and practices (ibid). Some of these so-called men could do femininity much better than I ever could, ever wanted to, ever would (ibid). I employ Butler's notion of 'drag' to 'distinguish between the anatomy of the performer (biological male) and the gender (fa'afafine or whakawahine) that is being performed' (ibid). Simone de Beauvoir's (1974: p. 15) notion of ‘one becoming a woman' will be a useful theoretical perspective in a fa' afafine and whakawahine context in terms of whether one becomes a fa' afafine and whakawahine (social construction/nurture) or one is born a fa' afafine and whakawahine (biological determinism/nature) (see de Beauvoir, 1974).

\section{Feminist research}

There is a continuous debate in feminist literature about whether feminist research can be undertaken by men. Feminist research is a popular research model carried out by women and men who identify as feminists to capture women's lived experiences (Wadsworth, 2001; Vardhan, 2012). It studies the social condition of women and other oppressed groups often silenced and ignored in a sexist, malestream and patriarchal society (ibid). Feminist research is by definition, research that utilizes feminist concerns 
and beliefs to ground the research process (Brayton, 2012: p. 1). 'It seeks to benefit or empower the researched population in a direct and personal way’ (McInnes cited in Garrett 2010).

As with men researching male experiences, I aimed to employ appropriate 'feminist principles throughout all stages of my research' (Brayton, 2012: p. 10). These principles (below) are central tenets which inform and act as the framework guiding the decisions being made by me throughout my research (ibid).

- Research by, for and about fa’afafine and whakawahine

- Narrators voices prioritised in the research

- Ethical behaviour

- Acknowledgment of shifting power between researcher and researched

- Empowerment of narrators and giving them a voice to speak from their own perspectives

- Reflexivity

\section{Why fa'afafine and whakawahine?}

My initial research was to be a comparative study of outwardly similar Polynesian identities - the fa' afafine of Samoa, the fakaleiti of Tonga, the mahu of Hawaii and the whakawahine of Aotearoa/New Zealand.

However, this project proved too vast in scope for a Master thesis. I therefore narrowed my focus to fa'afafine and whakawahine. Preliminary research reveals that whakawahine is similar linguistically to fa'afafine and terms in other Polynesian languages (see Chapter 2; NZAF, 2010). A review of existing literature on fa'afafine led me to write this thesis because some information about fa'afafine by non-fa'afafine requires further explanation. The dearth of whakawahine literature also led me to question why research about whakawahine had not been carried out earlier, and reinforced the view that research into this topic was timely. 
As Chapter 2 revealed, Mead's (1943) research has been influential in western understandings. In addition, fa'afafine has a predominantly western focus in most the literature. Many other researchers, as mentioned in my literature review have associated fa'afafine with homosexuality, transgender, transvestite, transsexual, gay, androphilic males and hermaphrodite. These researchers have interpreted much of their findings through their non-fa' afafine lens making generalizations about fa'afafine that are often challenged and rejected.

Fa' afafine and whakawahine have been "silenced in a major way both by research and research writers” (Nabobo-Baba, 2004: p. 18). However, research (particularly oral history) can allow the silenced to speak (ibid, p. 26). Part of the focus of this study is to fill in some of the gaps in the current literature from the perspectives of self-identified fa'afafine and whakawahine in a Samoan and Maori context. Because of this, I aimed to avoid the problem that 'research has generally served the purposes of the researcher rather than the researched' (Letherby, 2003: p. 6). I attempt to counter this by making narrators' voices prominent in my research.

\section{Insider research}

'Insider research' is used to describe projects where the researcher has a direct involvement or connection with the research setting (Rooney, 2012: p. 1). My situated perspective is that I am a self-identified Samoan fa'afafine, fluent in the Samoan language and have several fa'afafine family members on my mother's side and a few on my father's side of the family. Feminist researchers locate themselves within the research and experience is considered a valid form of data (Letherby, 2003: p. 6). I bring my own fa' afafine experiences and 'history into the role of research and the research process' (Brayton, 1997: p. 5). I am studying narrators from my ‘own community' and ‘identity group’ which I ‘come from' and 'belong to and identify with' (Pillow and Mayo, 2007: p. 162). My personal experience as a fa' afafine gives me an insider perspective which I argue allowed me ease of access to locate and contact fa'afafine in Wellington for my research. 
Smith (1999: p. 138) claims that there are different ways of both 'being an insider and outsider in indigenous contexts'. Being an insider provided both advantages and disadvantages with fa'afafine narrators. In most respects, I had the advantages of connecting with fa'afafine participants through commonalities such as the Samoan language and culture, similar upbringings and experience of living in Samoa and Aotearoa/New Zealand as a youth. One of my fa'afafine narrators, Honey, had this to say:

“...I really do hope you can prove all these European authors and writers with their books and their so-called facts which are all bullshit and rubbish...I believe and I know that only a fa'afafine can tell the story of a fa'afafine and about fa'afafine...”.

From a post-colonial perspective, Rohatynskyj and Jaarsma (2000, p. 4) claim that natives are in the best position to represent themselves and speak with their own voice to conduct research. To paraphrase, I do not believe that only fa'afafine interviewers should record fa'afafine oral histories, or obtain narratives describing fa' afafine (Laurie, 2004: p. 62). But it is important to consider, who speaks for whom, how and for whose benefit? (Spivak, 1998: p. 5).

Laurie (2004: p. 62) argues that 'no oral history interviewer is fully an insider since we always stand outside peoples lives'. While I am an insider by ethnicity and as a fa'afafine, I am an outsider because of my level of tertiary education and youth compared to some fa' afafine. With whakawahine I am an outsider as I am not Maori. However, my fa'afafine identity meant that I shared some common experiences with whakawahine. In order to guide my research, I enlisted the assistance of Maori 'guardians' who are insiders to ensure I acted in accordance with Maori tikanga (see page. 45).

\section{Power, empowerment and ethical behaviour}

How did I attempt to empower narrators in my research? My relationship with narrators was based on mutual trust and respect. They were aware 
that participation was voluntary and that if that they did decide to take part, they could withdraw any information traceable to them from my project before data was analysed without having to give reasons or without penalty of any sort. They chose the location of the interview such as their workplace, the library or wherever they felt comfortable. Some volunteered to be identified in the recorded interviews and the published results (see Appendix 4, p. 102). Not all narrators want to remain anonymous; some are adamant that their name should appear in research (Hall, 2004: p. 158). Eight narrators wanted their full names to be published in my thesis. Two narrators chose a pseudonym. I explained to all participants that they could refuse any questions I asked them and they could stop the interview at any time if they felt uncomfortable. As Portelli (1997: p. 54) argues, the narrator decides what he or she wishes to tell. I gave narrators the opportunity at the end of each interview to add anything they felt had been left out. Confidentiality and archiving were determined by narrators (see Appendix 4, p. 102). I returned interviews to them on compact discs and provided transcripts for adding, editing or making changes.

Transcribing interviews involves 'a word for word copy, but it is impossible to translate the associated body language and the subtle nuances of speech - the deliberate pause, the ironic inflection, the raised eyebrow that accompanies a statement’ (Edwards, 2004: p. 104). Also 'volume range and the rhythm of speech carry implicit meaning and social connotations which are not reproducible in writing' (Portelli, 1997: p. 47). Recorded interviews are the 'original and verbatim records - the primary document' (Ritchie, 2003: p. 66). I focused on what Portelli (1997: p. 47) terms ‘orality of narrators' and decided not to fully transcribe narrator's interviews. Considerable time was spent transcribing selected extracts from narrators' interviews. This process allowed me to 'familiarize myself with the data by reflecting on them time and again and this formed the basis of the subsequent analysis of transcript data' (Harrison, 2001: p. 17). I reassured narrators that their stories were of great value and unique. 
I discussed with narrators the information from their transcripts to 'realign balance of power in the research relationship by minimizing appropriation through deliberate attempt to misrepresentation and stereotype' (Costa, 2005: p. 50). I aimed to 'protect narrators who may have spoken too freely during the interview due to the informal nature of the interviews and close friendship between us' (ibid, p. 52). I did this by returning transcripts containing extracts which I wished to use in my research and obtained each narrator's agreement to do so. I was aware that narrators may have been surprised when reading their transcripts because 'there was no guarantee that informants will realize before any interview begins what they might reveal, in what ways, or at what risk' (Hall, 2004: p. 158). In addition, the shifting nature of interviews between informal and formal may have 'created a blurred line between the role of a friend and that of research participant' (Lee, 1993: p. 107). This is the reason why I asked narrators to sign the 'agreements at the end rather than the beginning of the project' (Hall, 2000: p. 15) [see Appendix 4, p. 102].

I employed what Smith (1999: p. 137) calls a 'mentor' as the first point of contact with whakawahine participants' because I did not have the same advantages as when interviewing fa'afafine participants. This process involved whakawahine narrators guiding and suggesting relevant material which may be useful for my research. Although, I did not involve them in the formulation of the interview guide, I did give narrators their transcripts to read and comment on before commencing my analysis and asked follow up questions as required. However, as Reinharz (1992: p. 15) argues that there are boundaries to empowerment because at the end of the day it is the researcher who takes away the information and interprets it.

\section{Reflexivity}

Reflexivity involves critically examining and exploring the nature of the research process (see Jaggar, 2008). This may entail reflecting on methods of data collection and analysis or what works well for the researcher, what does not and question why (Hall, 2003: p. 37). Upon reflection, I had to constantly remember that the purpose of this project was to discuss 
fa' afafine and whakawahine from the perspectives of narrators. Although my fa' afafine experiences are relevant in this research, narrators' voices should dominate. Smith (1999: p. 137) notes the problem of 'insider research is the constant need for reflexivity'. I found myself continuously being reflexive and reminding myself that this thesis is not about me. I aimed to avoid assuming that personal experience is all that is required. As Smith (1999: p. 139) says, this would have been 'arrogant'.

Researchers must always reflect on the ways in which their research is influenced by their own social positioning, their gender, race and class (Jaggar, 2008: p. 10). I shared an ethnicity (Samoan) and identity (fa' afafine) with fa' afafine narrators. This can 'promote a genuine rapport in the interview which leads to greater self-disclosure and the collection of better data' (Lee, 1993: p. 108). However, I have not experienced hormone treatment or gender re-assignment like some fa'afafine and whakawahine narrators’, so I was not a complete insider.

As mentioned earlier in this chapter, I was influenced by the feminist oral history tenet to give a voice to narrators. Like some of the narrators, my story has been largely unheard. I endeavored to respect narrators regardless of class, ethnicity and their opinions of fa'afafine and whakawahine issues. I was aware of the age gap between myself and all narrators. Respecting older people proved to be of great value in my research (a custom of the Samoan culture). I kept in mind that narrators could not comment on what they did not know such as detailed history of the fa' afafine in Samoa and the whakawahine in Aotearoa/New Zealand.

Being non-Maori and non-whakawahine created problems. The dearth of literature about whakawahine meant that there was less information about whakawahine than fa' afafine in my literature review, issues beyond my control. I had little knowledge of the Maori language and the Maori culture. I endeavoured to be 'humble, listen carefully and show respect to avoid the issue of walking over the mana of my whakawahine narrators' as advised by Smith (1999: p. 139). As a Samoan interviewing Maori, it 
was an instructive experience that brought much comparison and contrast with fa'afafine narrators. For example, we share certain aspects of their identities and the translation of 'like a woman'.

In researching whakawahine, I could have chosen 'Kaupapa Maori' approaches of Maori research by, about and for Maori (Smith 1999: p. 183). However, I am not Maori nor whakawahine, therefore it was not useful for this present study. I utilized what Smith (1999: p. 139) labels a 'guardian of the researcher' whereby I enlisted assistance and guidance of prominent Maori people - Elizabeth Kerekere, previous Chair of Tiwhanawhana Trust and a board member of Lesbian and Gay Archive of New Zealand (LAGANZ); Dr. Ngahuia Te Awekotoku, Professor of Research and Development at the University of Waikato; Karen and Peri Te Wao, Organizers of Tapatoru; and Maori researcher, Kevin Haunui. Given the lack of academic research about whakawahine, I was fortunate to have the guidance of people with insider knowledge and experience.

\section{Ethics and procedures}

My research involves human participants in oral history interviews and Victoria University of Wellington Ethics Committee approval was therefore required. I submitted an 'Ethics Application' to the Ethics Committee supported by my supervisor Dr. Lesley Hall. Participants were first approached by phone. Each participant showed interest and all agreed to be interviewed and we arranged a suitable time and place to meet faceto-face so I could clarify in greater detail the Information Sheet (see Appendix 3: p. 100), Consent Form (see Appendix 4: p. 102) and Oral History Recording Agreement Form (see Appendix 5: p. 104). I explained to participants that I would like to interview them about their personal experiences, for example their upbringing, family roles and their own and others' understanding of what it means to be a fa'afafine or a whakawahine. I also made clear to participants that material collected would be treated confidentially and no other person besides me and my supervisor would listen to the recordings unless they specified otherwise. The pilot interview was also an opportunity for participants to ask 
questions. After the initial face-to-face process, we then arranged a convenient time and place to conduct the oral history interviews. The recording equipment was the Digital Recording Equipment Fostex FR2LE ${ }^{1}$ with AKG C417PP clip-on microphones. I hired this equipment from the Oral History Centre at Alexander Turnbull Library in Wellington.

Any topic could potentially be sensitive depending on the people being researched and their feelings about the topic (Dickson-Swift et.al, 2012: p. 5). Anne-Marie Tupuola's thesis (1998) discusses the issue of addressing taboo or sensitive topics in her study which conflicted with the values of some participants she interviewed, for example, Samoan sexuality and the discontent some participants' expressed towards discussing anything sexual (1998: p. 106). Some participants in her research argued that it is not appropriate to do research about sexual identity or anything sexual because it is showing disrespect to the Samoan culture (ibid).

Consequently, Tupuola (1998: p. 108) altered sexual identity to personal identity in her thesis. The underlying reason for that was that she did not want to condone homophobic perspectives of sexuality, nor did she wish to overly emphasize any Christian values or judgments (ibid).

My research also deals with some sensitive issues. Some narrators in my research were more open than others to discussing delicate topics of sexuality, hormone treatment, sexual re-assignment and the general acceptance of fa'afafine and whakawahine. What people perceive to be sensitive may vary across different cultures, genders, age, situations or a number of other factors (Dickson-Swift et.al, 2008: p. 5). One potential narrator was slightly reluctant to answer questions about fa'afafine sexuality and hormone treatment. I dealt with this by following her lead about what topics were discussed and when. I was cautious not to push this narrator with the result that in later interviews she seemed more comfortable answering questions about fa'afafine sexuality.

I encouraged each participant to have their recorded interview archived at the Alexander Turnbull Library given that fa' afafine and whakawahine is 
an under-documented area. Four fa' afafine and four whakawahine chose this option. I explained the 'Oral History Recording Agreement Form' (see Appendix 5: p. 104) to participants whereby it protects their privacy and interests if they choose to archive their recorded interview. In the 'Oral History Recording Agreement Form' under 'Section 4 - Availability of interview', participants determine which content is available and restricted. The recorded interview, questionnaires, interview notes and similar materials will be archived if that is what participants choose. Participants who choose not to archive or have their taped interview returned to them will have their interviews removed from my recorder and hard-drive after the conclusion of my research.

\section{Oral history interview data analysis}

My main research question is what is the meaning of the fa'afafine of Samoa and the whakawahine of Aotearoa/New Zealand from the perspectives of those who identify this way. Open-ended interviews allow narrators to freely talk about their experiences and to elaborate as much as they choose (Yow, 2005: p. 14). I chose an open-ended approach for my interviews because it allows fa’afafine and whakawahine narrators to answer in 'any way they want and reveal things they feel important or relevant to the research' (ibid). I focused on what Portelli (1991: p. 50) calls 'thick dialogue' to 'reveal unknown events and cast new light on unexplored areas'. I liked Morrissey’s (1998: p. 14) notion of 'letting the interviewee talk as it is his or her show'. Interviewees volunteer their own accounts and have enough time to include all of the material they think is relevant to the subject (Richie, 2006: p. 15). The whole point of this research was to get information about self-identifed fa'afafine and whakawahine and an open-ended approach was useful.

Data collected from the oral history interviews with narrators have formed the basis of my research. My role was to listen and seek emerging themes from the oral history interviews. As an insider and outsider, interviews were analyzed for comparisons and contrasts between narrators' stories. I could then begin to find commonalities and differences between narrators’ 
such as upbringing, family roles, expectations, responsibilities and influences.

Through this process of analyzing, I uncovered that narrators are not the same and differences such as place of birth, class, age, education and ethnicity appear to influence how narrators’ remember the past. For example, a few whakawahine narrators' were older than others. Age difference meant that what they experienced was often different than other whakawahine narrators’. This illustrates Cotty’s (1998: p. 9) argument that people construct meaning in different ways. For instance, some narrators' associate the terms fa'afafine and whakawahine with gay, transgender and queen and are likely to view their definition differently to one another.

Portelli (1997: p. 5) reminds us that 'many stories or anecdotes may have been told many times within a narrator's immediate circle but the whole story has hardly ever been told in sequence as a coherent and organized whole'. What is discussed on or off tape depends on what narrators wish to reveal and communicate to that particular person at that particular time. An interviewer who is non-Samoan or non-Maori, a man or a woman, a gay person or a transgender person, another fa'afafine or whakawahine may have ended up with different stories than I did, or the same stories told in different ways. Of course not every detail is disclosed in every interview. As Hall (2010: p. 2) argues:

"Stories told in any oral history are not necessarily 'the truth'; they are simply versions of the truth, a snapshot taken at a particular moment in time when it was recorded”.

\section{Queer methodology}

In this research, I also draw on the work of Judith Halberstam (1998: p. 3) who uses ‘queer methodology', specifically what she refers to as 'scavenger methodology', by using different qualitative research methods. Halberstam employs 'queer methodology' to provide a 'complex and variegated picture of sexuality and its constructiveness' (ibid). She 
describes it as an 'interdisciplinary approach that combines information from people with information culled from texts' (ibid). Halberstam rejects the traditional social science project of surveying people and expecting to squeeze the truth from raw data (ibid). Her 'queer methodology' is consistent with 'grey literature' - research which is not formally published (see http://library.victoria.ac.nz/library/resources/guides/clnr401.html\#guidese ction.1151) and which suits my purposes for this research because of the lack of published research about certain aspects of fa'afafine and more generally of whakawahine. Lack of academic literature, especially about whakawahine, has meant that data collection for my thesis has involved books, journals, newspapers, articles, magazines, websites, blogs, youtube clips, pamphlets, brochures and digital versatile disc (DVD) documentaries to produce sufficient background information. Even so, there is somewhat of an imbalance between information obtained about fa' afafine and whakawahine. Rather than viewing this as a problem, I suggest it emphasises the need for academic study of whakawahine to be undertaken.

\section{Selection of participants}

I interviewed six fa'afafines and four whakawahines who were known to me. I am not using a sampling method and narrators are not representative in a methodological sense. As argued in Chapter 1, information from their narratives cannot be generalised to all fa'afafine and all whakawahine. I cannot speak for all fa'afafine and whakawahine 'but can provide new knowledge grounded in the realities of narrators experiences' (Brayton, 2007: p. 12). The narratives are snapshots of their experiences at the time of the recorded interviews. Therefore, this research is for the fa' afafine and whakawahine participants whose stories are told in this study.

\section{Conclusion}

In this chapter I have discussed the various theories: oral history, feminist, queer and indigenous that are most useful for this research. Oral history feminist, queer and indigenous methodologies have been described in 
order to demonstrate their usefulness for the current research. In the next chapters I discuss the findings from my research. 


\section{Chapter 4}

\section{Nature versus nurture}

"It is only that we are born, not made as fa'afafines and...the Samoan culture has a lot to with it... They embrace us as a child of Samoa ..". - Latoya

“...the woman determines the sex or gender of the child before its born and basically before the egg is fertilized by the male. So if the woman strongly wants a daughter but the male has a dominant male gene then there is a possibility maybe that child will be born masculine. Born male but yet have retained all the mother's genes as in the femininity...”. - Kayla

\section{Introduction}

This chapter discusses the meaning of fa' afafine and whakawahine from narrators’ perspectives. Most narrators associate fa’afafine and whakawahine with the translation 'like a woman', as having been 'born that way', as a 'gender identity' or 'gender role'. In addition, narrators share their understanding of the history of fa'afafine and whakawahine.

\section{The history of fa'afafine}

As shown earlier, previous research by all self-identified fa'afafine and most non-fa' afafine assert that fa' afafine have a lengthy history in Samoa and American Samoa. However, Mageo (1996, 1998; cited in Croall and Altmann 2005) casts doubts on early reports of fa' afafine by early visitors to Samoa. Despite Mageo’s and others' claims to the contrary, all fa'afafine narrators in this study state that fa'afafine have a very long history that began prior to colonization. For example:

“....the history [of fa' afafine] in Samoa [and in American Samoa] has always been there. It was there before the missionaries came in [circa 1830]”. - Athena

“I'm only going by what I heard...the history of fa'afafine in Samoa is something that has been around for centuries. Fa' afafine did exist before the missionaries came along. ”. - Latoya 
"I know for a fact that fa'afafine has been around for a long time”. Viane

"I believe that [fa' afafine have] always been around...I'm sure there were fa' afafine around before the missionaries arrived [in Samoa]”. - Honey

These narrators are adamant that fa'afafine have existed in Samoa and American Samoa for a very long time. Their viewpoints are supported by Pratt's writing (1839: p. 345); Mead's (1943: p. 121) depiction of Sasi in the 1920s; and Dology’s (2000: p. 200) findings of fa'afafine in the 1940s, 1950s and 1960s (see Chapter 2). In addition, the narratives reinforce some western research (see for example, http://www.teara.govt.nz/en/gender-diversityseefa'afafine) and most fa'afafine research (see for example, Vanessa, 2007; Pulotu-Endemann, 1997, 2012) which argues that fa'afafine have been part of Samoan communities for centuries. These narratives challenge Mageo’s (1992: p. 2) claim that fa' afafine is 'innovative' i.e. recent (see Chapter 2).

Hutching (1993: p. 58) argues that 'a testimony cannot simply be taken at face value' so the reliability of narratives should, like documents, be subjected to some scrutiny. Obviously the fa'afafine narrators I interviewed were not alive before the nineteenth century but that does not mean that their oral testimonies are false. As Portelli argues their narratives could be described as examples of 'historical fact' (1997: p. 50 ), what fa' afafine narrators actually believe to be true. In the extracts above - "I know for a fact....”, "I am sure....”, “I am only going by what I heard...." and "I am not an expert....”, 'do not cast doubt on what really happened' (ibid). Using Portelli's argument (1997: p. 51), when we discover that similar stories are told by each narrator, we recognize a 'half-formed legendary complex' in which the history of fa'afafine is disclosed. In reality 'many stories are told over and over, or discussed with members of the community’ (ibid: p. 52). As Hall (2003) argues, the 'truth' of oral accounts may be less important than the telling: "what people believe happened is often as important as what actually happened, 
for people think, and react in accordance with what they believe to be true” (McWhinnie, 1996: p. 7 - 8).

I cannot prove that a fa'afafine culture existed prior to circa 1830 in Samoa and American Samoa but, as demonstrated in Chapter 2, and as James Morrison has argued, the history of the colonized has rarely appeared in documents (1998: p. 1). However, it seems reasonable to claim that the history of fa' afafine did not commence yesterday.

Oral traditions are evident in Samoan explanations of the origin of the earth, the Samoan Islands, the chiefs and the people of Samoa from the time of creation (Meleisea, 1987: p. 10). And for oral cultures such as Samoa: 'rituals, dances, chants, songs, honorifics, family genealogies, names of places, people and events were [all] tools for recording history’ (Sua'ali'i-Sauni et.al, 2009: p. 115). Family genealogies, for example, trace back to ancestors and to a particular God. It is possible that Athena's, Latoya's, Viane's and Honey's statements are a consequence of an oral tradition in which information about fa' afafine has 'been handed down by word of mouth from generation to generation' (Hutching, 1993: p. 2). Confirmation of this view can be seen in Latoya's narrative:

“Before the missionaries came in, we [Samoans] weren't able to document our history.... because in our day [pre-contact] everything was passed by memory and it was passed down [from] generation to the next generation. When the missionaries came in of course everything from then on was written about the history of Samoa and...in their eyes fa'afafine was taboo, it was hushed or never mentioned”.

Research about 'third genders' in other cultures such as two-spirit people in North America (Hemmilä, 2005) reinforce Latoya’s understanding. In historical European accounts information was often filtered out: "the exact nature of their (third gender) sexuality is most often left vague” (ibid: 129). Latoya appears to believe that the missionaries had some effect, not necessarily positive, on the changing perception of fa'afafine. They, with the exception of Pratt, were instrumental in ensuring that fa'afafine were 
left out of the historical record, perhaps because it was something they could not relate to. Hemmilä's claim seems equally applicable to fa'afafine:

“The disjointed representation of the status [of two-spirit people] in historical documents must partly be due to the difficulties the colonizers experienced when reporting about something alien to them and of which they obviously had only partial understanding (ibid: p. 8)".

Societies are complex; culture is not static; they change as shown by the westernisation of Samoa. Each fa'afafine narrator told their own version of the history of fa' afafine and as Meleisea (1987: p. 10) argues, 'each version has special meaning and importance' to that narrator. Lia's story harks back to faleaitu, the form of entertainment in Samoa's pre-colonial and pre-missionary period (Mageo, 1992: p. 4).

“There [were] fa' afafine back in the days pre-colonial...they were seen as comedians, they were not allowed soo [sic] much to be girls...they were like in between. I think back in the days when you become a comedian people just call you.... fa'afafine because of being a comedian. But not soo much, not as you are expected to fully be a fa'afafine, you can be a comedian, portray yourself as a fa'afafine back in the days but you still a straight guy, still have a life, wife and children”.

This narrative portrays fa'afafine in the traditional role of entertainers. Her understanding is that in the past fa' afafine were heterosexual, married men with children who, as entertainers, took on a feminine role. Similar examples can be found in entertainment today with Samoan entertainers such as Aunty Tala and Fai of Laughing Samoans.

Viane's narrative contrasts with those above: “I don’t think there were fa' afafine [present when the missionaries arrived in Samoa]”. How she arrived at this conclusion is unclear but it is possible that she, like many Western researchers, is influenced by the lack of supporting written evidence (see Chapter 6 for further discussion of this). However, one function of oral traditions is legitimization (Meleisea, 1987: p. 10). Confirmation of the historical presence of fa'afafine pre-colonization, if 
that were possible, could serve to validate their identity in contemporary Samoa. Later, Viane does say that “there were fa'afafines in my grandfather's family before the 1950s”. This supports Dology’s findings (2000: p. 200).

\section{The history of whakawahine}

As Chapter 2 revealed, there is a relatively small body of literature about whakawahine. However, all whakawahine narrators in this study claim that a whakawahine culture existed prior to missionary and colonial contact in Aotearoa/New Zealand. For example:

"In pre-European history, a lot of our traditions and legends and our stories... were oral. Most of them relate to two males....but there would have been men who were very effeminate in their ways ...". Chanel

Chanel appears to suggest that whakawahine are largely absent in any Maori tradition or legend. The two male tradition she refers to is demonstrated in Te Awekotuku's retelling of the famous Maori romance 'Hinemoa and Tutanekai’:

"Tutanekai, with his flute and his favourite intimate friend, his hoa takatapui, Tiki and Hinemoa, the determined, valorous, superbly athletic woman - my ancestress - who took the initiative herself, superbly swam the midnight water of lake to reach him and interestlingly, consciously and deliberately masqueraded as a man, as a warrior, to lure him to her arm” (1991: p.37).

What this suggests is that Tutanekai had a male intimate friend and that Hinemoa had to behave as a man to get his attention. As in the history of fa' afafine, I cannot prove that whakawahine existed in Aotearoa/New Zealand's pre-missionary and pre-colonial period. However, Salmond's research suggests they did (see Chaper 2, p. 28) and this would appear to support Maori narrators' convinction that people now labelled whakawahine existed pre-contact. Shaniqua says:

“...there was a whakawahine culture in Aotearoa pre-European contact....The greatest influence for the loss of our understanding of whakawahine was through colonisation....our culture was oral....By 
the time that the tauiwi [non-Maori] got here, they had noticed certain things in our culture which were different from theirs, such as whakawahine.... Whakawahine was considered a natural crime... and people were put to death by natural crimes in their laws.... d doubt if they [were] interested [in] writing about anything un-natural.... Most of all our knowledge has been fragmented through colonisation and, because our history has been handed down orally and not written.... all that knowledge we had about whakawahine would have gone 100 years ago....”.

Similarly to the Samoan culture, Maori culture is also an oral culture (see Mallon et.al, 2012; Te Awekotuku, 1991): 'that has been passed down through generations' (Keevan, 2004: p. 145). Chanel and Shaniqua reinforce Keevan’s (ibid) and Aspin’s (2012: p. 115) view that Maori oral accounts have always been an important means of transmitting knowledge from generation to generation. This is similar to Latoya's narrative in a Samoan context. For Shaniqua, colonization has impacted on the traditional understanding of whakawahine. Smith (1999, p. 174), from a post-colonial perspective, argues that the colonization of Maori culture has threatened the maintenance of knowledge and the transmission of knowledge that is exclusively or particularly Maori. Maori history has been filtered through colonial, heterosexual eyes, to the exclusion of stories that reflect Maori history and traditions (Hutchings and Aspin, 2007: p. 15). Colonization perspectives have 'undermined acceptance and celebration of sexual diversity’ amongst Maori (Aspin, 2011: p. 113).

Shaniqua's narrative echoes Latoya's view that tauiwi (non-Maori) had some effect, not necessarily positive, on the perception of whakawahine and their absence from the historical record. As with two-spirit people, the point of view Europeans took in their representations of whakawahine was tied to their social background and the socio-political currents of the time (Hemmilä, 2005: p. 8). The colonizers “shame and fear” may account for people being excluded from their written historical records (McBreen, 2012: p. 13).

Chanel and Kayla evoke the 'Whakatane' legend (see Chapter 2) as an explanation for the term 'whakawahine': 
"The word whakawahine comes from the story of Whakatane. Whakatane, Whakatane i ahau which means 'give to me the strength of a man so I can pull this boat in'...she pulled the boat into the shore and that's where the term whakatane comes from; give me the strength to pull this boat in because the men were ashore. So...the opposite of Whakatane is whakawahine. It means basically to be like, to have the essence of, or to have the ways of a woman”. Chanel

"[whakawahine relates to the term]....whakatane which means...' like a male [and] goes back to the Maori legend when the place Whakatane was realized and the boat being brought in, it was a woman, Maori woman, who called to the crew 'Pull the boat in'...Whakatane... 'like a man'....But the name Whakatane..., it's a name, place and it relates to a specific thing like a historical event sort of thing, cultural thing...”. - Kayla

What both these narratives do is to explain whakawahine (like a woman) as the gender opposite of whakatane (like a man). Although Kayla links the place Whakatane with an historical event well rooted in Maori culture, she is, like Te Awekotuku (1997: p. 37), retelling the story in a way that is not only "intriguing” (ibid: p. 37) but also gives credibility to the term whakawahine.

All whakawahine narrators claim that the term is a recent phenomenon compared to fa'afafine. For example:

"First time I ever heard the word whakawahine was not even a year ago”. - Renee

“...that word whakawahine is really a new word. It is not as old as the word that they use in Samoa....[whakawahine is] probably similar to fa' afafine, fakaleiti, 'akava'ine.... We like the one that sounds like our Pacific sisters [whakawahine]”. -Chanel

"The term whakawahine has only been brought to light in the last decade or so....that name [fa'afafine] was around decades before whakawahine! I think we maybe one of the last Pacific Island nations to bring up our name in the last ten or so years....Even though it's a recent term, it's built momentum over the years.... Over all I see it as a progression. There's more awareness being made of a collective for Pacific Island cultures... It's just that in our own culture we have our own name. In Samoa you have one name fa'afafine....in Fiji they have another name for it. Same as Tonga, Rarotonga, Niue....”. - Kayla 
What these narratives show is that the use of the term whakawahine is relatively recent in Aotearoa/New Zealand. However, that does not mean that there were not people who would now be called whakawahine precolonization. Reinforcing Te Awekotuku’s (1991: p. 36) claim, however in a whakawahine context, whakawahine are inheritors of a Polynesian tradition - the mahu of Hawaii, the fakafefine of Niue, the fakaleiti of Tonga, the 'akava'ine of the Cook Islands and the fa'afafine of Samoa. According to the NZAF (2010: p. 18), it seems that the use of whakawhine as a term of description has developed as a response to other Polynesian traditions and is a Maori translation of fa'afafine. Athena, for example, highlights the similarities which support this claim:

"If the Maori have placed whakawahine as a term to identify their ...males who are playing the female gender then I would say whakawahine is the same as fa' afafine but note...that these two terms come from two cultures and different settings”.

\section{Is fa'afafine 'like a woman'?}

As discussed in Chapter 2, the meaning of fa'afafine is difficult to pin down. One cannot isolate a set of characteristics such as sex, gender, culture, sexuality, status, identity, ethnicity, femininity and masculinity to describe a fa'afafine. Fa' afafine narrators seek the definition which best suits them based on factors such as place of birth, age, upbringing, influences and so forth. As this study reveals, fa'afafine means different things to different fa'afafine narrators. For example:

"[fa' afafine is a] term or a label that is referred to biological men or someone that is born a man with masculine characteristics, who embraces both the masculinity and femininity side”. - Honey

Honey's depiction echoes feminist debates about the sex and gender distinction (see for example Butler 1999; Lykke 2010; de Beauvoir, 1984; Oakley, 1986). For Honey, to be labelled a fa'afafine means that one is born a male (one’s biological sex) but one who embraces both masculinity and femininity (gender). Athena has a similar understanding of what being a fa'afafine means: 
"[Fa' afafine is] basically a Samoan boy who grew up to be a girl in the family.... The word fa'a means 'way of' and fafine is 'woman' in Samoa so basically if you look it in those terms its 'way of a woman'...and in Samoa we have fa' afafine meaning boys or males who take up the female gender roles within their families and not necessarily just within their families. They [fa'afafine] go from family, in the church and at work, in the workplace and basically it means living life twenty-four seven as a woman....We (fa' afafine) place a big value on our family”. - Athena

Athena emphasizes the importance of family which links back to the Hibiscus flower model. What she appears to argue is that 'ways of a woman' relate to female roles that fa'afafine perform. Athena foregrounds femininity throughout her narrative. She says that she "leans more to the female side, not [so] much to the masculine side”. Lia's and Athena's narratives suggest that their identities encompass all things that relate to being womanly from domestic roles to wearing female clothing and undertaking 'women's work', occupations such as seamstress and housegirl.

Clearly, in Honey's and Athena's narratives to identify as a fa'afafine is to make a statement about a person's culture, gender and/or role. Their extracts confirm Schmidt's (2005: p. 203) claim that:

“[t]o be fa'afafine is to necessarily imply two things - that one has a male body but engages in some behaviours that would be considered feminine, and that one is Samoan. Thus, to identify as fa'afafine is to make a statement about one's identity in relation to both gender and ethnicity".

Reinforcing Schmidt's claim, Athena describes fa' afafine as: 'Samoan'; a sex: 'boy/male'; and a gender role: 'female'. Honey’s and Athena’s extracts explain what fa'afafine actually do.

Viane differentiates between different kinds of fa'afafine:

“Fa' afafine to me, one is like a woman - fa'a is like and the fafine is woman who is like a woman. Then you have the other sort of fa' afafines....males attracted to females but have that woman, feminine inside, has the woman spirit”. - Viane 
For Viane some fa' afafines are males who are attracted to females but who may feel 'more like a woman'. Sexual orientation and fa' afafine will be discussed further in Chapter 5. Latoya had a different view:

“[fa'afafine means] 'wanting to be a woman' or 'feeling like a woman'. Fa'a means 'mannerism' or 'ways'; fafine means 'woman'”. - Latoya

Latoya's narrative seems to be similar to transgender narratives in feeling like a 'woman'. A common theme in transgender literature is that one ‘feels’ a different gender from one’s biological sex. For example, Aunty Daphne says:

“It's not that I can't or won't be a man, it's just that I'm not used to it, I've always been a girl...I feel that way, I don't know what it's like to be a man, I know what it's like to be a woman (NZAF, 2010: p. 13)”.

Honey, Athena, Viane and Latoya seem to share the idea that fa'afafine is 'like a woman' but what does this mean? Schmidtargues:

"[I]n the reality in which palagi women and transsexuals live, to be woman necessitates having a vagina and in the reality of most Samoan women and fa' afafine lives, to be a woman necessitates bearing children (or at least having the capacity)” (2005: p. 105).

As will be discussed in Chapter 5, most fa'afafine narrators have had gender reassignment surgery. Thus, by Schmidt’s assessment they are to some extent women.

\section{Is fa' afafine a role?}

As previous western research revealed, [t]he preference for women's work is the most cited marker of the femininity of fa' afafine' (Schmidt, 2003: p. 99). '[R]egarding chores around the house, fa' afafine differ from other Samoan males in that they are known to perform women's chores instead of, or in addition to, men's chores' (Kaltenborn, 2003: p. 77). Most fa' afafine in this study associated femininity with the domestic roles that 
one performs. Their narratives are good examples of what Butler (1999: p.

18) calls 'gender as performance'. For example:

“...sweeping the floor, tiding up the house, raising of kids, helping your mum and stuff like that, all the femininity stuff and all chores that a girl would do, [that would] be imitated by the fa'afafine or would be carried by a fa'afafine”. - Lia

“...cleaning, washing, weaving mats, we are an asset to the family in terms of gender role. Caring for our elderly, sick and young ones. We are our mother's right, shadow... wherever a mother would go a fa'afafine would follow. We are attached more to our mothers and we are the back of the family in term of providing service....”. Latoya

“...house cleaning, cooking and helping around the house, providing for the family and parents...there are fa'afafines in Samoa basically doing the same roles. Fa'afafines usually take up the female roles of what girls usually do house cleaning, ironing, cooking food, taking care of the elderly....”. -Athena

"Roles for me were cooking, cleaning which were similar to what my sisters do... responsibilities [were] babysitting.... think you it's like a mixture like you can be outside mowing the lawns or doing something outside and could be doing the washing at the same time and still be a fa' afafine... When it comes to chores...[fa'afafine] can do both”. - Max

Clearly, these fa'afafine narrators illustrate that the role of fa'afafine is defined in relation to what is perceived as women's work. Their narratives are supported by Pratt's definition of "belonging to women” in relation to domestic roles (cited in Dology 2000: p. 7). What Lia appears to argue is that fa'afafine undertake the domestic roles of a female. Her narrative has some similarity with Kaltenborn’s (2003: p. 100) findings that fa'afafine generally imitate women through domestic activities. Does that mean fa' afafine are imitations of females? Butler (1999: p. 175) claims that in imitating gender, drag implicitly reveals the imitative structure of gender (this will be discussed in Chapter 5). However, as explained by a lawyer from the Samoan Attorney-General's office:

“A person who is fa' afafine is not impersonating a woman. He [sic] represents the fa'afafine.... (cited in Schmidt, 2005: p. 120). 
Butler (1999: p, 4) argues that 'various acts of gender create the idea of being a gender and without those acts there would not be a gender'. This suggests that the female chores Honey, Athena, Lia and Max do are performances that are repeated (ibid). They produce gender identity through the 'stylized repetition of acts' (ibid). However, it should be noted here that fa'afafine insist that they were born and not made this way (discussed later in this chapter).

These narratives are possibly examples of what Besnier (1994: p. 308) calls 'specific instantiations of womanhood in various contexts'. In Honey's narrative, she defines fa'afafine in relation to the tasks one performs - masculine (working in the plantation) and feminine roles (cleaning the house, looking after the kitchen, looking after the household). This reinforces Drozdow-St Christian's (2002: p. 32) claim that fa'afafine act in the manner of a woman, that is perform a closely circumscribed range of tasks in one context but may act like a male in other contexts. Although agreeing that fa'afafine perform both feminine and masculine tasks, most narrators prefer feminine labour over masculine labour, as determined by the beliefs, attitudes and expectations of the society in which they live.

\section{Fa'afafine are born not made}

As revealed in Chapter 2, how one becomes a fa'afafine is a complex matter. Similar to Kaltenborn's (2003: p. 75) findings, all fa'afafine narrators in this study assert that they were born and not made fa'afafine; nature was the root cause, not nurture:

"I think I was born like that and I think most of us [fa' afafine] are [born that way]". - Max

"Fa' afafine is nature...born that way...it's in their nature being fa' afafine... No-one influenced me to being a fa' afafine”. - Athena

"Well to my understanding and my own personal experience...fa'afafines aren't made they are born as fa'afafine...fa' afafines are just born as fa'afafines....”. - Honey 
“[Family] didn’t bring me up as a fa’afafine. I was born a fa’afafine. I was not made a fa'afafine and I don't think fa'afafines are made...we are born this way”. - Latoya

Biological explanations are emphasised in the three extracts above. Narrators claim that it is in their nature to be fa' afafine. To paraphrase de Beauvoir's (1974: p. 4) notion 'one becomes a fa'afafine'. There is little evidence to support the view that fa' afafine are boys who are raised as girls due to the shortage of girls in a Samoan family. They do not believe that their family forced, imposed or selected them as fa' afafine. Their narratives reinforce Opera's view (see Chapter 2; see also Croall and Altmann, 2005).

"I have read a lot of books....and seen some of the documentaries and stuff and what they think about fa' afafine is that something that is being imposed, it's something that your family force you to become. If you grew up in a family with boys so the parents will end up raising one of the son's as a daughter but that wasn't the case with me. I have sisters, I have brothers and it also wasn't something I chose, it wasn't a decision that I woke up one day and I thought oh I want to be a fa'afafine [or] I want to live my life as a woman....I don't believe that fa'afafines are just males in their families who families raise as women because of...the lack of... women in the family...I don't believe that's true...fa'afafines are just born as fa'afafine”. - Honey

“For us [fa'afafine] we know who we are but there's.... a myth about fa' afafine of Samoa that these are people... who have been imposed, influenced to being fa'afafine...the parents only have sons. And so there's this myth that they influence or...force one of the sons to be fa'afafine...you know funny sort of explanations of fa' afafine”. Athena

"The myth is they [previous researchers] say if a family has a line of boys, boys, boys that the last boy should become a woman. No, that is not true as our family is an extended family so it's a very wide netted family so if we did have a shortage of girls we could go to our...our aunties and uncles and so forth and ask them for a child of theirs, that's maybe a female ... That is not true that Samoan families bring up their youngest child as a fa'afafine”. - Latoya

“[P]rojecting, expecting a fa'afafine within the family consisting of guys and few girls to ..become feminine male, I don't believe in that theory”. - Lia 
Previous western research seems to conflict with narrators' understanding (see Frances, Leo's and Lionel's experiences in chapter 2). Latoya's narrative strongly reinforces Aiono Dr. Fanaafi Le Tagaloa’s claim that there is never a shortage of girls in any family in Samoa, arguing that a family in Samoa is always an extended family and there is no problem of asking extended family members such as uncles, aunties and cousins for their daughters to help with domestic labour (see Croall and Altmann 2005). Also Honey’s, Latoya’s, Lia’s and Viane’s experiences demonstrate that they do not come from families with a shortage of males in families:

“I am second to youngest so I wasn't the youngest. I was the youngest boy but ...my father had three daughters and only two sons and I'm one of them.... but for my mother's children there's twelve of us [six brothers and six sisters]...”. - Latoya

"I have five siblings, I have two older brothers and two younger sisters and a baby brother and I'm in the middle. I' $m$ the third eldest...”. - Honey

“I have three brothers and three sisters and I'm the seventh of the...children...". - Lia

"I come from a family of eight children. I have three sisters and five brothers. I am the second youngest in my family". - Viane

"All together there are seven of us, four girls and three boys. I am the third eldest". - Max

Unlike other narrators, Athena is an only child:

"I come from a family of three. It's just me and my parents...For me growing up...I was the only child but then of course I have fa'afafine friends who have a lot of brothers and sisters so that's not necessarily the case [that] if you are the only child you end up being a fa'afafine...”

\section{Whakawahine are born not made}

Like the fa'afafine narrators, most whakawahine narrators' argue that they were born and not made whakawahine. For example, 
"I think one is actually born that way when it comes to whakawahine...”. - Renee

“...whakawahine is a description of a person's nature. So in other words my nature is more whakawahine as opposed to my body, as opposed to my gender, as opposed to my identity...the natural condition of whakawahine... born a male, now live as a woman but the main idea being is while I'm living as a woman I'm living as a natural woman as opposed to taking hormone treatment...having gender reassignment surgery to have the sex change. For me personally, that doesn't really make whakawahine...we shouldn't define whakawahine by our organs. Whether its the breasts whether it's any other organ that you may know symbolizes a wahine....for me it was more nature and my argument for that is because I was sort of nurtured to be male in every single way, I was put into rugby league when I was young. I was made to do male chores and sort of represent the male side of the gender as much as I could in my father's eyes anyway...I was born this way from a young age”. Shaniqua

Like all fa'afafine narrators, Shaniqua claims that she was born and not made a whakawahine. What she appears to argue is that whakawahine is a 'natural' condition but 'like a woman' does not mean physically looking like a woman in relation to medical intervention such as hormone treatment, gender and/or sex reassignment. Clearly, like me, she was brought up to behave like a boy not a girl (see also the example of Opera discussed in Chapter 2). My parents discouraged me from behaving in what they considered feminine ways, with commands like "Don’t act like a girl".

\section{Femininity and masculinity of whakawahine}

Most whakawahine carry out both masculine and feminine roles. For example:

"The majority [of the tasks] are the feminine tasks as in the cooking for large crowds, taking care of accommodation, sleeping arrangements for other people but when it comes to yeah it does tend to slightly go to the masculine side like as in moving furniture, moving heavy objects, going out and digging this and that up. I do things like that out of respect mainly for my parents. But if I'm back in my own environment, it's totally different. I will not participate in anything that requires me to do masculine work. So I'm trying to maintain a balance to what I see is family and culture, traditions and 
the normality of the family and then of course maintaining what I do in my own life... outside of the family....Being a whakawahine is not a role”. - Kayla

"...Whakawahine...prefer to do the feminine roles....the cooking, cleaning but...it's hard to differentiate between some of the things [like]...masculine tasks like driving a van full of rubbish to the dump. To a whakawahine it would be considered as a masculine job, pulling down the tent, folding tables, lifting things ...But most of the time it's what they enjoy, cooking, cleaning, washing and all the feminine things. The male things is/the male roles to them is digging holes, laying [the] hangi, digging burial holes... [they] are all masculine tasks.... [that] doesn't require shovel and spade which is probably considered masculine .". - Chanel

Kayla and Chanel highlight gender which links back to the Hibiscus flower model. Their narratives are examples of what Butler (1999: p. 4) calls 'gender as performance'. What Kayla appears to argue is that she mainly performs feminine roles but will undertake male tasks when required. Although she does not see whakawahine as a role what she describes above suggests otherwise. Chanel, however, distinguishes between male and female roles. This appears to Chanel a complex matter, as is understanding the sex and gender distinction (see Butler 1999, Lykke, 2010). Their narratives show that to them femininity refers to performing domestic roles of cooking, cleaning and washing whereas masculinity has an expectation that one will carry out to chores that require heavy lifting. The roles that Kayla performs are a 'series of acts whereby they are renewed, revised and consolidated through time' (Butler, 1999: p. 4). Female domestic roles are also performed at formal occasions such as on the Marae. For example:

"For whakawahine, our roles really come in more when we are on a Marae, you know, straight through the kitchen, tidy up...”. - Chanel

"As a whakawahine, our tasks are the feminine side of things...for instance, when you go on a Marae as I learnt from going to a tangi...we're... accepted as a wahine...we're...treated like one. because I'm whakawahine when I go on the Marae...I am not allowed to sit on the front row of seats because that is for the men and the front row speakers... On a Marae we [get] to do everything that is required of us when it comes to the wahine side of things you know the way they behave, where we sit, when we're allowed to 
talk and that you're only allowed to talk... what areas you're allowed to go to...". - Renee

It appears that, on the Marae whakawahine are treated as women. Renee says that on the Marae she is accepted as a whakawahine and wahine but points out that there are restrictions on just how whakawahine perform their role as wahine. It could be argued that she might be discouraged from sitting with the men because, as whakawahine, she is not a 'real man' even though biologically she was born a male. Self-identified takatapui, Carl Mika, suggests that there may be some discomfort on the marae when it comes to sexual or gender variance:

“...Some takatapui are prevented from speaking on the marae ātea, even though tikanga dictates they can, some perceived equivocality over their gender” (McBreen, 2012: p. 4 - 5).

What the narratives above suggests that even though they "play a key role in their whanau, hapu and iwi” (Aspin cited in McBreen, 2012: p. 4) acceptance of sexual diversity on the Marae is a complex matter.

\section{Conclusion}

The main theme of this chapter is that fa'afafine and whakawahine mean different things to different narrators; there is no universal meaning of fa' afafine and whakawahine from narrators' perspectives. Previous history of fa'afafine and whakawahine has been explored as such legitimation may be important in fostering dignity and self-confidence (Robertson, 2006: p. 3). Narrators argue that they were born not made as fa'afafine and whakawahine. Such identities are biological in origin and performance of femininity includes dressing, behaving and acting 'like a woman'. The sort of women they are like are probably what feminists would describe as stereotypical.

This chapter has focused on fa'afafine and whakawahine as, mostly, a gender role. In the next chapter I discuss sexual aspects of these identities. 


\title{
Chapter 5
}

\section{The impact of western understanding of sexual identity and sexual orientation on what it means to be fa'afafine and whakawahine}

\begin{abstract}
"Fa' afafine is not a sexual term. [It] is a term given to biological men who live their lives as women or who embrace both their femininity and masculinity within the Samoan society”. - Honey

"Whakawahine....it's another word for queen....I just look at myself as a queen. They say, 'What are you/what do you class yourself?' and I go, 'I class myself as a queen', they go, 'What's that?', 'Well it’s transsexual, pre-op transsexual if you wanna be fancy about it. But to me, I’m a queen full-stop”. - Renee
\end{abstract}

\section{Introduction}

As the quotes above demonstrate, and as discussed in Chapter 2, there is an on-going debate about what is meant by fa'afafine and whakawahine, particularly in relation to using western labels such as gay, transgender, transvestite and drag queen. In this chapter, I draw on feminist, queer and indigenous approaches to analyse fa' afafine and whakawahine narratives about aspects of sexuality. Some narrators argue that fa'afafine or whakawahine are transgender, while others insist they are not gay, transvestites or drag queens. Rather fa' afafine and whakawahine are culturally specific terms that can only be understood with reference to the Samoan and Maori societies in which they evolved. Narrators generally reject western labels although they claim they can be useful when trying to explain one’s identity to a Pakeha (Palagi).

\section{Are fa'afafine gay?}

Most fa' afafine narrators argue that fa' afafine are really distinct from gay, men and women who they say have a same-sex orientation. Gay sexual preference and sexual orientation, they claim, is different to that of a fa' afafine, and the term gay is western in origin: 
"I see gay guys that go with gay guys... and then with fa' afafines, I don't think they go for that type. They will probably go with a straight guy rather than one that's gay...I wouldn't see one fa' afafine going out with another [fa' afafine] but I would see them going out with a straight man”. - Max

“Well gay is European, it's not a Samoan term and there’s no term for gays in [a] Samoan context... Gay refers [to] a male who likes another male, wants to go out with another male...”. -Lia

"When the term gay pops into my head, I think of two men having sex. It doesn't [mean] a fa' afafine having sex with a man. Fa' afafine is not a sexual term.... whereas the term gay...labels men who are attracted to other men, or women who are attracted to other women. So there is a big difference...I live my life as a woman, my family respects me as a woman...”. - Honey

“Gay men are men who like men. Fa'afafine is simply a man who has taken up female roles... and also you throw in the feelings and emotions [of being a female]. But there's a difference here right. Men for men is simply men for men. But fa'afafine in Samoa have taken up the identity of women like going as women.

Fa' afafine... have this basic belief that they are all women ....we go around as women....The fa'afafine perspective of them liking men it's like a female, a normal female, liking another male... [M] ost of us fa' afafine in Samoa... we only like straight males... we don't go around liking ...gay men or other fa' afafine for sexual conduct....

We have people fromabroad who .. have no idea of Samoa. They come in and in their observation and with their conclusions they usually say that the relationship of a fa' afafine with another man is a gay relationship. But you know you have to come to understand where the fa'afafine is coming from. The mind set of a fa'afafine going out with another guy.... is that she is a 'she' and he is a 'he'....our relationship with the men we go out with are [categorized] as a normal female and male relationship, a heterosexual relationship, unlike a gay man going out with another gay man. That's where homosexuality comes in”. - Athena

According to all the narrators above, being gay is a sexual identity in which someone is attracted to another person of the same sex. However, they insist that fa'afafine are not identified primarily by what they do sexually. This supports Schmidt's (2005: p. 54) claim that sexuality is not a key aspect of the definition of fa'afafine. The narratives also reinforce Farran's (2010: p. 137) argument that the definition of fa'afafine centres 
on gender i.e. role behaviour rather than sex. This is particularly evident in Honey's and Athena's extracts in which they argue that fa' afafine behave like women in that Samoan biological males perform women’s roles, whereas the term gay relates to sexual preference.

Of course, there is a sexual aspect to a fa'afafine, just as there is a sexual aspect to all human beings. Athena references Samoan culture to demonstrate her distinction between gay and fa'afafine in terms of sexual relationships. Her description reinforces claims that the sexuality of a fa' afafine must be seen in the Samoan and not European cultural context (Pulotu-Endemann and Peteru, 2001: p 130). Also her extract supports the view that:

“As Pacific people and Samoan, our culture identity is first and then our sexuality which is the other way around for European, yous [sic] is sexuality and then you may acknowledge your culture" (see http://www.media567.com/player2/2-1305798211-48.html,).

A frequent theme in the work of Schmidt (2005) and Farran (2010) is echoed in Athena's narrative: fa'afafine do not have sexual relations with other fa' afafine or with gay men. As Schmidt's research showed, the sex that fa' afafine engage in with heterosexual men should not be viewed as homosexual (2005: p. 121). The narrators above all reject being described as gay. From their perspective because fa'afafine generally adopt behaviour which is associated with "being a woman", they have sex with straight males: a fa’afafine is a "she" and the straight male is a "he", therefore they have "a normal female and male relationship”. Athena's description of a "normal relationship” reinforces Schmidt's finding that fa' afafine are attracted to, and receive sexual attention from, straight men and their sexual relationships with men are understood as heterosexual (2005: p. 121; see also Le Atio’o, $\leq$ http://www.pridenz.com/apog naeaulumanua le atioo.html >).

Vasey and Bartlett (2007: p. 484) describe fa'afafine as 'androphilic males', that is males who are sexually attracted to males. However, Honey 
consistently describes herself "as a woman" whose "straight male partner respects” her "as a woman”. She perceives her relationship with her straight male partner as a "heterosexual relationship" regardless of having been born biologically male. Viane, who is sexually attracted to straight males, also rejects the gay label for fa'afafine:

“...I identify myself as a female. I don’t identify as a male....I’m not sexually attracted to another female, to another fa'afafine female. We are sisters, I'm not lesbian”. - Viane.

What these narratives confirm is that other fa' afafine are perceived as female and as their sisters, not as potential sexual partners, whereas gay people are attracted to someone of the same sex. It is gender not one's biological sex that determines the object of one's sexual desire. Narrators separate their biological sex from their performance of gender (or role) and it is the latter that determines the nature of their sexual relationships. Athena is critical of outsiders who are fascinated with fa'afafine and claim that fa'afafine are gay. Her narrative reinforces Vanessa's view that researchers relate much of their findings to their own cultural experiences (2007: p. 67), making generalizations about fa’afafines which satisfactorily explain their observations and answer their research questions. Athena claims that it would be difficult for a non-fa'afafine to understand the relationship of a fa'afafine with a straight male. Aiono Dr. Fanaafi Le Tagaloa confirms this, arguing that it must be difficult for Palagi to see the outward signs of an effeminate man and accept that this is a different being moving in a completely different world than an effeminate man moving in the Western world (see Hacker, 2008). I would argue that a non-fa'afafine would have to try to stand in the shoes of a fa' afafine to understand their sexual orientation, that is at times classified as a gay relationship. In addition, a person must have an understanding of the Samoan culture (Teake, 2010: p. 12).

\section{Are whakawahine gay and/or takatapui?}

Several whakawahine narrators contend that whakawahine is a different identity to gay and takatapui. The common themes in the fa' afafine 
extracts above are shown in Kayla and Chanel's stories: gay is not an apt description for them and a whakawahine's sexual orientation is not the same as that of a gay person.

“...I’ve always thought of gay as a male person [who] goes with another male.... I'm not attracted to gay males ...I'm attracted to straight males....”. - Renee

"[Whakawahine] are actually in a separate community and therefore ours is basically a gender, how we perceive ourselves. Ours is not [a] sexual orientation unlike other sub communities... within the LGB communities. We're actually slightly on another side, where[as] gays, lesbians, bisexuals, they're all sexual orientations, and being whakawahine or transgender and transsexual are actual gender identities so it's totally different....The term gay to me relates specifically to male and male, female and female intimacy....We see ourselves as female, having sex with the male... When we're in a relationship with heterosexual men, it's a heterosexual relationship that we're seeing....takatapui, to understand them, they like their own sex....”. -Kayla

"A gay man is different from a whakawahine because a gay man is about sexual orientation...I'm not attracted to women...I'm attracted to heterosexual men....I'm not attracted to gay men... Gay men like gay males and we like heterosexual males.... one being [a] male attracted to another male and the other one being formally a male but has transitioned to the other side by taking hormones and still being attracted to males, which is funny because you're like, there's takatapui and whakawahine, you both are biologically the same but you are both attracted to males except...takatapui are very much attracted to other takatapui, whakawahine are attracted to more the heterosexual side....straight men are a little bit more comfortable with a whakawahine because of the whole feminine image...that's what they are attracted to...the hetero version of someone feminine even though they're something different...”. Chanel

“I'm usually attracted to the...more straight, hetero guys....Well I wouldn't really call it a gay relationship because I don't identify as a man, but I couldn't really call it a heterosexual relationship either because technically I am not a woman...I don’t really have a term for what kind of relationship it is. I'd just like to call it a 'loving relationship' with trust and respect just like any other relationship between two people. Some... would see my relationship...with a guy as a gay relationship. Others would see it as a hetero relationship, and then others would be thinking... what's he doing with her?... Even the concept itself of whakawahine to [be like a] 
woman in that sense whereas takatapui...same-sex don't wanna change gender or change sex anyway”. - Shaniqua

Gay and/or takatapui are concepts these whakawahine do not accept as a description that fits them. Kayla describes whakawahine as a separate community or identity from takatapui, lesbian and gay because the latter describe male and male, female and female intimacy. This supports Murray's claim that takatapui is a way of identifying oneself as homosexual and Maori (2004: p. 164). As Schmidt (2005: p. 174) argues, to be gay is associated with sexual practices and is not contingent on specifically gendered behaviour, which a whakawahine identity is. This is demonstrated in the narratives in that gay and takatapui are seen primarily as sexual descriptors which, as a term for whakawahine, they reject.

For most whakawahine narrators, it is not only gender identity that is important, but also the fact that their sexual preference to straight males be accepted as a heterosexual relationship regardless of them having been born male. They assert that whakawahine are defined in terms of gender and not sexuality. Their narratives have some similarity to descriptions of the sexuality of the fakaleiti of Tonga (Besnier, 2003; Farran, 2010). Farran (2010: p. 137) claims that the definition of fakaleiti is focused on gender rather than sex. This is a view shared by Kayla, Chanel, Shaniqua, Honey and Athena in both whakawahine and fa'afafine contexts. To paraphrase Besnier (2003: p. 285), Chanel, Kayla and Shaniqua have sexual relations with straight men, that is, with men who are not identified as whakawahine. Consequently, the terms gay and takatapui do not fit their identities because they view themselves as women. Chanel, for example, claims that takatapui and gay are attracted to other takatapui or gay people. Fakaleiti does not equal homosexual, nor does whakawahine. (see $\leq$ http://peoplesofoceaniafinal.wordpress.com/2010/05/20/thefakaleitis-of-tonga>).

Chanel, Kayla and Shaniqua perceive themselves differently from gay and takatapui. Chanel explains that the difference lies in that these terms 
describe a male attracted to another male (gay or takatapui) who has no wish to "change sex" i.e have gender reassignment surgery. The implication is that she, a whakawahine who is not "technically" a woman, someone without breasts and female genitalia, might consider this option. Gender reassignment will be discussed further in the next section.

\section{Are fa'afafine transgender?}

Some fa'afafine narrators describe themselves as fa'afafine and transgender or that fa'afafine is like transgender.

"[I]n the culture I was brought up with...[and] I class myself as a fa' afafine. Fa'afafine is my category that I actually identify... [in the western world to people who understand it]...[At other times] I class myself as transgender because it is much...easier for the white man [to] categorize [me] in their way of understanding....being transgender, being transvestite, cross dresser, transsexual....I'm fed up with educating society.... These are all labels that [the] 'white man' has put upon us and [they are] not satisfied unless we are put under a label or category [they understand]”. -Latoya

Although Latoya appears to prefer to be described as fa'afafine she uses transgender as a descriptor for people who she thinks will find it easier to understand. Her narrative is an example of what Schmidt calls 'shifting and flexible nature' (2005: p. 429), whereby Latoya maintains and enacts identities through processes that are distinctly Samoan (fa'afafine) while adopting and adapting to aspects of globalized western culture (transgender). As Spoonley argues (1999: p. 213), how Pasifika people explain themselves to Palagi, and those outside the community, is problematic especially when many of the images of, and beliefs about them tend to be negative ones. Latoya's frustration with having to continually educate Palagi is obvious.

Latoya distinguishes between fa'afafine from gay, cross-dresser, transvestite and transgender. She talks about the three types of fa'afafines:

"The first type of fa' afafine is a male who dresses, works and lives as a male but, as an effeminate male, would be categorized and labelled in the western world as gay, but in Samoan terms a 
fa' afafine. The second type of fa'afafine is an effeminate male who has very feminine mannerisms and adores woman's attire but does not dress femininely full time. [He] would be categorized and labelled in the western world as a cross-dresser or a transvestite but in Samoan terms [is] fa' afafine. The third type of fa'afafine is a male who has fully transformed into a female through hormone treatment, sex re-assignment and plastic surgery like me [and] would be categorized and labeled as a transgender in the western world although in Samoan terms [is still] a fa' afafine”. - Latoya

In a similar vein to Latoya, Lia defines fa'afafine by using a scale:

"I draw a scale whereby at the bottom line, where the gays are you know, because if you're a gay in Samoa and you're attracted to the same sex you are also referred as a fa'afafine. So the bottom scale as gay people or as a boy fa' afafine... The top will refer to transgender people or the girl fa'afafine whereby they either change or [have] gone through hormonal treatment therapy. Along the way...there's a whole lot of definition involved here and different stories from different fa’afafines”.

Both Latoya and Lia appear to define transgender as someone who has undergone surgery to become a member of the opposite sex. For Lia this is the top of her scale, the goal she herself is working towards. From this perspective, transgender appears to be an appropriate term to use for fa'afafine although the Samoan culturally specific term is one that they both prefer. However, as shown previously not all fa'afafine (or whakawahine) desire gender reassignment surgery. The Gay Centre (a U.S. organisation) defines transgender more broadly as "both male and female; or outside the two-gender system, entirely, neither male nor female (seehttp://www.gaycenter.org/gip/transbasics/whatistrans):

“Transgender" can...be used as an umbrella term, meaning it groups together a variety of people with different identities. The common link is that people under the "transgender umbrella" don't really fit within their society's standards of how women and men are supposed to look and act (in other words, they're "gender nonconforming"). A transgender identity is not dependent upon medical procedures. In other words, some transgender people have surgeries or take hormones to bring their body into alignment with their gender identity, BUT many do not medically alter their bodies, and that doesn't mean they're not transgender”. 
Latoya not only distinguishes between various ways of being fa'afafine but also emphasises that it may usefully be described as an umbrella term, similar to queer, for a variety of roles and behaviours. However, Lia puts gay at the bottom of her scale because, according to her, if you're attracted to the same sex you are also referred to as a fa'afafine in the Samoan context. She also claims that in Samoa gay men are often labelled fa' afafine although who by and how often is not made clear. As her discussion earlier in this chapter showed, from her perspective, fa'afafine does not equate to gay so using it as an umbrella term could be something with which she disagrees.

The Rainbow Youth Organization's definition of “queer” is a more inclusive, and possibly more acceptable Western term:

“[Queer encompasses] lesbian, gay, bisexual, transgender, intersex, fa'afafine, and takatapui identities, as well as everyone in between and not sure. This word is used by many people, but it is also appreciated that it is not the preferred term for everybody" (<http://www.rainbowyouth.org.nz/about/whereby queer>, 2009: p. $1)$.

Athena, however, would in all likelihood reject 'queer' as a descriptor. She argues that:

"[transgender] is a gender identity like fa' afafine men who have taken up female roles. Transgender is a non-Samoan word and it's a term given in the western world, for example in the States. You have transgenders there and like I said, you have to have an understanding of [how] the word came about and what was it for and that kind of stuff. Fa' afafine, we are solid with our identity here in Samoa [and American Samoa]. But if that's how the United States [of America], people...see these men taking up female roles... and the word is transgender...I say it's like fa'afafine. You cannot really say transgender is fa'afafine because Samoans do not label us transgender. This is a totally differentstory...

If you are going to classify fa' afafine as transgenders, the thing is in the United States continental US, from the East Coast to the West Coast and its terrorities aside from American Samoa, a transgender in the classroom is simple unacceptable...If one was to do the research on how many transgenders are teaching, one would find maybe one or two but you wouldn't find a big enough amount. But 
you come to American Samoa, you would most likely run into a fa'afafine teacher”. - Athena

Athena's narrative 'illustrates that it is difficult to find an appropriate label in the English language for fa' afafine’ (Murray, 2003: p. 235). What her, Latoya's and Lia's narratives above demonstrate is that defining fa'afafine and transgender is complicated. Their interpretations seem to support Besnier's claim that 'in Polynesia there is no clearly articulated ideology associated with gender variants, no uniformly consistent role” (cited in Matzner, 2001). However, what is absolutely clear is that all narrators prefer Samoan terminology to terms used in Western societies. From Latoya's perspective, there is one unique term (fa'afafine) which includes all fa'afafine who identify as fa'afafine. These fa'afafines may not appear identical, for example, some may not wear feminine dress regularly (first type of fa'afafine) and others may have had hormone treatment (third type of fa' afafine). What Latoya's and Lia's extracts do confirm is Kaltenborn's (2003: p. 68) descriptions of “fa’afafine-tama (fa'afafine-boy)” and “fa’afafine-teine (fa' afafine-girl)” and that the latter employ women's dress styles and feminine mannerisms.

The role of language is clearly evident in Lia's, Latoya's and Athena's narratives. From a linguistic perspective, their statements could possibly be examples of what Lynch calls ‘code-switching':

"Very often, even in the same conversation, people switch from one language to another. This may be because certain topics are easier to talk about in the languages all the participants know rather than another, or it may be because something just sounds better in one language than in another” (1998: p. 264 -265).

It is beyond the scope of this thesis to examine the influence of English on the Samoan language. However, I draw attention to the fact that Lia and Latoya use the English language to link fa'afafine with some western terms. Possibly, from Latoya's and Lia’s perspectives, fa’afafine has entered the English language as it has in Aotearoa/New Zealand where Auckland is the city with the largest Polynesian population. However, 
there is some evidence to suggest that here it may be understood by nonSamoans as gay and/or transgender. I would argue that 'English does have one clear advantage' (Kachru, 1995: p. 292) when defining fa'afafine. I would argue that translating and/or labelling fa'afafine as transgender is useful for people who are not familiar with the former but understand the latter. As Pulotu-Endemann argues, using Palagi queer identities has some merit because it "cuts to the chase” for Palagi people (1997: p. 1).

\section{Are whakawahine transgender?}

Some whakawahine narrators' claim that transgender is similar to whakawahine.

“...a whakawahine is somebody who has transitioned...to living the life as a female twenty-four seven....Well - transgender - you can put that in [an] English word for a whakawahine...So yeah I'll compare it to whakawahine....not a cross-dresser, not a drag queen...”. - Chanel

“...Whakawahine are not all different to transgender. As I say, whakawahine is a descriptive term...Transgender is in between, it actually basically means or implies both female to male, male to female. It's all encompassing.... But in my own culture, I choose to go with the name that fits and I choose whakawahine because that's descriptive, it's part of my culture....we have European [terms] which are trans/transgender, then whakawahine which are basically like European transgender...”. - Kayla

Like the fa'afafine narratives discussed previously, these whakawahine prefer Maori rather than Western terms. However, they do appear to agree that transgender and whakawahine are similar identities. Shaniqua disagrees:

“[T]ransgender is trying to say that I'm trying to change my gender.... transgender is a medical condition, that's how it's treated, as a medical condition. Therefore we need HRT (Hormonal Replacement Therapy) to fix that...but whakawahine is a natural condition, therefore no medicines are needed. It's not... a sickness or a disease”. - Shaniqua

Shaniqua is insisting that whakawahine is a 'natural' condition; for her whakawahine are 'born that way'. From her perspective, transgender is a 
medical condition requiring treatment. Her understanding is similar to that of Latoya and Lia in relation to fa'afafine.

\section{Are fa'afafine drag queens?}

Some fa'afafine narrators argue that a drag queen is significantly different from a fa'afafine:

"The term drag queen to me is just basically a gay guy... who might dress up as a woman, puts on heavy make-up, big wigs, glitter...just big frocks, and just goes out and performs and parades...just for entertainment reasons...It's probably just a one off thing....likes to dress as a woman at night but during the day they're...back as just gay men. When the sun comes out all the make-up and the wigs and everything goes off and they're back in their suitcases. That's my understanding of a drag queen....It's not a permanent thing...”. Honey

“[Drag queens] put on some heavy make-up, full-blown out wigs and dress up like girls. Very loud...loud make-up, loud attitude, needing some attention....A drag queen is very different from a fa'afafine...this goes back to the origin of the word or who's the person behind the label...Y You will find a Samoan fa'afafine [is] a normal looking or almost like a normal looking girl. But a drag queen, they are males who feel the need to put on heavy make-up... to feel complete about themselves being women... Most of the fa'afafines in Samoa [and American Samoa], we don't feel the need to put on make-up or to put on all these fancy clothes, or to put on a wig just to show that we are women. No it's not like that in Samoa. When we say we are fa'afafine, it doesn't mean I have to have long hair, or put on make-up, or put on girl clothes in order for me to fully identify with being a fa'afafine... when you are a drag queen, you have to put on all that nonsense or good stuff, however way you want to see it, in order to be a drag queen”. -Athena

What Athena and Honey seem to argue is that a drag queen's performance is one of over the top femininity. By using heavy make-up and wigs they are unlikely to be taken for 'real women' unlike a fa'afafine who looks “almost like a normal looking female” and can often pass as women.

Another important difference between fa'afafine and drag queens is that the former behave and dress as women all, or most, of the time whereas the latter wear women's clothes for special occasions or performances. Lia offers another perspective: 
"Yeah, I think [a drag queen is] quite similar to fa'afafines.

Fa' afafine are quite the same as drag queens because back in the islands, there are fa' afafines who also dress up during...the Miss Drag Queen and other charity balls, shows and fashion shows... They're not referred to as transgender, they're referred to as drag queens back in the islands. Fa'afafine are translated as drag queens; they're not translated as transgender”.

Lia's narrative appears to argue that the label fa'afafine is an umbrella term that includes drag queens. Schmidt also claims that some fa'afafine identify themselves as drag queens (2005: p. 14). Some fa'afafine do engage in drag entertainment both in Samoa and Aotearoa/New Zealand. For example, Buckwheat and Cindy of Samoa are well-known fa' afafine entertainers in Auckland and Samoa.

In her theory of gender as performance, Butler claims that:

"[t]he performance of drag plays upon the distinction between the anatomy of the performer and the gender that is being performed...drag creates a unified picture of a woman....In imitating gender, drag implicitly reveals the imitative structure of gender itself... (1999: p. 37).

Whakawahine use the term transvestite rather than drag queen. This will be discussed later in this chapter.

\section{Are fa'afafine transvestite and/or transsexual?}

Some fa' afafine narrators argue that fa'afafine does not mean transvestite and transsexual:

"These terms [transsexual and transvestite] come from off island...these terms the Westerners use to coin the males who go around behaving like females. Fa'afafine is specifically unique to Samoa and to us Samoan fa' afafine. So we consider ourselves not gay, neither bisexual, not transgender nor transsexual nor transvestite... We take fa' afafine and that is who we are. We do not want, for me personally, my thinking is I hate to be labelled transsexual and transvestite...”. - Athena

From Athena's standpoint, the term fa'afafine is part of Samoan society and can only be understood in that context. Western terms are rejected by 
her because they have no meaning for her. As I argued earlier, because of my perceived female mannerisms, I was labelled a faggot, a poofter and gay (see Chapter 1). These terms were used to tease and/or ridicule me whereas in Samoa I was labelled a fa'afafine and this did not have the negative connotations of the terms used to describe me in Titahi Bay. Like Athena, my experience demonstrates that what it means to be fa'afafine in Samoa is completely qualitatively different from being a fa' afafine in the western setting. However, I was never labelled a transvestite, probably because I wore a boy's school uniform. Clearly, however, some fa' afafine are described this way:

“...defining fa'afafine as transvestites is not only wrong but culturally offensive...By redefining fa' afafine to exclusive palagi terms like gays, bisexuals, transvestites, the unique cultural persona is lost into a generalisation. Using palagi terms [transvestite and transsexual] not only puts fa'afafine in a totally foreign culture but subject to a different and negative attitude” (Pulotu-Endemann, 1997: p. 1).

\section{Are whakawahine transsexual and/or transvestite?}

Most whakawahine narrators identify as whakawahine and transsexual but reject the terms transvestite and transgender as a description that fits them:

"I was transsexual not transvestite and that was the difference in the two....transvestite was just a man that occasionally hopped into drag...for the fun of it...transsexual was a person either gonna go all the way and have the full op or be just a pre-op transsexual... and live the life of [a] woman...”. - Renee

"[P]re-op transsexual, transsexual, sex change....To me transsexual [and] whakawahine is basically a person who lives their life twentyfour seven in the gender they identify with, as we have male to female and female to male trans....If I go under any category it would be whakawahine first and foremost. The European terminology I prefer to go with is transsexual, so transgender yeah it does incorporate both but it's in a secondary name to transsexual. Transsexual used to be those who have the operation...”. - Kayla

Renee's and Kayla's narratives seem to echo Lomax's (2007: p. 83) claim that transsexuals are similar to whakawahine; they are males that have been sufficiently compelled to take hormones and/or undergo surgery in 
order to appear and live as women. Their statements also support Maori self-identified transsexuals Carmen's (1988: p. 213) and ex Member of Parliament Georgina Beyer’s (1999: p. 97) descriptions of males and females who have passed through or who are in the process of sex change. They use transsexual rather than whakawahine to describe themselves. The term transexual was used prior to transgender and it appears to be, from the perspectives of the whakawahine interviewed for this thesis, a more acceptable term. However, as with fa' afafine narrators above, Kayla, prefers to use the term specific to her culture: whakawahine.

\section{Conclusion}

What this chapter reveals is that both fa' afafine and whakawahine prefer to use terms specific to their own culture. However, some use western terms, unwillingly it seems, in order to be understood by outsiders, particularly transgender and, for whakawahine, transsexual. Most narrators argue that gay and takatapui are not terms that fit them. In the next chapter I expand on some of the issues raised in this and the previous chapter. 


\section{Chapter 6}

\section{Discussion}

"I remember going to my first gay night club in Australia in Melbourne... [I] introduced myself [to a tranny] and she goes, 'Are you tranny?' and I went 'Training for what?', and she started laughing and then she asked, 'Are you pre-op or post-op' and I went, 'Honey, I don’t work in a post office', and she still laughed”. -Latoya.

“...CD (cross dresser), transvestite, transgender, pansexual now you got genderqueer....is that sex with a frying pan?...”. - Chanel

\section{Introduction}

In this chapter, I discuss the findings of this study and further develop some of the themes raised in Chapters 4 and 5 such as the history of fa' afafine and whakawahine and various descriptors of what it means to be fa'afafine and whakawahine. I also compare and contrast the Samoan and Maori experiences provided in the oral data.

\section{History of fa'afafine and whakawahine}

Most narrators argue that Samoa and Aotearoa/New Zealand are not alone in having a tradition of 'men behaving as women'. Other Pacific islands such as Tonga, Fiji, Hawaii and the Cook Islands were referenced as cultures who have similar gender identities, sometimes called 'third genders'. Clearly evident in their extracts is that they believe that a fa'afafine and a whakawahine culture existed in Samoa and Aotearoa/New Zealand before and after colonization. Given that 'all societies have a history and all history begins as oral' (Morrison, 1998: p. 2), the source of their certainty of a tradition of fa' afafine and whakawahine is possibly to be found in oral traditions.

There is little written evidence to confirm that whakawahine did exist in traditional Maori society though many scholars have tried. McBreen claims that much research about sexual diversity in a Maori context 'reflects the opinions of those putting it, rather than historical evidence.... 
[and often] looks like an attempt to justify our existence in a currently hostile society by looking to a pre-colonial, authentically Maori past” (2012: p. 6).

It is likely that some narrators in this study were also trying to justify or authenticate their gender identity. Shaniqua pointed out that no-one can actually comment on the status of whakawahine traditionally because of the impact of colonization on Maori culture. Her insightful comment reinforces McBreen’s argument that: “the actual experiences, attitudes and tikanga of [Maori] ancestors relating to sexuality are impossible to reconstruct” and, as stated earlier, surety of the past does not exist (Morrison, 1998: p. 9).

Several fa'afafine researchers are critical of non-Samoan research, particularly of U.S academic Mageo $(1996,1998)$ who argues that as fa'afafine are not mentioned in early reports by missionaries to Samoa so they must therefore be a relatively recent phenomenon. Narrators challenge this finding, claiming that fa' afafine have always existed in Samoa. This is supported by other research by fa' afafine (see for example Pulotu-Endemann 1997, 2011; Brown-Acton, 2011; Toelupe, 2011; Vanessa, 2007; McMullin, 2012; Atio’o, 2011).

As well as examining previous research about fa' afafine and whakawahine I have cross-checked this with documentary sources about other cultures who, like Samoa and Aotearoa/New Zealand, were colonized by the British (see Hernandez, 2007; Hemmilä, 2005). It is reasonable to assume that British colonial rule everywhere in the eighteenth and nineteenth centuries "was inspired by a monoculturalism that was derived from beliefs about the inherent superiority of European religious views [and] the advantages of British institutions and beliefs” (Fleras and Spoonley, 1999: p. 192), and would therefore have led to similar outcomes. 
Oral historians have consistently argued that oral history as a method and a theory recovers people previously hidden from history. I would argue that fa' afafine have, until recently, been largely invisible in the literature. This is doubly so for whakawahine. Therefore, oral history is a method which makes possible the opening up of "a virtually unexplored avenue of knowledge" (ibid) and provides 'valuable information about aspects of the past inaccessible through written sources' (Green, 2004: p.3).

My research suggests that the missionaries had some effect, not necessarily positive, on societal perception of fa'afafine and whakawahine. The narratives reinforce Harker's (2008) view that missionaries in Samoa (as in other cultures colonized by the British) chose not to mention fa'afafine in their journals, possibly because they and colonial officers had little familiarity with the inner workings of the societies they described (Besnier, 2000: p. 25). In turn, Maori were affected by Christian missionaries’ abhorrence sexual and gender diversity (Te Awekotuku, 1991: p. 37) and the colonizing culture's "shame and fear of sexuality” (McBreen, 2012: p. 3) may have ensured that whakawahine's absence from the written record.

Although people who might today be described as whakawahine probably existed in Maori society prior to colonization, the more common use of the term today seems related to the increasing visibility and awareness of other Pacific identities: fa’afafine, fakaleiti, fakafefine, mahu and ‘akava’ine. Many New Zealanders would be familiar with the term fa' afafine but I would argue that whakawahine is less well-known. Maori narrators reference the 'Whakatane' legend to explain the formation of the term whakawahine. Oral historians claim that the discussion of myths and legends in this way allows narrators to "communicate the meaning they want to give their experience” (Chanfrault-Duchet cited in Gluck/Patai, 1991: p. 81). Despite being a recent development, Kayla argues that the term whakawahine has built momentum and is now widely used by many Maori who are born biologically male but live as women and/or undertake gender reassignment. It may therefore replace the term 'transsexual which has been common in the past. 


\section{Meanings of fa'afafine and whakawahine}

A common theme in this study is the various meanings of fa'afafine and whakawhine from the perspectives of narrators. No universal understanding and/or experience emerged from the oral data. Most narrators perceive themselves differently from one another due to factors such as their upbringing, where they were born and/or live now, and age. Also, being a fa'afafine or whakawahine in Samoa or Aotearoa/New Zealand is quite different to being one outside the cultural context. Consequently, the meaning of fa' afafine and whakawahine from the narrators’ perspectives seems fluid rather than fixed.

Most narratives reinforce Phylesha Acton-Brown's view that each fa'afafine has a different perception of how they define themselves (see pacificbeatst - http://www.youtube.com/watch?v=GV_g6X2PEvs). To identify as a fa'afafine or whakawahine is to make a statement about a person's sex, gender and identity. From a Maori perspective, Aspin (cited in McBreen, 2012: p. 7) says: "Identity means understanding our [takatapui] place in the world: where we each belong and where we each stand; it is fundamental to health and well-being”.

Viane, Max, Athena, Lia, Kayla and Renee claim that whakawahine and fa'afafine are gender roles and/or gender identities while Shaniqua and Chanel imply otherwise. Shaniqua argues: “for a person to say it's a gender, it's like limiting whakawhine that they have to be one or the other”. For Athena, Max, Lia, Viane, Latoya and Honey, fa'afafine is a gender role in which fa'afafine undertake women's domestic tasks. For Athena performing 'feminine' tasks is to fulfil her gender role as a fa'afafine. Whakawahine narrators contrasted with fa'afafine in this respect: "it is not [a] role that you work [at] for your entire life".

Most narrators’ align themselves with what Besnier (1994: p. 308) calls 'specific instantiations of womanhood'. All narrators' seem to share the idea of fa'afafine and whakawahine as being 'like a woman'. This may include dressing in female clothing; having or adopting feminine 
behaviours; undertaking domestic roles; or even seeking medical assistance (hormone treatment, breasts and gender re-assignment).

While there is no one universal experience of what it means to be a fa'afafine, whakawahine, or 'like a woman', all narrators agree that the meanings are (and have been) changing. Unusually for such a small number of participants, most narrators have feminized their appearances through hormone and/or laser treatment and/or plastic surgery, something that was not possible historically. However, such treatments are only partial; narrators do not menstruate nor are they able to give birth to children, both of which are usually central to definitions of what it means to be a woman. Nevertheless, surgery was the path most chose in order to have what they describe as a more womanly appearance. Other narrators, particularly whakawahine Shaniqua, claim that gender reassignment surgery is not essential to one's identity.

For most narrators', femininity is signified through the role one plays in relation to domestic labour. The adoption of female clothing and make-up are enactments of femininity that facilitate their acceptance as women. Surgery can be understood in the same way. Schmidt (2005: p. 189) argues that the medical technologies fa'afafine utilize (and I would add whakawahine) can be understood as an extension of the use of more cosmetic signifiers of femininity. However, my experience would suggest that those who have had gender reassignment treatment are still in the minority in Samoa.

\section{Born and not made that way}

Previous research (see Demeter, 2004; Harker, 2008) suggesting that fa'afafine are boys raised as girls was largely rejected by all fa'afafine narrators. Latoya, Viane, Max, Honey and Lia come from large nuclear families; they have female siblings while Athena is an only child. None of them were brought up to fulfil a daughter and/or a sister role in their families. Their narratives challenge Frances's, Leo’s and Lionel's experiences but reinforce those of Opera and Dan discussed in Chapter 2. 
Latoya reminds us that a Samoan family is always an extended family, an idea that is shared by Meleisea (1987) and Aiono Dr. Fanaafi Le Tagaloa (see Harker, 2008).

All narrators argue that they were born and not made fa'afafine or whakawahine. They believe that biology determines their identity as fa'afafine or whakawahine. Most narrators' oppose the view that fa'afafine or whakawahine was a role imposed on them. Instead, many discussed how their families discouraged feminine mannerisms or behaviour and Kayla's family, even now, does not acknowledge her as whakawahine. Viane's view supports Kaltenborn’s research (2003: p. 75). She says that God made her a fa'afafine, therefore suggesting that the identity of fa'afafine was imposed upon her, but not by her family.

\section{Culturally specific terms}

Several narrators' argue that fa'afafine and whakawahine should be viewed in their own cultural context as these identities are specific to the cultures from which they come. Part of being a fa'afafine or a whakawahine is to make a statement about one's ethnicity - Samoan or Maori respectively. Shaniqua and Honey, for example, insist that fa'afafine and whakawahine are cultural identities. Their narratives reinforce Besnier's (1994: p. 308) view that 'queer identities - transsexual, gay, or homosexual only capture one aspect of the category and at worst [are] misinterpreted as sexual identities'.

Most narrators preferred to use the culturally specific label of fa'afafine or whakawahine rather than western labels. Athena stated her abhorrence of being labelled transsexual or transvestite. Like Pulotu-Endemann, she finds such Palagi terms ‘culturally offensive’ (1997: p. 1). In addition, NZAF (2010) note that "transgender communities" such as whakawahine, fa'afafine, fakaleiti and 'akava'ine have their own "perception of their history" and various ways of being “integrated into their cultures”. Not all are necessarily transgender (NZAF, 2010: p. 18). 


\section{Queer identities}

This study shows that what it means to be fa'afafine or whakawahine appears to have been modified by westernisation, colonization and advances in medical technology. With the exception of Athena and Latoya, most narrators who participated in the research live in Aotearoa/New Zealand. Queer identities of transgender and/or transsexual have influenced several narrators in relation to how they identify outside of their cultural contexts. This reinforces Kaltenborn's (2003: p. 184) claim that fa'afafine (and I would argue whakawahine) are familiar with the terms transgender and transsexual, and some even acknowledge and accept these terms. Kayla for example, identifies as a transsexual and whakawahine, and Latoya identifies as a fa'afafine and transgender. These examples support Schmidt's (2005: p. 429) notion of 'shifting and flexible nature' whereby they identify with their cultural term (fa'afafine or whakawahine) but at the same they are influenced by western terminology.

Most narrators challenge the claim that fa'afafine are gay and/or drag queens and/or transvestites. However, as Wallace has shown, fa'afafine and western identities such as gay, transvestite or transsexual 'cannot avoid interpellating each other' (2003: p. 140, 186). Schmidt (2005: p. 4) claims that definitions of fa'afafine (and I would argue whakawahine) as transvestites are significantly influenced by the particular participants authors selected to focus on in their research. Mageo's (1996) claim that fa'afafine are transvestites is rejected by all fa’afafine narrators.

\section{Fa'afafine and whakawahine are not gay}

Equating being gay with being fa' afafine and whakawahine is rejected by Athena, Honey, Latoya, Chanel and Kayla who claim that their intimate relationships are more accurately equated with heterosexual rather than same-sex relationships. This reinforces Schmidt's view:

“...the perception of fa'afafine as feminine that the sex they engage in with masculine men [should] not be seen as homosexual. Fa'afafine....are only attracted to, and receive sexual attention from, 
straight men, as it is imperative to their sense of themselves as feminine that their relationships with masculine men be understood as heterosexual” (2005: p. 121).

Shaniqua, describes her relationship as a 'loving relationship’ while Renee depicted hers as a 'real close bond'. For Shaniqua and Renee, there is no term that fits their sexual relationship. All narrators appear to argue that fa'afafine and whakawahine are not sexual identities like takatapui and gay. Their narratives confirm Farran's (2010: 137) view that the definition of fa'afafine (and I would argue whakawahine) is more gender than sex related. This supports Schmidt's (2005: p. 17) view that being perceived as gay is related to sexual practices and not, like fa' afafine, contingent on specifically gendered behaviour.

The oral data highlights that all whakawahine narrators see themselves differently from takatapui. Kayla and Chanel, for example, assert that whakawahine are not part of any takatapui, lesbian, gay and bisexual community, arguing that theirs is a gender identity. Takatapui, they argue, is associated with sexuality whereas whakawahine is not. Gay and takatapui are labels that Chanel, Renee, Kayla and Shaniqua do not accept as a description that fits them. However, as Tupuola's (see chapter 2) research showed, discussing sexual identity or anything sexual, or prioritising it, could be seen as disrespectful to the Samoan culture. Whether that may apply to Maori is unclear and perhaps could warrant further research in the future.

\section{The role of whakawahine}

It appears that the feminine domestic role for Chanel and Renee is most evident on formal occasions. Unlike all fa'afafine narrators, for Chanel, a whakawahine, her domestic role is rather part-time than full-time. She claims that cooking and cleaning are expected of some whakawahine on the Marae and she acts accordingly. From a feminist perspective, it is interesting that in an era when challenges to rigid gender roles for men and women are frequent, fa'afafine and whakawahine strive to perform the stereotypical female roles many women wish to shed. For Renee, 
being accepted as a whakawahine and wahine was unexpected because, as previous research has argued, there are restrictions as to how one who is not heterosexual behaves on the Marae. This tends to suggest that acceptance plays an important part in terms of the role one plays on the Marae.

\section{Conclusion}

This chapter has expanded further on themes which appeared in Chapter 4 and 5. A common thread in the oral data is that fa'afafine and whakawahine have existed in Samoan and Maori societies for centuries. Narrators describe themselves as 'like a woman' in various ways: in relation to domestic roles and in appearance and behaviours. It appears that the domestic role of some fa'afafine is a full-time role for them while part-time for some whakawahine. Gender re-assignment surgery has been discussed as a method of enhancing femininity. Sexual preference and orientation has been explored. Fa'afafine and whakawahine argue that they are not gay. Because they are 'like women' and therefore have sex with straight men then their relationships are heterosexual.

In the next chapter, I discuss my conclusions following completion of my research. 


\section{Chapter 7}

\section{Conclusion}

“...This is how things are retained through work like this [my thesis] you know. If we would have had it... a writing culture back before, we could have kept a lot of records”. - Chanel

“...I am really proud/really glad that someone is actually willing to do a research like this and to make people's eyes open up a bit more further than what they are now”. - Renee

“...I would do anything to educate more people and help them...I must specific that these are my views and not the fa'afafine views...”. Latoya

\section{Introduction}

This chapter summarises key points of my thesis and discusses some of its limitations. I have become very passionate about this topic so hope that other research about, for and by fa'afafine and whakawahine will take place. Recommendations for how the body of knowledge can be further developed are suggested.

\section{Summary of research}

In this study, I have undertaken a comparative study of the fa'afafine of Samoa and the whakawahine of Aotearoa/New Zealand. More importantly, I have:

- described and analysed the meaning of fa' afafine and whakawahine from narrators' perspectives.

- examined the evidence for the historical existence of fa'afafine in Samoa and whakawahine in Aotearoa/New Zealand.

- compared and contrasted the similar and/or different role behaviours of fa' afafine and whakawahine in Samoan and Maori societies. 
- described and analysed how narrators understand and/or make meaning of westernised categories of identification such as gay, transgender, drag queen and/or transsexual.

Some of my findings, (there is no universal meaning of fa'afafine and whakawahine; how one behaves 'like a woman' varies; fa' afafine and whakawahine are distinct from gay and takatapui; one is 'born that way'; fa' afafine and whakawhine are culturally specific terms) reinforce previous studies by both insider and outsider researchers while others (fa'afafine are boys raised as girls; equating fa' afafine and whakawahine to transvestites and drag queens; prioritising sex over gender) challenge what could be described as myths, particularly of fa'afafine. Both fa' afafine and whakawahine say that they feel like women, behave like women and act like women despite the fact that there are multiple ways of performing these roles.

It is argued that the term whakawahine is a fairly new term in Aotearoa/New Zealand but that its usage has built momentum in the last decade. This is not to suggest that there were not Maori men who lived as women in pre-colonial and pre-missionary Maori society. The gender identity may have a longer history than the term whakawahine.

Despite Mageo's claim that fa'afafine are not mentioned by early visitors to Samoa, it is claimed that a fa'afafafine culture has existed for centuries in Samoa and American Samoa. However, the problems of trying to confirm the existence of both fa' afafine and whakawahine identities prior to colonization have been discussed in relation to their absence from written records, given that both Maori and Samoan cultures were oral before the arrival of missionaries.

I argue that the terms fa'afafine and whakawahine can be usefully described as umbrella terms, similar to queer. However, caution must be taken when viewing these identities outside of their cultural context. 


\section{Limitations of study}

Only ten narrators were interviewed for this study so the information provided in their stories, extremely valuable though it is in adding to the body of knowledge, cannot be generalised to all fa'afafine and whakawahine.

Most narrators were previously known to me or my fa' afafine/transgender Aunty. This was helpful in getting participants to help me with my research. However, I acknowledge that on occasion this meant that I may have been reluctant to challenge some of their statements. In addition, the Samoan expectation that a younger person should show respect to elders may have been an inhibiting factor at times.

Most narrators have had gender reassignment surgery which probably means that they have focused more heavily on some aspects of what it means to be a fa'afafine and whakawahine in relation to western terminology such as transgender and/or transsexual. Others who have not had and/or choose not to have hormone treatment or surgery may have focused on different aspects of what this identity means to them. They may even have discussed some issues not mentionedhere.

My knowledge of the Samoan language was an advantage when interviewing fa'afafine as narrators often shifted from one language to another. I do not speak Te Reo Maori so this meant that whakawahine spoke to me mostly in English and, when they used Maori terms, they had to explain them to me. This, and my lack of knowledge of tikanga Maori, may have had an effect on the stories they told. This research supports Smith's (1999: 137) claim that there are multiple ways of being an insider and outsider in indigenous contexts. As a self-identified fa'afafine, there were advantages and disadvantages ofinterviewing fa’afafine.

\section{Future research}

Although my research has helped to fill in some gaps about our knowledge of fa'afafine and whakawahine there is still lots of research 
left to do. I would welcome future research which could help to provide a more holistic description of these identities suchas:

- More in depth research with a more varied group of research participants in terms of geographic location and age.

- A comparison of fa'afafine who live in Samoa and American Samoa with those who live elsewhere would be useful in order to learn the extent to which non-Samoan cultures modify what it means to be fa'afafine.

- More insider research about whakawahine, preferably by Maori and/or whakawahine researchers.

- Historical research of fa'afafine and whakawahine that includes 'grey literature’ or uses scavenger methodology (see Chapter 3) using sources which include journals, diaries, myths, songs, chants, carvings, weaving. These sources could add more to the body of knowledge about the history of ‘third gender’ identities in Samoa and Aotearoa/New Zealand.

- Research into other Polynesian cultures with a history of 'third gender' identities would also provide useful information. Studies of individual societies such as Tonga, Fiji, Cook Islands and Hawaii as well as a study that examines their similarities and differences is necessary.

\section{Conclusion}

Narrators insist that fa'afafine and whakawahine are culturally specific terms to Samoa and Aotearoa/New Zealand respectively. However, explaining that outside of the cultural context often means having to use western terms if one is to be understood. This often influences some fa' afafine and whakawahine to classify themselves along with transgender and transsexual in the western world. Such terms often focus on sexual aspects rather than gender role or gender identity, and is a major factor in why such terms are rejected by most narrators. 
There is no universal meaning of what it means to be a fa'afafine or whakawahine and the notion of being fa'afafine or whakawahine is continuously changing. Some of these changes are related to international discussion of gender variance, people who do not fit the rigid binary of male and female. In Samoa attitudes towards fa'afafine appear to be changing for the better as laws have been passed which have decriminalised men wearing women's clothes. In Aotearoa/ New Zealand the term whakawahine is still not widely known although narrators claim that its use is increasing.

This research has expanded our knowledge of fa'afafine and whakawahine because, to paraphrase the NZAF, narrators have been willing to share personal feelings, thoughts and emotions about what their identity means to them: “They are in our history, they are in our communities, and they are in [our aiga and] Whanau” (2010: p. 15). This thesis contributes towards redressing the balance and putting fa' afafine or whakawahine into the historical record. 
Appendix 1: Map

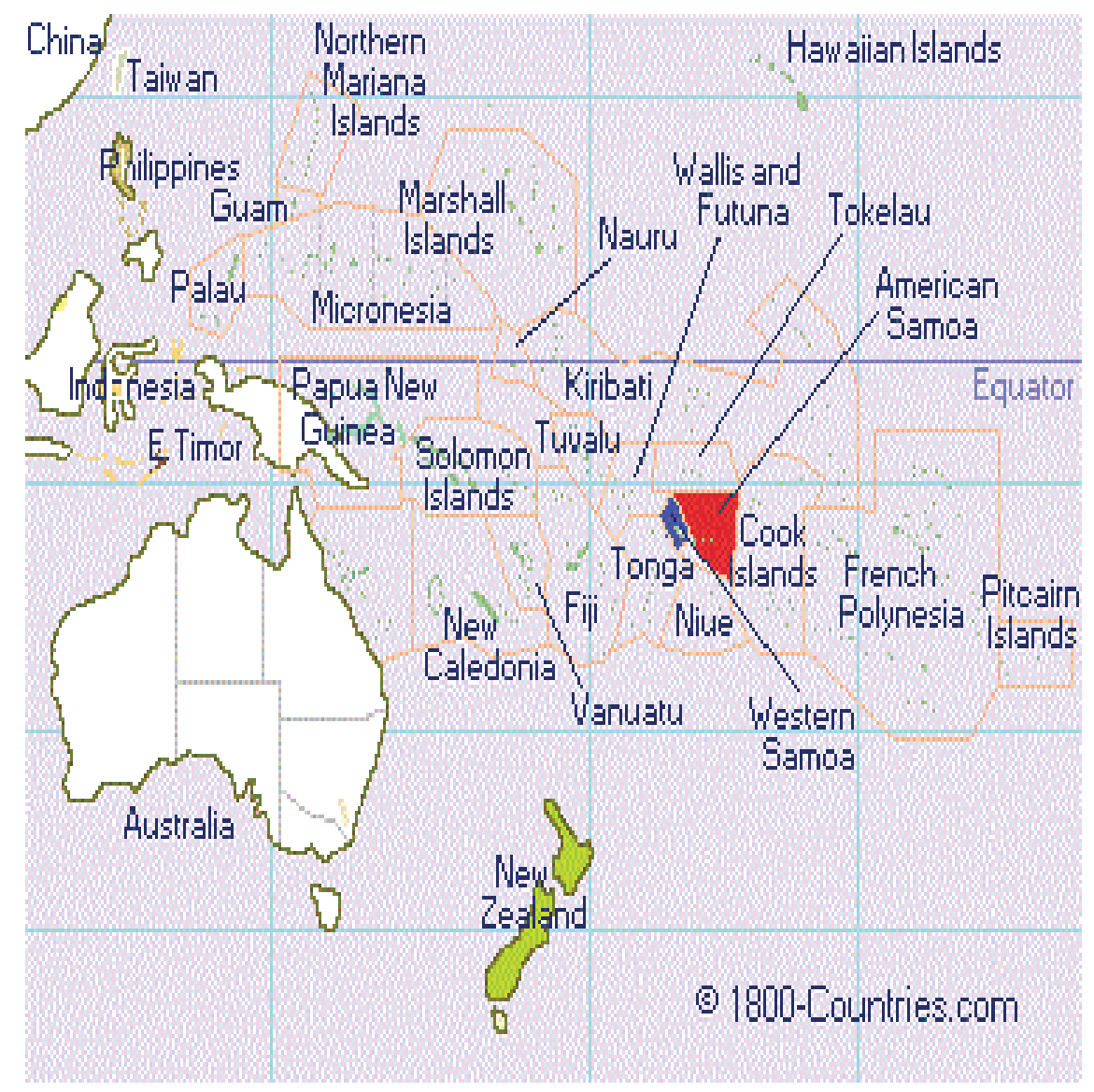

Source - http://www.travelnotes.org/Oceania/\#.UtJn8j2_IU

Key
Aotearoa/New Zealand - Green
Samoa - Blue
American Samoa - Red


Appendix 2: Interview Questions

1. Tell me about your family?

2. What does fa'afafine or whakawahine mean to you?

3. How do you explain and describe yourself when you are out of the Samoan or Maori society?

4. When did you first know that you are a fa'afafine or whakawahine?

5. Was it something you chose or imposed upon you?

6. Do you tell everyone that you are a fa' afafine or whakawahine?

7. What age did you start wearing female clothing?

8. How did people for example family and friends respond to your female clothing?

9. What do you know of the history and traditional understanding of fa'afafine or whakawahine in Samoa or Aotearoa/New Zealand?

10. What do you know about the contemporary or modern understanding of fa' afafine or whakwahine in Samoa or Aotearoa/New Zealand?

11. How would you describe a fa' afafine or whakawahine to a nonSamoan or non-Maori?

12. What do fa'afafine or whakawahine do in their families of origin for example their roles, tasks, expectations and responsibilities?

13. Describe the behaviour of fa'afafine or whakawahine in terms of masculinity and femininity?

14. Is fa'afafine or whakawahine a gender?

15. Is fa'afafine or whakawahine a role?

16. Is fa' afafine or whakawahine an identity?

17. Is fa' afafine or whakawahine a sexual identity?

18. Do you think the idea of third gender is useful to understand fa'afafine or whakawahine?

19. What is your understanding of the term gay? 
20. Is a gay man different to a fa' afafine or whakawahine? If yes, how?

21. What is your understanding of the term transgender?

22. Is a transgender different from a fa' afafine or whakawahine? If yes, how?

23. What is your understanding of a drag queen?

24. Is a drag queen different from a fa'afafine or whakawahine? If yes, how?

25. What gender are you sexually attracted to?

26. What relationship would you consider that as?

27. How would non-fa' afafine or non-whakawahine perceive that relationship?

28. Does one become a fa' afafine or whakawahine or is one born that way?

29. Are fa'afafine or whakawahine accepted?

30. What makes a woman a woman in Maori culture and society in Aotearoa/New Zealand?

31. What makes a man and man in Samoan or Maori culture and society?

32. What makes a woman a woman in Samoan or Maori culture and society?

33. What is the difference between a fa'afafine or whakawahine and a woman who is biologically born a woman?

34. At what stage does a fa' afafine or whakawahine become a woman?

35. What made you choose to undergo hormone treatment?

36. What do western categories such as gay, bisexual, transgender, transsexual and transvestite offer fa'afafine or whakawahine?

37. Is a takatapui similar to a whakawahine? 
Appendix 3: Information Sheet

\title{
Participant Information Sheet for a comparative study of the fa'afafine of Samoa and the whakawahine of Aotearoa/New Zealand.
}

\author{
Researcher: Ashleigh McFall: School of Education Policy and \\ Implementation.
}

My name is Ashleigh McFall and I am a student at the Victoria University of Wellington. I am enrolled for a Master of Arts by thesis in Gender and Women's Studies. In my research I wish to compare the experiences of the fa'afafine of Samoa and the whakawahine of Aotearoa/New Zealand. I am myself a New Zealand born fa' afafine. This research has been approved by Victoria University of Wellington Faculty of Education Ethics Committee.

Little published material exists about the experiences of fa'afafine and whakawahine from their own point of view. I am therefore hoping to interview fa'afafine and whakawahine about their personal experiences including for example your upbringing, family roles and your own and others' understanding of what it means to be a fa'afafine or a whakawahine. I would like to invite you to participate in this research. You do not have to take part in this research but I would be grateful if you do agree to be involved. This will take approximately an hour and will take place in a location of your choice.

The interview will be recorded with the Digital Recording Equipment Fostex FR-2LE ${ }^{1}$. Should you feel the need to withdraw from the project, you may do so without question at any time before the data is analysed by $31^{\text {st }}$ March 2011.

Data collected from the oral history interviews will form the basis of my research. All material collected will be treated confidentially unless you specify otherwise. No other person besides me and my supervisor, Dr. Lesley Hall will listen to the recording. The published results will not use your name and no opinions will be attributed to you in any way that will identify you unless you specify otherwise for example full name, first name or pseudonym.

You may choose either to have your recorded interview returned back to you or archived in the Oral History Centre. The National Oral History Association of New Zealand (2001) promotes the practice and methods of oral history for other future researchers and research. Should you agree to take part in this research I shall bring an 'Oral History Recording Agreement Form' to our first meeting or this can be emailed to you if you prefer. The form protects your privacy and interests if you choose to 
archive your recorded interview and allow people other than myself and my Supervisor Dr. Lesley Hall access thematerial.

If you choose not to have the interview archived all information related to you will be destroyed from my digital recorder and hard-drive after the conclusion of my research at the end of 2011.

Once completed, my thesis will be submitted to the School of Education Policy and Implementation and deposited in the Victoria University of Wellington Library. A copy will also be provided to you on a CD if you so wish.

If you have any questions about my thesis please contact me at my address and phone number below or my Supervisor Dr. Lesley Hall.

My supervisor: Dr. Lesley Hall

Senior Lecturer

Gender and Women's Studies

Faculty of Education

Victoria University of Wellington 
Appendix 4: Consent Form

\section{Consent to Participation in Research}

\section{Title of Project: A comparative study of the fa'afafine of Samoa and} the whakawahine of Aotearoa/New Zealand.

I have been given and have understood an explanation of this research project by Ashleigh McFall I have had an opportunity to ask questions and have them answered to my satisfaction. This research has been approved by Victoria University of Wellington Faculty of Education Ethics Committee.

I understand that any information I provide will be kept confidential to the researcher and his Supervisor.

I give permission for my name to be used in the published results as follows:
Full name
First name only
Pseudonym

I give permission for the inclusion of information which can identify me in the published results as follows:

Full information

Modified information

Fully disguised

information as

specified below

Comments:

I understand that interviews will be recorded. I may choose to have my interview returned back to me or archived.

I understand that I may listen to the recordings and ask for deletions.

Information or extracts from my recorded interview may be used for presentation at academic or professional conferences.

Information or extracts from my recorded interview may be used in publications by the researcher in academic or professional journals.

$\square \quad$ I understand that I may withdraw myself or any information traceable to me from this project before data is analysed 31 ${ }^{\text {st }}$ March 2011 without having to give reasons or without penalty of any sort. 
$\square \quad$ I wish to be provided with a copy of the research on a CD.

$\square \quad$ I agree to take part in this research.

Signed:

Name of participant

(Please print clearly) Date 
Appendix 5: Oral History Recording Agreement Form

\title{
Oral History Recording Agreement Form
}

\author{
FULL NAME OF PERSON INTERVIEWED
}

NAME OF INTERVIEWER

DATE OF INTERVIEW

COMMISSIONING ORGANISATION/PERSON

COPYRIGHT HOLDER

1. PLACEMENT I, the person interview ed, agree that a recording of $m y$ interview and accompanying $m$ aterial w ill b e h eld at

2. ACCESS I underst and that the recording of my interview and acco $m$ panying $m$ aterial $m$ ay be $m$ ade availab le to research ers at $t h e$ ab o ve lo cat io $n$, subject to any restrictions in paragraph 4 below.

3. PUBLICATION I agree that the recording of $\mathrm{my}$ interview and acco $m$ panying $m$ aterial $m$ ay be quoted in $p$ ub lish ed $w$ o rks in $f$ ull o $r$ in $p$ art an $d t h$ at $t h$ e r eco rd in $g \mathrm{~m}$ ay $b$ e $b$ ro ad cast o r used in $p$ ub lic $p$ erf o rm an ces in $f$ ull

o $r$ in $p$ art (in clud in g elect ro $n$ ic $p$ ub licat ion on $t h e$ in $t$ ern et ), $w$ it $h t h e$ $w r$ it $t$ en co $n$ sen $t$ of $t h$ e co $p$ yrigh $t h$ old er, subject to any restrictions in paragraph 4 below.

4. I require that there will be NO access to (tick appropriate box) I require that there be NO publication of I require that there be NO electronic publication on the intern et of $\ll$

the following sections of my interview and accompanying $m$ at erial $b$ ef o re $t h$ e review/release $d$ at e in $d$ icat ed

WITHOUT MY PRIOR WRITTEN PERMISSION. SIDE NUMBERS: REVIEW/ RELEASEDATE:

5. PRIVACY ACT: I underst and that this Agreem ent Form does not affect $m y$ rights and responsibilities under th e Privacy Act 1993. 


\section{COMMENTS}

Person interview ed Int erview er

Dat e Dat e

NOTE: Th e t erm $\mathrm{s}$ o $\mathrm{ft} \mathrm{h}$ is agreem en $\mathrm{t} f \mathrm{orm} \mathrm{m}$ ay be revised o $\mathrm{r}$ am en $\mathrm{d}$ ed o nly b y th e perso $\mathrm{n}$ reco rd ed o $\mathrm{rb}$ y the co $\mathrm{m} \mathrm{m}$ issio $\mathrm{n}$ in $\mathrm{g}$ o rgan isat ion o r p erso $\mathrm{n} \mathrm{w}$ it $\mathrm{h} t$ he aut $\mathrm{h}$ or it $\mathrm{y}$ of $\mathrm{th}$ e $\mathrm{p}$ erso $\mathrm{n}$ in t erview ed. An y am en $\mathrm{d} m$ en $\mathrm{t} m$ ust $\mathrm{b}$ e regist ered $\mathrm{w}$ it $\mathrm{h} \mathrm{t} \mathrm{h}$ e co $m \mathrm{~m}$ issio $\mathrm{n}$ in $\mathrm{g}$ o rgan isat ion or $\mathrm{p}$ erso $\mathrm{n}$.

\section{Source -}

http://www.oralhistory.org.nz/documents/nohanzagreementform.pdf 


\section{Bibliography}

ABC Radio Australia. 2013. 'Samoan fa'afafine reject same sex marriage'.

http://www.radioaustralia.net.au/international/radio/program/pacific-

beat/samoan-faafafine-reject-same-sex-marriage/1121736 accessed

05/05/2013

American Samoa Visitors Bureau. 2012. 'About our islands: Introduction and Overview'.

http://www.americansamoa.travel/about accessed 23/11/2012)

Amsamoa.net 2012. 'HistoryAmerican Samoa: History'. http://amsamoa.net/historyaccessed 23/11/2012

Ana. 2007. Whenua Fenua Enua Vanua: Revolutionaly Anti Colonialism \& Anti Capitalism in the Pacific.

http://uriohau.blogspot.co.nz/2007/10/whakawahine-mahu-faafafineakavaine.html accessed: 16/05/2013

Ann, 2012. 'Fa'afafine: the Pacific's third gender', in The Anchorage Daily News

http://www.thefreelibrary.com/Fa'afafine\%3A+the+Pacific's+\%22third+g ender\%22.-a0203336107 accessed: 16/05/2012

Anderson, K. and Dana C. Jack. 1998. 'Learning to listen: interview techniques and analyses', in Robert Perks and Alistair Thomson, eds. The Oral History Reader. London : Routledge

Aspin, Clive. 2011. 'Exploring Takatapui identity within the Maori community : implications for health and well-being', in Qwo-Li Driskill, Chris Finley, Brian Joseph Gilley and Scott Lauria Morgensen, eds. Queer indigenous studies: critical interventions in theory, politics, and literature. Tucson : University of Arizona Press

Babbie, Earl. R. 1992. The Practice of Social Research. Belmount : Wadsworth

Besnier, Niko. 1994. 'Polynesian Gender Liminality Through Time and Space’, in Gilbert Herdt, ed. Third Sex, Third Gender: Beyond Sexual Dimorphism in Culture and History. New York: Zone Books

Besnier, Niko. 2000. 'The Politics of Representation on a Polynesian Atoll', in Sjoerd R. Jaarsma and Marta A. Rohatynskyj, eds. Ethnographic 
Artifacts: Challenges to a Reflexive Anthropology. Honolulu: University of Hawai'i Press

Besnier, Niko. 2003. 'Crossing genders, mixing languages: The linguistic construction of transgenderism in Tonga', in Janet Holmes and Miriam, eds. The handbook and language and gender. Malden MA : Blackwell

Beauvoir, Simone de. 1974. The second sex. London : David Campbell

Beyer, Georgina. 1999. Change for the better: the story of Georgina Beyer as told to Cathy Casey. Auckland : Random House

Binney, Judith. 2004. 'Bringing the stories back home: Dialogues over 25 years', in Anna Green and Megan Hutching, eds. Remembering: Writing Oral History, Auckland : Auckland University Press.

Blackwood, Evelyn and Saskia E. Wieringa, eds. 1999. Female Desires: Same Sex Relations and Transgender Practices Across Cultures. New York : Columbia University Press.

Boon, Kevin. 1998. The Maori before the Europeans came to New Zealand. Auckland : Waiatarua

Bornat, J. 2012. 'TIMESCAPES METHODS GUIDES SERIES 2012 Guide No. 12 Oral History and Qualitative' http://www.timescapes.leeds.ac.uk/assets/files/methodsguides/timescapes-bornat-oral-history.pdf: accessed 12/12/2012

Brayton, Jennifer. 2012 'What makes Feminist Research Feminist? The structure of Feminist Research within the Social Sciences' http://www.unb.ca/PAR-L/win/feminimethod.htm accessed 07/13/2012

Brown-Acton, 2011. Phylesha. ' $2{ }^{\text {nd }}$ AsiaPacific Outgames Human Rights Conference', http://www.wellington2011.org/transcript.html?id=2$\underline{1306228428-826}$ accessed 11/09/2011

Butler, Judith. 1990. Gender Trouble: Feminism and the Subversion of Identity. New York : Routledge.

Claire, Marie. 2013. 'The Islands where boys grow up to be girls'. http://people.wku.edu/barry.kaufkins/280/THE\%20ISLANDS\%20WHER E\%20BOYS\%20GROW\%20UP\%20TO\%20BE\%20GIRLS.htm accessed 28/06/2013

Connell, Raewyn. W. 2005. Masculinities. Berkeley, CA : University of California Press

Croall, Heather and Karin Altmann. 2005 Paradise bent [videorecording]: boys will be girls in Samoa. New York: Filmakers Library 
Davidson, Janet. 2012. 'Explorers and Pioneers: The first Pacific people in New Zealand'. in Sean Mallon, Kolokesa Māhina-Tuai and Damon Salesa, eds. Tangata o le moana: New Zealand and the people of the Pacific. Wellington : Te Papa Press

Demeter. 2004. Fa'afafine (person). http://everything2.com/user/Demeter/writeups/fa\%2527afafine accessed 20/03/2007

Denzin, Norman K. and Yvonna S. Lincoln. 2005. 'Introduction: the discipline and practice of qualitative research', eds. in Norman K. Denzin, Yvonna S. Lincoln. The SAGE handbook of qualitative research. Thousand Oaks : Sage Publications.

Dickson-Swift, Virginia. Erica Lyn James and Pranee Liamputtong. 2008. Undertaking Sensitive Research in the Health and Social Sciences:

Managing Boundaries, Emotions and Risks. Cambridge, New York : Cambridge University Press

Dology, Reevan. 2000. The Search for Recognition and Social Movement Emergence: Towards an Understanding of the Transformation of the Fa'afafine of Samoa. PhD thesis. Canada : University of Alberta

Etter-Lewis, Gwendolyn. 1991. ‘Black Women’s Life Stories: Reclaiming Self in Narrative Texts'. In Sherna Berger Gluck and Daphne Patai. Women's Words: The Feminist Practice of Oral History. United States of America : Routledge

Fairbairn-Dunlop, Peggy. 1996. Tamatai Samoa; Their Stories, Carson: California Kin Publications

Farran, Sue. 2004. 'Transsexuals, Fa'afafine, Fakaleiti and Marriage Law in the Pacific: Considerations for the Future', in Journal of the Polynesian Society. The. Vol. 113, No. 2. June 2004. pp.119-142. http://search.informit.com.au/documentSummary; dn=260264749747703;r es=IELHSS accessed 08/05/2010

Fenaughty, John. 2004. 'The End of Queer: Heteronormativity and Suicide'. in Lynne Alice and Lynne Star, eds. Queer in Aotearoa/New Zealand. Palmerston North : Dunmore Press Ltd

Figiel. Sia. 1999. Where We Once Belonged. New York : Kaya Press

Fleras, Augie and Paul Spoonley. 1999. Recalling Aotearoa: Indigenous Politics and Ethnic Relations in New Zealand. Auckland : Oxford University Press

Foss Karen, A. and Foss, Sonja. K. 2012. 'Personal Experience as Evidence in Feminist Scholarship'. http://www.sonjafoss.com/html/Foss25.pdfaccessed 23/05/2013 
Freeman, Derek. 1983. Margaret Mead and Samoa: the making and unmaking of an anthropological myth. Cambridge, Mass : Harvard University Press

Garrett, Robyn. 2010. 'Feminist research dilemmas' in How Young Women Move.

http://publications.aare.edu.au/99pap/gar99199.htm accessed 18/6/2010

Goldsmith, Michael. 2000. 'On Not Knowing One’s Place’, in Sjoerd R. Jaarsma and Marta A. Rohatynskyj, ed. Ethnographic Artifacts :

Challenges to a Reflexive Anthropology. Honolulu : University of Hawai'i Press

Gluck, Sherna Berger and Daphne Patai. 1991. Women's Words: The Feminist Practice of Oral History. United States of America : Routledge

Green, Anna. 2004. 'Oral History and History', in Anna Green and Megan Hutching, eds. Remembering: Writing Oral History. Auckland: Auckland University Press

Green, Anna. 2004. 'Unpacking the Stories', in Anna Green and Megan Hutching, eds. Remembering: Writing Oral History. Auckland: Auckland University Press

Halberstam, Judith. 1998. Female Masculinity. Durham: Duke University Press

Hall, Lesley. 2003. Better Red Than Wed: The Role of Women and Gender Relations in the Communist Party of New Zealand 1921-1979. Unpublished PhD thesis, Victoria University of Wellington.

Hall, Lesley. 2007. 'Confidence Tricks: Re-visiting Ethics in Interviewing Situations', in Oral History in New Zealand, Wellington : NOHANZ

Hall, Lesley. 2009. 'Looking for answers: Striking the right balance', NOHANZ Journal, Wellington : NOHANZ

Harker, C. 2008. Fa'afafine: Queens of Samoa. in Made in New Zealand [videorecording]

Harrison, Faye V. 2008. Outsider within: reworking anthropology in the global age. Urbana: University of Illinois Press

Harrison, Lisa. 2001. Political Research: An Introduction. London: Routledge

Havelock, Ellis, John Addington Symonds. 2008. Sexual Inversion: A Critical edition Basingstoke [England]. New York: Palgrave Macmillan 
Hemmilä, Anita. 2005. Ancestors of Two-Spirits: Representation of Native American Third Gender https://jyx.jyu.fi/dspace/bitstream/handle/123456789/7281/URN_NBN fi jyu2005460.pdf?sequence $=1$ accessed 01/06/2013

Holmes Lowell D. 1957 The Restudy of Manu'an Culture: A Problem in Methodology. PhD.

Hutchings, Jessica and Clive Aspin, eds. 2007. Sexuality and the stories of indigenous People. Wellington : Huia Publishers

Hutching, Megan. 1993. Talking History. A short guide to Oral History. Wellington : Bridget Williams Books Limited

Hutching, Megan. 2005. 'The Distance Between Voice and Transcript', in Anna Green and Megan Hutching, eds. Remembering: Writing Oral History. Auckland : Auckland University Press

Jaggar, Alison M. 2008. Just Methods: An interdisciplinary Feminist Reader. United States of America : Paradigm Publishers

Jagose, Annamarie. 1996. Queer Theory. Dunedin : University of Otago Press

Kaltenborn, Benedicte. 2003. The Fa'afafine, Gender Benders in Samoa: On cultural Construction of Gender and Role Change. Norway : Department of Social Anthropology

Kamu, Lalomilo. 1996. The Samoan culture and the Christian gospel. Suva : Donna Lou Kamu

Keenan, Danny. 2004. 'The Past from the Paepae: Uses of the Past in Maori Oral History’, in Anna Green and Megan Hutching, eds. Remembering: Writing Oral History, Auckland : Auckland University Press

Kerekere, Elizabeth. http://www.wellington2011.org/transcript.html?id=2-1305931792-274 accessed 03/11/2011

Keresoma, Lagi. 2013. 'PM wants lesbians and faafafine to marry', in Talamua Media and Productions http://www.talamua.com/pm-wants-lesbians-and-faafafine-to-marry/ accessed 03/01/2013

Ketchel, Juanita. 2004. 'Getting Free: Oral Histories of Violence, Resilience and Recovery’, in Anna Green and Megan Hutching, eds. Remembering: Writing Oral History, Auckland: Auckland University Press 
Kirsch, Gesa. 1999. Ethical Dilemmas in Feminist Research: The politics of Location, Interpretation and Publication. United States of America : State University of New York

Laurie, Alison. 2004. 'Speaking the Unspoken : Lesbian Oral Histories in Aotearoa New Zealand', in Anna Green and Megan Hutching, eds. Remembering: Writing Oral History, Auckland : Auckland University Press

Leavy, Patricia. 2011. Oral History: Understanding Qualitative Research. New York: Oxford University Press, Inc.

Lee, Raymond. 1993. Doing Research On Sensitive Topics. London : Sage Publications

Letherby, Gayle. 2003. 'Introduction', in Feminist Research in Theory and Practice, Buckingham : Open University Press.

Lomax, Tess. 2007. 'Whakawahine - a Given or a Becoming', in Jessica Hutchings and Clive Aspin, eds. Sexuality and the stories of indigenous people. Wellington : Huia Publishers.

Lykke, Nina. 2010. Feminist Studies: A Guide to Intersectional Theory, Methodology and Writing. New York : Routledge.

Lynch, John. 1998. Pacific Languages [txt] : An introduction. Honolulu : University of Hawai'i Press

Mageo, Jeannette Marie. 1996. 'Samoa, on the Wilde Side: Male Transvestism, Oscar Wilde, and Liminality in Making Gender’ in Ethos, Vol. 24. No 4. pp. 588-626 http://libarts.wsu.edu/anthro/pdf/samoa-wilde-mageo.pdf accessed $28 / 03 / 2013$

Mageo, Jeannette Marie. 1998. Theorizing Self in Samoa: Emotions, Genders and Sexualities. Ann Arbor: University of Michigan Press.

Manning, Erin. Queering Disrupted Methodology.

http://www.kvinfo.su.se/femmet09/papers/pdf/Manning.pdf accessed $15 / 07 / 10$

Maori Tourism Limited. 2012 'Aotearoa - the Maori name for New Zealand http://www.maori.com/aotearoa accessed 20/05/2013

Matzner, A. 2000 Gender Diversity: Crosscultural Variations http://intersections.anu.edu.au/issue6/matzner_review.html accessed 26/06/2013

McMullin, Dan Taulapapa. 2011. 'Fa' afafine notes: on Tagaloa, Jesus, and Nafanua’, in Qwo-Li Driskill, Chris Finley, Brian Joseph Gilley and 
Scott Lauria Morgensen, eds. Queer indigenous studies : critical interventions in theory, politics, and literature. Tucson : University of Arizona Press

McPhail, Beverley A. 2004. "Questioning gender and sexuality binaries”, Journal of Lesbian Social Services, 17:1, 3-21

Mead, Hirini Moko. 2003. Tikanga Maori = living by Maori values. Wellington : Huia Publishers

Mead, Margaret. 1943. Coming of Age in Samoa. Harmondsworth, Middlesex : Penguin Books.

Meleisea, Malama. 1987. LAGAGA : A short history of Western Samoa. Samoa: Institute of Pacific Studies and the Western Samoa Extension Centre of the University of the South Pacific.

Miles, Paul. 2007. 'Transgender in the Pacific - Fa'afafine, Fakaleiti and Mahu'.

http://collections.infocollections.org/ukedu/uk/d/Jh1395e/2.5.2.html accessed 20/12/2007

Ministry of Business, Innovation and Employment. 2013. Transgender people at work. http://www.dol.govt.nz/er/minimumrights/transgender/ accessed 16/05/2013

Morrison, James. H. 1998. 'A global perspective of oral history in Southeast Asia', in P.Lim Pui Huen James H. Morrison and Kwa Chong Guan, eds. Oral History in Southeast Asia. Institute of Southeast Asian Studies : Singapore

Morrissey, Charles T. 1998. ‘On Oral History Interviewing', in Robert Perks and Alistair Thomson, eds. The Oral History Reader. London : Routledge

Mulgan, Richard. 2004. Politics in New Zealand. Auckland: Auckland University Press

Murray, David A.B. 2003. 'Who is Takatapui? Maori Language, Sexuality and Identity in Aotearoa/New Zealand', in Anthropologica, Vol 5, no 5 http://books.google.co.nz/books?id=2ycZjQeZ278C\&pg=PA240\&dq=ant hropologica $+(2003)++$ whakawahine\&hl=en\&sa=X\&ei=FSf3Up2nH8bilA XdvYGQDw\&ved=0CCwQ6AEwAA\#v=onepage\&q=anthropologica $\% 2$ 0(2003)\%20-\%20whakawahine\&f=false accessed 13/06/2013

Murray, David A. B. 2004. 'Takatapui, Gay, or Just Ho-mo-sexual, Darling? Maori Language, Sexual Terminology, and Identity in Aotearoa/New Zealand', in William L. Leap and Tom Boellstorff, eds. Speaking in queer tongues: globalization and gay language. Urbana : University of Illinois Press 
Nabobo-Baba, Unaisi. 'Research and Pacific indigenous peoples : silenced pasts and challenged futures'. in Tupeni L. Baba. Researching Pacific and indigenous peoples : issues and perspectives. Auckland : Centre for Pacific Studies, The University of Auckland

The New Zealand Aids Foundation. 2010. Ko Ia: He or she

Oakley, Ann. 2000. Experiments in knowing: Gender and Method in the Social Sciences. Cambridge : Polity Press

Pacificbeatst. 2013. 'Pacific Beat St Ep 167 - What is a Fa'afafine'. http://www.youtube.com/watch?v=GV_g6X2PEvs accessed 21/06/2013 Palmer, Geoffery and Matthew Palmer. 1997. Bridled Power: New Zealand Government under MMP. Auckland : Oxford University Press

Park, Julie. Tamasailau Suaalii-Sauni, Melani Anae, Ieti Lima, Nite Faumatu and Kirk Mariner. 2002. 'Late Twentieth-Century Auckland Perspective on Samoan Masculinities', in Heather Worth, Anna Paris and Lauisa Allen, eds. The life of Brian: Masculinities, Sexualities and Health in New Zealand. Dunedin : University of Otago Press

Pillow, Wanda. S. and Cris Mayo. 2007. 'Toward Understandings of Feminist Ethnography'. in Sharlene Nagy Hesse-Biber, ed. Handbook of Feminist Research : Theory and Praxis. California : Thousand Oaks

Popular Memory Group. 1998 'Popular memory: theory, politics, method', in Robert Perks and Alistair Thomson, eds. The Oral History Reader. London: Routledge.

Portelli, Alessandro. 1991. The Death of Luigi Trastulli \& Other Stories: Form and Meaning in Oral History. Albany, N.Y.: State University of New York Press

Pulotu-Endemann, Fuimaono Karl and Carmel Leinatioletuitoga Peteru. 2001. 'Beyond the paradise myth: sexuality and identity', in Cluny Macpherson, Paul Spoonley, Melani Anae, eds. Tangata o Te moana nui : The evolving identities of Pacific people in Aotearoa/New Zealand. Palmerston North : Dunmore Press Ltd

Pulotu-Endemann, Fuimaono Karl. 1997. 'Being Samoan and Fa'afafine is Being Unique', in Hero 6 Magazine

Pulotu-Endemann, Fuimaono Karl. 1997. 'The fa’afafine experience’

Pulotu-Endemann, Fuimaono Karl. 2009. Fonofale Model of Health. http://www.hauora.co.nz/resources/Fonofalemodelexplanation.pdf accessed 10/06/2012 
Pulotu-Endemann, Fuimaono Karl. 2011. '2 2 nd AsiaPacific Outgames Human Rights Conference', http://www.wellington2011.org/transcritp.html?id=2-1305931920-386 accessed 11/09/2011

Rainbowyouth. 2012. 'Queer+Trans* Youth' http://www.rainbowyouth.org.nz/ accessed 20/12/2012

Reinharz, Shulamit. 1992. Feminist methods in social research. New York : Oxford University Press

Richard, Donald. A. 2003. Doing Oral History: a practical guide. New York : Oxford University Press

Robertson, Beth M. 2006. Oral History Handbook, Oral History Association of Australia : South Australia

Rohatynbskyj, Marta A. and Sjoerd R. Jaarsma. 2000. 'Introduction: Ethnographic Artifacts'. in Sjoerd R. Jaarsma and Marta A. Rohatynskyj, eds. Ethnographic Artifacts: Challenges to a Reflective Anthropology. United States of America : University of Hawai'i Press.

Roscoe, Will. 1994. 'How to Become a Berdache: Toward a Unified Analysis of Gender Diversity', in Gilbert Herdt, ed. Third Sex, Third Gender: Beyond Sexual Dimorphism in Culture and History. New York: Zone Books. pp. 329 - 372.

Rupe, Carmen. 1988. Carmen: my life as told by Paul Martin. Auckland: Benton Ross Publishers

Samoa Tourism Authority. 2013. 'History' http://www.samoa.travel/about/a13/History/ accessed 05/06/2013

Sangster, Joan. 1998. 'Telling our stories: feminist debates and the use of oral history', in Robert Perks and Alistair Thomson, eds. The Oral History Reader. London : Routledge

SBS2Australia. 2013. FA'AFAFINE - The boys raised to be girls (The Feed) http://www.youtube.com/user/SBS2Australia?feature=watch accessed 19/07/2013

Schmidt, Johanna. 2005. Migrating Genders: Westernisation, Migration and Samoan Fa'afafine Thesis. Unpublished PhD Thesis, Auckland University

Schmidt, Johanna. 2013. 'Gender diversity - Fa'afafine', in Te Ara - the Encyclopedia of New Zealand, updated 13-Jul-12 http://www.TeAra.govt.nz/en/gender-diversity/page-3 accessed 20/06/2013 
Seedsavers - Fafafine: Boys raised as Girls in Samoa,

http://www.youtube.com/watch?v=6_x2NU-ewe0; polyfreshtv - FRESH

- Know Your Roots - Fa'afafine accessed 05/06/2013

Shopes, Linda. and Paula Hamilton. 2008. Oral history and Public

Memories. Philadelphia : Temple University Press

Smith, Linda Tuhiwai. 1999. Decolonizing Methodologies: Research and Indigenous Peoples. Dunedin : University of Otago

Smith, Linda Tuhiwai. 2004. Building research capability in the Pacific, for the Pacific and by Pacific peoples, in Tupeni L. Baba. Researching

Pacific and indigenous peoples : issues and perspectives. Auckland:

Centre for Pacific Studies, The University of Auckland

Society Of Fa'afafine In American Samoa - S.O.F.I.A.S.

https://www.facebook.com/pages/Society-Of-Faafafine-In-American-

Samoa-SOFIAS/168150006613160 accessed 01/06/2012

Sparrow, Margaret. 2008. Notes for Health Educators: Sexual Diversity, Family Planning Seminar

SPASIFIK Magazine. no 55. 2013

SPASIFIKA Magazine. no 56. 2013

Spears, James. T. 2005. Youth, Education and Sexualities, Vol 2 K-Z.

United States of America : Greenwood Publishing Group

Spivak, Gayatri Chakravorty. 1997. Can the subaltern Speak?, in Bill Ashcroft, Gareth Griffiths, Helen Tiffin. The Post-colonial studies reader. London : Routledge

Sua'ali'i, Tamasailau. 2001. 'Samoans and Gender: Some reflections on Male, Female and Fa'afafine Gender Identities, in Cluny Macpherson, Paul Spoonley, Melani Anae. Tangata o te moana nui: The evolving identities of Pacific people in Aotearoa/New Zealand. Palmerston North : Dunmore Press Ltd

Tapatoru, 2011. Maori proverbs and the people of Aotearoa. Published in Wellington : Tapatoru

Te Awekotuku, Ngahuia. 1991. Mana Wahine Maori: Selected Writings on Maori Women's Art, Culture and Politics. Auckland : New Women's Press Ltd

Te Awekotuku, Ngahuia. 2003. Ruahine: mythic women. Wellington : Huia 
Teake. 2010. Conditional Acceptance: Asserting Fa'afafine Claims to Legitimacy in Samoan Society'. Independent Study Project (ISP)

Collection. Paper 923. http://digitalcollections.sit.edu/isp collection/923

Thomson, Alistair. 1995. Anzac memories : living with the legend.

Melbourne : Oxford University Press

Toelupe, Vaitoa. 2011.'2 ${ }^{\text {nd }}$ AsiaPacific Outgames Human Rights

Conference', http://www.wellington2001.org/transcript.html?id=2-

1306229310-701 accessed: 11/09/2011

Tupuola, Anne-Marie. 1998. Adolescence: myth or reality for Samoan women? : beyond the stage-like toward shifting boundaries and identities. PhD Thesis, Victoria University of Wellington

Vanessa. 2007. Memoirs of a Samoan, Catholic and Fa'afafine. Publish America

Vardhan, Ranjay. 2012. 'Feminist Research: Challenges before Male Researchers'. Govt. College for Girls, Sector 42, Chandigarh (affiliated to Panjab University, Chandigarh), India http://www.kvinfo.su.se/femmet09/papers/pdf/Vardhan_revised.pdf accessed 20/10/2012

Vasey, Paul and Doug VanderLaan. 2007. 'Birth order and male androphilia in samoa Fa' afafine', in Proceedings of the Royal Society B, Vol. 274. pp. 1437-1442

http://rspb.royalsocietypublishing.org/content/274/1616/1437.full.htm\#ref .list-1 accessed 01/06/2013

Vasey, Paul. and Doug VanderLan. 2008. 'Avuncular Tendencies and the Evolution of Male Androphilia in Samoan Fa'afafine', in Arch Sex Behav. doi: 10.1007/s10508-008-9404-3 http://psy2.ucsd.edu/ mgorman/Vasey2009.pdf accessed 01/06/2013

Vasey, Paul. and Nancy Bartlett. 2007. 'What can the samoan 'Fa' afafine' teach us about the western concept of gender identity disorder in childhood?', in Perspectives in Biology and Medicine. Vol. 50, No. 4. pp. 481-90

Wadsworth, Yoland 2001. What is Feminist Research?. in Bridging the Gap: Feminisms and Participatory Action Research Conference Conference Papers. June 22-24. 2001 at Boston College http://ggsc.wnmu.edu/gap/wadsworth.htm accessed 20/12/2012

Wallace, Lee. 2003. Sexual Encounters: Pacific Texts Modern Sexualities. United States of America : Cornell University

Warnerbh. 1988. 'Margaret Mead and Samoa (1988) - part 1 of 6 http://www.youtube.com/watch?v=Pw1NZjNkAYI accessed 23/05/2013 
Wilson, John. 'History', Te Ara - the Encyclopedia of New Zealand, updated 4-Dec-12

http://www.TeAra.govt.nz/en/history accessed 01/06/2013

Worth, Heather. 2002. 'As far as sex goes, I don't really think about my body’: Young Men’s Corporeal Experiences of (Hetero)sexual Pleasure', in Heather Worth and Anna Paris and Lousia Allen, eds. The life of Brian: Masculinities, Sexualities and Health in New Zealand. Dunedin :

University of Otago Press

Worth Heather, Anna Paris and Louisa Allen. 2002. The Life of Brian: Masculinities, Sexualities and Health in New Zealand. Dunedin :

University of Otago Press

Young, Craig. 2004. Queers versus the New Zealand Christian Right, 1985-1998, in Lynne Alice and Lynne Star. Queer in Aotearoa New Zealand. Palmerston North : Dunmore Press

Yow, Valerie Raleigh. 2005. Recording Oral History: A Guide for the Humanities and Social Sciences. Walnut Creek, CA : AltaMira Press

\section{Oral History:}

Oral history interviews by Ashleigh McFall 2010 - 2011

Interviews with Latoya, Athena, Lia, Honey, Max, Chanel, Shaniqua, Kayla, Renee, and Viane, in author's possession 
